\title{
O ESTRESSE EM CRIANÇAS E ADOLESCENTES COM SÍNDROME DE WILLIAMS-BEUREN NO CONTEXTO ESCOLAR
}

\author{
Dissertação apresentada à Faculdade de \\ Medicina da Universidade de São Paulo para \\ obtenção do título de Mestre em Ciências
}

Programa de: Pediatria

Orientadora: Profa. Dra. Chong Ae Kim

(Versão corrigida. Resolução CoPGr 5890, de 20 de dezembro de 2010.

A versão original está disponível na Biblioteca FMUSP)

São Paulo

2012 


\section{Dados Internacionais de Catalogação na Publicação (CIP)}

Preparada pela Biblioteca da

Faculdade de Medicina da Universidade de São Paulo

Creprodução autorizada pelo autor

Santos-Amaral, Vera Alice Alcântara dos

O estresse em crianças e adolescentes com síndrome de Williams-Beuren no

contexto escolar / Vera Alice Alcântara dos Santos Amaral. -- São Paulo, 2012.

Dissertação(mestrado)--Faculdade de Medicina da Universidade de São Paulo.

Programa de Pediatria.

Orientadora: Chong Ae Kim.

Descritores: 1.Síndrome de Williams 2.Estresse 3.Criança 4.Adolescente 5.Escolas

USP/FM/DBD-101/12 
Renda-se, como eu me rendi. Mergulhe no que você não conhece como eu mergulhei. Não se preocupe em entender, viver ultrapassa qualquer entendimento.

(Clarice Lispector) 
Ao Pai Celestial que me abençoou

nesta caminhada

e a Ele serei eternamente grata. 


\section{Agradecimentos}

À minha família: pai, mãe e irmãos por acreditarem no meu potencial e torcerem pela minha vitória.

Ao meu marido, filhas e genros por compreenderem as minhas ausências e por se fazerem minha engrenagem para que eu nunca desistisse.

À ABSW e suas colaboradoras Elisabeth, Lúcia e Esther por ser um início e terem considerado a minha singela contribuição.

Aos pacientes e familiares, sem os quais não seria possível esta pesquisa, e que me deram uma nova visão de mundo.

A Jô Nunes por ser um exemplo de coragem, força e determinação.

À Dra Chong Ae Kim por sua dedicação e preciosa orientação.

À Dra Michele Moreira Nunes por sua amizade, carinho e prontidão - será sempre minha amiga.

À Dra Rachel S. Honjo e Dr. Israel Gomy por seus apoios e orientações no ambulatório.

Aos professores do Ipq e do IP por terem acreditado nesta pesquisa e tanto me incentivaram e colaboraram com seus ensinamentos. 
Dr. Francisco Baptista Assumpção Jr, Dr. Clóvis Artur Almeida da Silva e Dra Maria Esther Jusfest Rivero Ceccon, membros de Comissão da banca examinadora, pelas preciosas orientações.

Funcionários da Biblioteca do $\mathrm{ICr}$ e Funcionários da Copiadora por estarem sempre dispostos a colaborar com o brilhantismo da apresentação do meu trabalho. 
Esta dissertação está de acordo com as seguintes normas, em vigor no momento desta publicação:

Referências: adaptado de International Committee of Medical Journals Editors (Vancouver).

Universidade de São Paulo. Faculdade de Medicina. Divisão de Biblioteca e Documentação. Guia de apresentação de dissertações, teses e monografias. Elaborado por Anneliese Carneiro da Cunha, Maria Julia de A. L. Freddi, Maria F. Crestana, Marinalva de Souza Aragão, Suely Campos Cardoso,Valéria Vilhena. 3a ed. São Paulo: Divisão de Biblioteca e Documentação; 2011.

Abreviaturas dos títulos dos periódicos de acordo com List of Journals Indexed in Index Medicus. 


\section{SUMÁRIO}

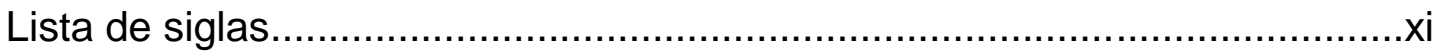

Lista de quadro, gráfico e tabela................................................... xiii

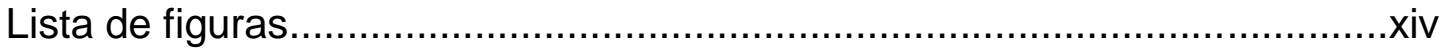

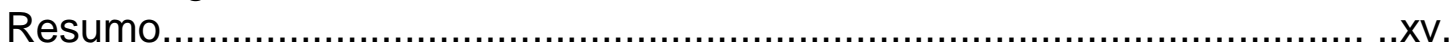

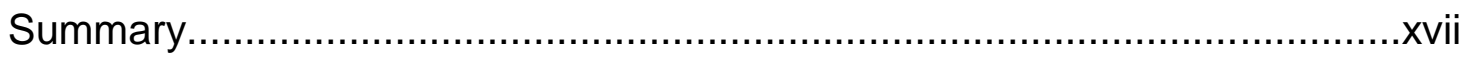

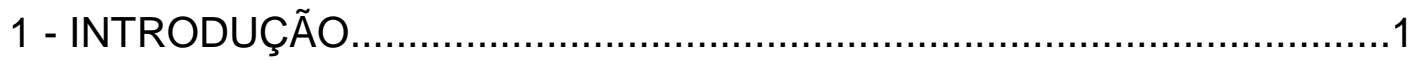

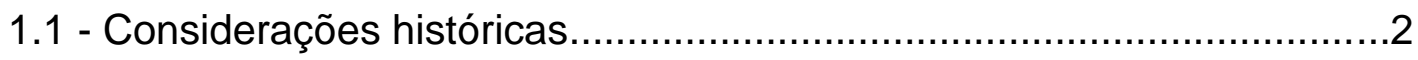

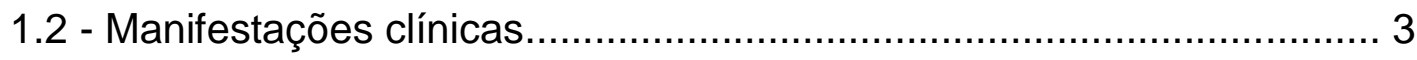

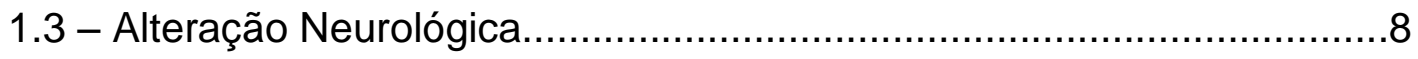

1.4 - Aspecto Sócio-comportamental........................................... 15

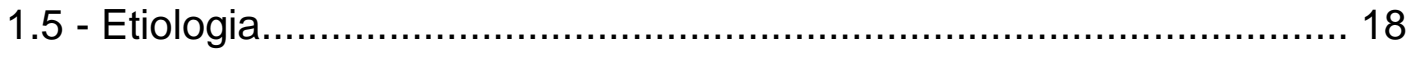

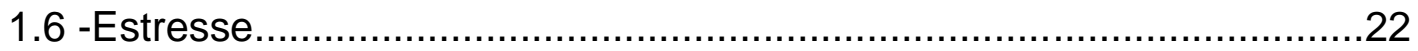

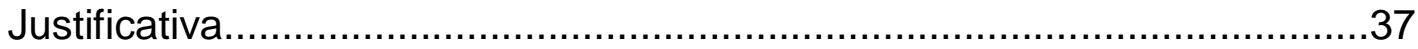

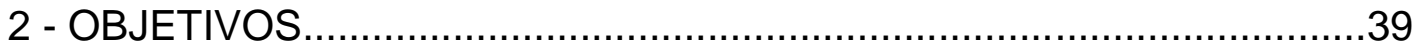

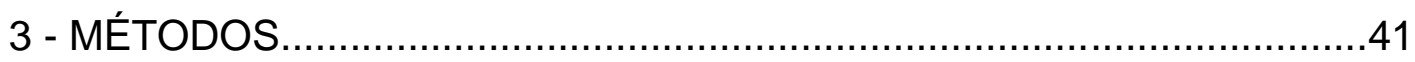

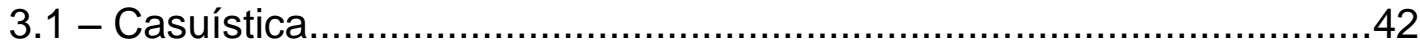

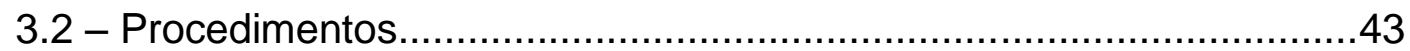

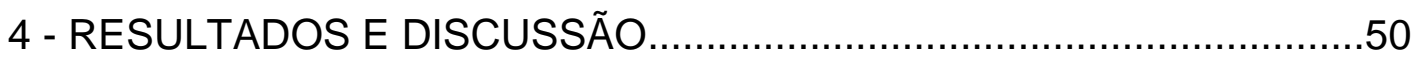

4.1 - Quadro Clínico das crianças e adolescentes com SWB.....................51

4.2 -Estresse em pacientes com SWB x Grupo controle.........................52

4.3 - Estresse x Ambiente escolar..............................................55

4.4 - Estresse x Coificiente de Inteligência...................................57

4.5 - Estresse x Tamanho da microdeleção....................................58

4.6 - Estresse $x$ Tipos de reações...............................................59 
4.7 - Caracterização sócio-demografica

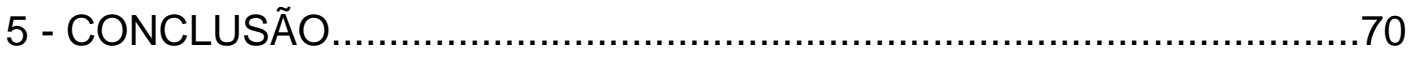

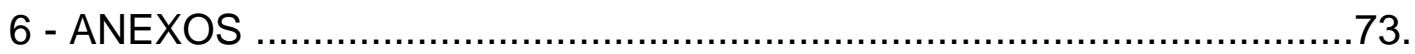

Anexo A - Aprovação do projeto

Anexo B - Termo de consentimento

Anexo C - Questionário sociodemográfico

Anexo D - ESI Escala de Stress Infantil

Anexo E - ISSL Inventário de Sintomas de Stress de Lipp

Anexo F - Quadro de características clínicas dos pacientes com SWB

Anexo G - Associação entre as reações de estresse e níveis de estresse na SWB

Anexo H - Caracterização sociodemográfica - Aspecto familiar

Anexo I - Caracterização sociodemográfica - Série escolar

Anexo J - Artigo publicado em periódico nacional

Anexo k - Artigo submetido em periódico internacional

7 - REFERÊNCIAS BIBLIOGRÁFICAS 


\section{LISTA DE SIGLAS}

$\begin{array}{ll}\text { CAPPesq } & \text { Comitê de Ética para Análise de Projetos e Pesquisas } \\ \text { CBCL } & \text { Population Child Behavior Checklist } \\ \text { DSM-IV } & \text { Diagnósticos e Estatísticos de Transtornos Mentais } \\ \text { EASV } & \text { Estenose Aórtica Supravalvar } \\ \text { FISH } & \text { "Fluorescence in situ Hibridization" } \\ \text { FMUSP } & \text { Faculdade de Medicina da Universidade de São Paulo } \\ \text { GC } & \text { Grupo Controle } \\ \text { HC } & \text { Hospital das Clínicas } \\ \text { HPA } & \text { Hipotálamo Pituitário-Adrenal } \\ \text { ICR } & \text { Instituto da Criança } \\ \text { QIV } & \text { Quociente Intelectual Verbal } \\ \text { ISSL } & \text { Inventário de Sintoma de Stress para adulto de Lipp } \\ \text { MLPA } & \text { "Multiplex-Ligation dependent Probe Amplification" } \\ \text { MW } & \text { Mann Whitney } \\ \text { Quociente Intelectual de Execução }\end{array}$




$\begin{array}{ll}\text { RF } & \text { Reações Físicas } \\ \text { RP } & \text { Reações Psicológicas } \\ \text { RPCD } & \text { Reações Psicológicas com Componentes Depressivos } \\ \text { RPF } & \text { Reações Psicofisiológicas } \\ \text { SWB } & \text { Síndrome de Williams-Beuren } \\ \text { TRF } & \text { Teacher's Report Form } \\ \text { WAIS } & \text { Wechsler Adult Intelligence Scale } \\ & \\ \text { WISC } & \text { Wechsler Intelligence Scale Children }\end{array}$




\section{LISTA DE QUADROS, GRÁFICOS E TABELAS}

QUADRO 1 - Média e Desvio Padrão em relação aos

fatores de estresse.

QUADRO 2 - Tipos de reações e níveis de estresse

QUADRO 3 - Respostas mais frequentes em reações físicas (swb)

QUADRO 4 - Respostas mais frequentes em reações

psicológicas com componente depressivo(SWB).

TABELA 1 - Estresse e Gênero na SWB e Grupo Controle. .53

TABELA 2 - Estresse e tipos de escolas (SWB) .56

TABELA 3 - Estresse e QI na SWB...................................................5

TABELA 4 - Estresse e tamanho da microdeleção na SWB .59

TABELA 5 - Comparação das reações de estresse na SWB

entre escolas de inclusão e especial.

TABELA 6 - Estresse em relação ao aspecto social (SWB). 63.

TABELA 7 - Estresse em relação a situação escolar (SWB). 


\section{LISTA DE FIGURAS}

FIGURA 1 - Região da microdeleção 7q11.23 que caracteriza a SWB....19

FIGURA 2 - Esquema do eixo Hipotálamo Pituitário-Adrenal...................27

FIGURA 3 - Comparação de estresse entre a SWB e GC......................54 


\section{RESUMO}

Santos-Amaral V A A. O estresse em crianças e adolescentes com síndrome de Williams-Beuren no contexto escolar. [Dissertação] - Faculdade de Medicina, Universidade de São Paulo; 2012

INTRODUÇÃO: Síndrome de Williams-Beuren (SWB) é uma doença genética causada por microdeleções em hemizigose de genes contíguos na região 7q11.23, caracterizada por aspectos faciais típicos, estenose aórtica supravalvar, déficit cognitivo e personalidade amigável. Associa-se com comprometimento funcional em diversas áreas, interferindo no desenvolvimento de habilidades adequadas de comunicação, socialização, realização de atividades da vida diária e desempenho acadêmico. É possível que muitas dessas limitações aumentem a vulnerabilidade de pessoas com SWB a reações de estresse. Não há na literatura nenhum estudo sobre estresse na SWB. OBJETIVOS: Determinar os níveis de estresse em crianças e adolescentes com SWB e comparar com o grupo controle; verificar o nível de estresse entre crianças e adolescentes com SWB que frequentam escola de inclusão e escola especial; correlacionar o nível de estresse em crianças e adolescentes com SWB com coeficiente de inteligência (QI) e caracterizar os tipos de reações de estresse em crianças e adolescentes com SWB. MÉTODOS: A amostra foi composta por um grupo de 40 crianças e adolescentes com idade entre 7 e 18 anos cujo diagnóstico genético-molecular foi positivo para SWB e 40 crianças e adolescentes sem a síndrome para grupo controle, pareado por idade e por sexo. Os instrumentos para avaliação de níveis (normal, alerta. resistência e exaustão) e tipos de reações (físicas, psicológicas, psicológicas com componente depressivo e psicofisiológicas) de estresse foram: Escala de Stress Infantil (ESI) e Inventário de Sintomas de Stress para adulto de Lipp (aplicado 
apenas para o grupo controle com mais de 14 anos de idade). A avaliação de QI foi obtida pelos instrumentos de Escala de Inteligência para Crianças (WISC) e Escala de Inteligência para Adulto (WAIS). RESULTADOS E DISCUSSÃO: Os índices elevados de estresse foram encontrados em $50 \%$ dos pacientes com SWB e em $28,6 \%$ do grupo controle, cuja diferença foi estatisticamente significante $(p<0.001)$. O nível de estresse total nos pacientes com SWB (alerta 13; resistência 6; exaustão 1) e no grupo controle (alerta 3; resistência 5). Em relação ao tipo da escola, os índices elevados de estresse foram mais frequentes em $69,2 \%$ das 13 que frequentaram escola especial do que $40,7 \%$ das 27 pacientes que estudaram em escola de inclusão, sem diferença estatisticamente significante. Os pacientes com $\mathrm{Ql}<60$ apresentaram maior índice de estresse em comparação aos pacientes com QI > 60 e $<89$ sem diferença estatisticamente significante. Os tipos de reações ao estresse nos pacientes com SWB físicas (57\%) e psicológicas com componente depressivo (67\%) foram mais frequentes, enquanto que no grupo controle não houve diferença. CONCLUSÃO: As crianças e adolescentes com SWB apresentaram índices elevados de estresse indiferente do tipo de escola que frequentavam. $O$ presente estudo alerta sobre os prejuízos físicos e emocionais que o estresse pode causar às crianças e adolescentes com SWB, que podem estar interferindo nas relações sociais, atividades de vida diária e desempenho acadêmico. Futuras pesquisas sobre estresse na SWB se fazem necessárias, visando melhorar a qualidade de vida.

Descritores: Síndrome de Williams, estresse, criança, adolescente e escola 


\section{SUMMARY}

INTRODUCTION: Williams-Beuren syndrome (WBS) is a genetic disease caused by microdeletions in contiguous gene hemizigose $7 q 11.23$ region, characterized by typical facial features, supravalvular aortic stenosis, cognitive impairment and friendly personality. It is associated with functional impairment in several areas, interfering in the development of appropriate communication skills, socialization, performing activities of daily living and academic performance. It is possible that many of these limitations increase the vulnerability of people with WBS to stress reactions. There are no studies in the literature on stress in WBS. OBJECTIVES: To determine the levels of stress in children and adolescents with WBS and compare with the control group, check the level of stress among children and adolescents with WBS attending inclusion school and special school; correlate the level of stress in children and adolescents with WBS with intelligence quotient (IQ) and characterize the types of stress reactions in children and adolescents with WBS. METHODS: The sample comprised a group of 40 children and adolescents aged between 7 and 18 years whose molecular genetic diagnosis was positive for WBS and 40 children and adolescents without the syndrome to the control group, matched by age and sex. The instruments for assessing levels (normal, alert. resistance and exhaustion) and types of reactions (physical, psychological, psychological with depressive components and psycho-physiological) stress were: Child Stress Scale (ESI) and Symptoms of Stress Inventory for adults Lipp (applied only to 
the control group with more than 14 years of age). The evaluation of IQ was obtained by instruments Intelligence Scale for Children (WISC) and Adult Intelligence Scale (WAIS). RESULTS AND DISCUSSION: The high levels of stress were found in $50 \%$ of patients with WBS and $28.6 \%$ in the control group, the difference was statistically significant $(p<0.001)$. The level of total stress in patients with WBS (alert,13; resistance 6; one exhaust) and the control group (alert 3, resistance 5). Regarding the type of school, the high levels of stress were more frequent in $69.2 \%$ of 13 who attended the special school that $40.7 \%$ of 27 patients who studied in inclusion school, but no statistically significant difference. Patients with IQ $<60$ had higher stress compared to those with IQ> 60 and $<89$ with no statistically significant difference. The types of responses to stress in patients with WBS physical (57\%) and psychological with depressive component $(67 \%)$ were more frequent, whereas in the control group there was no difference. CONCLUSION: Children and adolescents with WBS showed high levels of stress regardless of the type of school attended. This study warns about the physical and emotional damage that stress can cause to children and adolescents with WBS, which it may interfering in social relationships, daily activities and academic performance. Future researches on stress in WBS are necessary to improve the quality of life.

Keywords: Williams syndrome, Stress, Child, Adolescent and school 


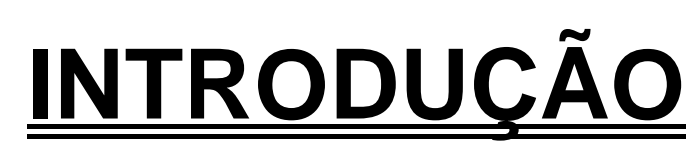


1 - INTRODUÇÃo

\section{1- Considerações históricas}

Em 1961, Williams J.C.P et al. estudaram um grupo de quatro crianças caracterizadas por fácies peculiar, deficiência mental e personalidade amigável, apresentando em seu quadro clínico estenose supravalvar da aorta. Com base neste estudo foi observada a associação da hipercalcemia idiopática infantil com cardiopatia (Rashkind et al., 1961).

Em 1962, Beuren A. J. et al. apontaram a associação da síndrome com estenose aórtica pulmonar, anomalias dentárias e estrabismo.

Este conjunto de alterações clínicas denominou-se, portanto Síndrome de Williams-Beuren (SWB).

Ewart (1993) atribuiu a etiologia a uma microdeleção hemizigótica do cromossomo 7 (região 11.23) envolvendo, entre outros, o gene da elastina que dá elasticidade aos tecidos, órgãos e paredes das artérias. Esta microdeleção é responsável por uma alteração multissistêmica.

Estudos realizados até a atualidade concluem que crianças com SWB têm um fenótipo incomum que inclui um perfil distinto de características física, médica, neuropsicológica, neuroanatômica e neurológica (Bellugi et al., 1990, 
1994, 2000; Johnson et al., 2001; Arrington et al., 2005; Kaplan, 2006; Morris, 2006; Gagliard et al., 2007; Verrengia et al., 2007).

A SWB afeta aproximadamente numa margem de 1 para 7.500 a 1 para 25.000 nativivos e é encontrada, mundialmente entre todos os grupos racial e étnico ( Stromme, 2002).

Na maioria dos casos, a ocorrência é esporádica, casos de novo, pois os genitores são normais e manifesta característica de forma autossômica dominante. Casos raros têm sido descritos na literatura.

\section{2- Manifestações clínicas}

\subsection{1- Características Craniofaciais}

As características faciais na SWB são tão peculiares que seu diagnóstico clínico oferece poucas dúvidas antes de se confirmar com o teste molecular. Tais características são: depressão bitemporal, edema supraorbitário, nariz arrebitado, filtro nasal longo, bochechas proeminentes, lábios espessos, boca grande e queixo pequeno (Williams et al., 1961). 


\subsection{2 - Anomalias Cardiovasculares}

Uma das principais características da SWB é a alteração cardiovascular que pode estar relacionada à deficiência da elastina. Problemas arteriais são encontrados em torno de $77 \%$ a $79 \%$ dos pacientes, sendo frequentes os casos relatados com estenose aórtica supravalvar (EASV), seguida pela estenose periférica de artérias pulmonares (EAP) e mais raramente, pela insuficiência mitral, coartação de aorta e defeito do septo ventricular (Preus, 1984; Morris et al., 1988).

Estenose da artéria coronária, infarto do miocárdio, isquemia e arritmia são achados patológicos que predispõe indivíduos com SWB à morte súbita (Conway et al., 1990; Bird et al., 1996; Suárez-Mier e Morentin, 1999; Krouset al., 2008; Pober et al., 2008). Wessel et al. (2004) revelaram um risco de morte súbita de 1/1000, concluindo que "morte cardíaca súbita é um risco particularmente alto na SWB". National Center for Health Statistics, (1988) constata que a incidência é de 25 a 100 vezes mais alta que na população normal, na qual existem 0,01 a 0,04 mortes por ano.

Segundo Wessel et al.

A severidade da EASV não é um preditor para morte cardíaca súbita e estenose da artéria coronária não é a única razão para morte súbita na SWB, mas as arritmias malignas que acompanham hipertrofia ventricular esquerda 
nos pacientes com SWB são fortes suspeitas (Wessel et al., 2004).

Nesta síndrome é comum também histórico de hipertensão arterial, sendo associada à coartação de aorta, estenose de artéria renal, arteriopatia, nefrocalcinose e malformações renais, como aplasia renal, hipoplasia, distopia, duplicação renal, cistos e divertículos de bexiga (Ounap et al., 1998). Pode-se acometer hipertensão arterial sistêmica, secundária à doença arterial difusa, com comprometimento de artérias renais podendo se manifestar tardiamente na idade escolar (Sylos et al., 2002).

Sugayama et al.(2003) avaliaram 20 pacientes com diagnóstico confirmado de SWB e constataram a microdeleção no lócus do gene da elastina em $85 \%$ dos afetados; 16 pacientes (94\%) apresentavam cardiopatia congênita; destes, 13 (81\%) apresentavam EASV. O estudo concluiu que na SWB podem também ocorrer estenoses localizadas e difusas da aorta torácica e abdominal, das artérias coronárias e cerebrais. Este e outros achados associados à anomalias cardiovasculares na SWB podem caracterizar uma fragilidade orgânica no enfrentamento do estresse.

Segundo Lipp e Rocha (1998) indivíduos hipertensos sofrem aumento de pressão de grande porte quando se alteram nas relações sociais devido ao estresse social que podem sentir. Entretanto, na SWB, uma pesquisa de Del Campo et al. (2006) revelou que a ausência do gene NCF1, muito comum na síndrome, protege tais indivíduos de hipertensão. Quanto mais números de 
cópias do gene NCF1 maior o risco de hipertensão, devido a participação da angiotensina que altera o equilíbrio intracelular.

\subsection{3 - Anormalidades Gastrointestinais}

Constipação crônica, problemas de alimentação e refluxo gastroesofágico são característicos em $40 \%$ em crianças com SWB; diverticulose é um problema comum. Dor abdominal crônica pode ser debilitante para adolescentes ou adultos com uma miríade de etiologias incluindo hérnia de hiato, refluxo gastroesofágico, úlcera péptica, colelitíase, diverticulite, doença intestinal isquêmico, constipação e somatização da ansiedade (Morris et al., 1990; Pober e Morris, 2007).

\subsection{4 - Anormalidades Osteoarticulares}

Articulações hiperextensíveis são comumente observados em lactentes e crianças jovens com SWB, as quais contribuem para a instabilidade articular e atraso na locomoção. Como resultado, as posturas anormais compensatórias para alcançar a estabilidade, podem ser notadas. 
Gradualmente, aperto dos tendões de Aquiles e isquiotibiais ocorre, resultando em uma postura rígida e inábil na adolescência. Sinostose radioulnar resulta em limitação da supinação do antebraço; contraturas articulares, principalmente dos membros inferiores, foram relatados em $50 \%$ das crianças com SWB. Cifose (20\%) e lordose (40\%) são complicações comuns (Morris et al., 1988; Kaplan et al., 1989).

\subsection{5 - Anormalidades no crescimento}

O padrão de crescimento na SWB é caracterizada pela deficiência de crescimento pré-natal em $25-70 \%$, e o crescimento linear é pobre com ganho de peso nos primeiros 2 - 4 anos de vida. Crescimento estatural, em seguida, melhora na infância, embora $70 \%$ permanece abaixo do percentil 3 para a altura média parental (Pankau et al., 1992).

\subsection{6 - Anormalidades Geniturinário}

A SWB pode apresentar anomalias estruturais, como: hipoplasia da aorta torácica, agenesia ou hipoplasia renal, estreitamento da aorta suprarenal, ectopia, rim em ferradura, hidronefrose e duplicidade pielocalicial. Pode 
apresentar anomalias renais funcionais, como: proteinúria, refluxo vesicouretral e disfunções vesicais (enurese e urgência, freqüência, incontinência e infecções urinárias repetidas) as quais podem causar significativo impacto negativo no bem estar social e na qualidade de vida destes indivíduos (Morris et al., 1988).

Sugayama et al. (2003) investigaram aspectos renal e urinário em 17 pacientes com diagnóstico confirmado de Síndrome de Williams-Beuren pelo exame molecular de FISH. Cinco destes pacientes apresentam alterações renais, quatro apresentam disfunção miccional, três foram diagnosticados com hipertensão arterial, sendo um deles com estenose bilateral da artéria renal.

Sammour et al. (2006) realizaram avaliação urológica, urodinâmica e radiológica em 28 pacientes com SWB com idades entre 3 a 19 anos. Dos 22 pacientes avaliados, 53\% são sintomáticos, 62,7\% apresentam freqüência urinária, $50 \%$ enurese e $42,8 \%$ incontinência urinária. Do total, 14 pacientes (50\%) apresentam anormalidades no trato urinário.

\section{3 - Alterações Neurológicas}

\subsection{1 - Deficiência mental}

Segundo a definição adotada pela American Association of Mental Retardation (AAMR) - Associação Americana de Deficiência Mental, 
a deficiência mental ${ }^{1}$ é um funcionamento intelectual significativamente abaixo da média, coexistindo com limitações relativas a duas ou mais das seguintes áreas de habilidades adaptativas: comunicação, auto-cuidado, habilidades sociais, participação familiar e comunitária, autonomia, saúde e segurança, funcionalidade acadêmica, de lazer e trabalho. Manifesta-se antes dos dezoito anos de idade.

Em geral, a SWB apresenta um acentuado déficit intelectual (Quociente de Inteligência - QI médio de 55 com desvio padrão de 11 pontos) associado a dificuldades generalizadas na realização de tarefas conceptuais e de soluções de problemas (Gonçalves et al., 2004).

Outras pesquisas que utilizaram o teste de medida de QI "Wechsler Intelligence Scale" apontam escores entre 55 a 69 e padrão global entre 40 e 90 (Bellugi et al., 2000; Searcy et al., 2004; Thomaidis et al., 2004). No estudo de Sampaio et al. (2008) os participantes com SWB apresentam nos três índices fatorial de "Wechsler Intelligence Scala", níveis de QI leve a moderado, sendo que pontuam mais em verbal, com índice de compreensão superior a 57,88 .

Um estudo recente sobre funcionamento cognitivo na SWB avaliou 31 pacientes e mostrou que $71 \%$ da amostra apresentam escore de QI leve seguido de $13 \%$ com escore moderado, com escores de QI total entre 51 e 86 (Nunes, 2010).

\footnotetext{
${ }^{1} \mathrm{O}$ termo utilizado atualmente é Deficiência Intelectual.
} 
$\mathrm{Na}$ orientação viso-espacial, há um significativo déficit, evidenciando grandes dificuldades quer nas tarefas de desenho livre quer nas cópias de figuras geométricas; assiste-se, sobretudo a uma grande dificuldade na integração e coesão da informação viso-espacial (Bellugi et al., 2001; Nunes, 2010).

\subsection{2- Linguagem}

Vários estudos têm sido realizados na tentativa de estudar a competência sintática de indivíduos com SWB. O perfil comunicativo desta população é intrigante e coloca em dúvida o real comprometimento no âmbito pragmático, social e funcional das habilidades lingüísticas por utilizarem recursos estratégicos de comunicação, como o uso de clichês, efeitos sonoros, recursos entonacionais e as pausas plenas. Sampaio et al. (2008) avaliaram um grupo com 17 indivíduos com SWB e grupo controle com desenvolvimento normal e afirmam que o componente inteligência verbal é claramente superior ao

componente inteligência execução. A suposta dissociação de aspectos cognitivos e lingüísticos é também um ponto bastante controvertido na literatura (Gonçalves et al., 2004; Rossi; Moretti-Ferreira ; Giacheti, 2007) .

Mervis et al., (2000) compararam o desempenho de um grupo de crianças e adolescentes com SWB ao de outro grupo de mesma idade mental e com 
ausência de dificuldades de linguagem e revelam que os indivíduos com a SWB apresentam desempenho adequado nas tarefas que avaliam a habilidade sintática. Alguns estudos se detiveram especificamente na avaliação da linguagem sob uma perspectiva pragmática, principalmente com enfoque nas habilidades conversacionais e constatam melhor desempenho no grupo de indivíduos com SWB comparado ao grupo controle com desenvolvimento típico (Mervis et al., 2000; Laws \& Bishop, 2004; Catterall et al., 2006).

\subsection{3- Habilidade Cognitiva}

A deleção de alguns genes como LIMK1 e CYLN2 responsáveis pela habilidade cognitiva podem caracterizar o déficit cognitivo em alguns indivíduos com SWB.

Estudos prévios encontraram anormalidade na Formação hipocampal e redução do volume cerebral. Estas alterações se encontram a uma preservação proporcional de determinadas estruturas contrastando com outras e podem contribuir para anormalidades neurocognitivas na SWB. Estudos tendem a sustentar a existência de uma preservação proporcional das áreas corticais anteriores e temporo-límbicas (circunvolução temporal-superior) e, sobretudo, para a predominância do neocerebelo, a par de um claro déficit occipital que 
podem justificar um espectro de déficits cognitivos (Galaburda e Bellugi, 2000; Reiss et al., 2001; Meyer-Linderberg et al., 2005).

Déficit de inteligência não verbal é definido como prejuízos primários e secundários nas áreas da percepção visual e tátil, prejuízos nas habilidades psicomotoras complexas, na memória visual, solução de problemas, formação de conceitos e testes de hipótese associados a problemas psicossociais de desenvolvimento externalizante e internalizante (Simon, 2007).

Simon (2007) analisou um extenso conjunto de investigações sobre o funcionamento cognitivo na SWB e constatou que a maioria destes indivíduos, cuja pontuação na escala total de QI entre 40 e 90, não há diferença significante entre QI verbal e QI de execução e apresentam déficits de domínios cognitivos, como conhecimento conceitual básico, visuo-espacial, de habilidades de atenção e domínio espacial. "Eles têm dificuldade em matemática e sua aplicação à vida cotidiana". Em contraste, as habilidades cognitivas dos indivíduos com SWB são relativamente poupadas nos domínios de expressão, processamento auditivo, linguagem e processamento de face.

Um estudo de Sampaio et al. (2008) ao avaliar um grupo composto de 17 indivíduos com SWB com escore de QI verbal igual 55, QI execução igual 51 e QI total 50 e um grupo controle com desenvolvimento normal com escore de QI verbal igual 80 , QI execução 78 e QI total 77 , mostra que a aparente capacidade em dimensões interpessoais da linguagem pode fortalecer a 
impressão clínica de um funcionamento verbal conservado, que não se confirma por avaliação específica de QI verbal.

Segundo Sampaio et al. (2008):

A habilidade que indivíduos com SWB têm em envolver pessoas na interação social e sua relativa preservação de componente expressivo social de construção narrativa pode compor a ideia de habilidade de linguagem proficiente. $O$ desempenho em tarefas de subescala de execução pode ser afetado pelas dimensões de coordenação motora e visuoespacial, severamente prejudicadas na SWB.

Esse déficit visuo-espacial descrito na SWB pode estar relacionado às anormalidades neuronais, com comprometimento nas funções do hemisfério direito e da percepção visual no hemisfério esquerdo (Tassabejhi et al., 2003).

\subsection{4- Hiperacusia}

Indivíduos com SWB podem apresentar Hiperacusia e/ou Hipersensibilidade aos sons. Ocorre em 85 a 95\% na população com SWB e não está associada à história de otite média crônica ou a Distúrbio de Déficit de Atenção (Van Borsel et al., 1997).

O primeiro estudo a sistematicamente distinguir as diferenças entre várias anomalias auditivas no SWB, que têm sido, algumas vezes indiscriminadamente, denominadas "hiperacusia" na literatura foi realizado por 
Livitin et al., (2005) e definem os seguintes conceitos: Hiperacusia são limiares auditivos reduzidos, responsáveis pela detecção de sons suaves (Dirckx, 2001; Venes et al, 2001apud Livitn et al. 2005). Odynacusis é um limiar reduzido de dor para sons altos, também conhecido na literatura como níveis de intensidade ou de calmarias desconfortávelmente reduzido. Alodinia auditiva é a aversão substancial ou medo de certos sons normalmente não considerados aversivos, um estado patológico tipicamente proveniente de dano nos nervos ou tecido em que os pacientes sentem dor ao receber estímulos que normalmente não são percebidos como dolorosos. Fascínio auditivo é uma atração substancial ou fascinação para com certos sons (Phillips \& Carr, 1998 apud Livitn et al., 2005).

Livitin et al. (2005) também avaliaram um grupo de 118 indivíduos com SWB, um com 40 indivíduos com Síndrome de Down e um com 30 indivíduos com Autismo; para grupo controle foram avaliados 118 adultos com desenvolvimento típico. Os resultados indicam que os indivíduos com SWB apresentam quatro comportamentos incomuns de percepção auditiva: hiperacusia, odynacusis, aversões e fascínios auditivos em relação aos grupos comparativos. Ambos odynacusis e alodinia auditivos criam perigo e desconforto em indivíduos com SWB, e juntos constituem aversão.

É possível que sons considerados insuportáveis pelas crianças e adolescentes com SWB se configurem em fator de estresse.

Elsabbagh et al. (2011) desenvolveram uma pesquisa sobre a severidade da hiperacusia e sua interferência no ritmo de atividades perceptivas em 
indivíduos com SWB e grupos controles. A pesquisa conclui que o desempenho global do grupo de crianças com SWB é significativamente pior do que em crianças com desenvolvimento típico ( $p=0,01)$, assim como em adultos com SWB $(P<0,001)$. Neste trabalho, os autores afirmam que pais de crianças e adolescentes com SWB "precisam substancialmente adaptar o ambiente em torno de seu filho para evitar reações adversas resultantes de hiperacusia".

\section{4 - Aspecto sócio-comportamental}

Distúrbios comportamentais e emocionais são achados compatíveis com a SWB, afetando a maior parte dos pacientes. As alterações desse âmbito incluem distúrbio de hiperatividade com déficit de atenção (TDAH), ansiedade generalizada e fobias. De personalidade expansiva, eles tendem a serem extrovertidos e a apresentarem alto grau de sociabilidade e loquacidade. São também, muito preocupados e obsessivos por pessoas e atividades. Comumente, as crianças afetadas relacionam-se pouco com indivíduos de mesma idade, procurando companhia de adultos (Klein-Tasman e Mervis, 2003; Law e Bishop, 2004; Rossi et al., 2007; Leyfer et al., 2009).

Muñoz et al. (2010) realizaram um estudo sobre anormalidades no processamento neural de estímulos emocionais na SWB e concluem que a desregulação na amigdala pode levar a alteração nos perfis de engajamento 
social. Observaram a existência de uma resposta diferencial na dificuldade de tarefa nas regiões pré-frontal como uma função e uma ativação persistente no aumento da amígdala para cenas não-social por indivíduos com SWB, independentemente da carga cognitiva. "Estes dados fornecem evidências adicionais de interrupção no circuito amígdala-pré-frontal em indivíduos com SWB".

\subsection{1 - Déficit de atenção}

Déficit de atenção e hiperatividade são achados nas avaliações de indivíduos com SWB. Rhodes et al. (2010) avaliaram déficit de atenção e hiperatividade em um grupo de 19 indivíduos com SWB e compararam com

grupo controle de 19 indivíduos com desenvolvimento normal, sintomas comportamentais e funcionamento neuropsicológico típicos de TDAH. O grupo com SWB demonstram sintomas de desatenção com escores que indicam anormalidade e não diferem dos resultados obtidos no grupo com hiperatividade e impulsividade.

\subsection{2 -- Ansiedade}


Várias pesquisas têm considerado como característica da síndrome transtornos mentais como, TDAH e Ansiedade. Alguns estudos mostram o transtorno de ansiedade como característica marcante nesta população. Switag (2000) revela um aumento de sintomas relacionados à ansiedade no decorrer das idades; Klein-Tasman e Mervis (2003) afirmam que um dos aspectos da personalidade distinta destas crianças é a tendência para a ansiedade; Leyfer et al., (2006) revelam fobia específica altamente prevalente na SWB, associada, entre outros, à sons altos/agudos; Leyfer, Woodruff-Borden e Mervis, (2009) analisaram o transtorno de ansiedade nas crianças com SWB, suas mães e irmãos e constatam que as crianças apresentam maior prevalência em ansiedade do tipo fobia específica, concordando com o estudo anterior, suas mães apresentam alta prevalência de ansiedade generalizada em comparação com grupo controle e os irmãos; níveis similares de ansiedade foram comparados com a população geral. Neste último estudo, verificou-se também a possibilidade da existência de um gene responsável pela ansiedade, cuja deleção justificaria a presença do transtorno na SWB. Devido a prevalência de ansiedade nas crianças com SWB, é possível que haja um gene específico relacionado, porém não há pesquisas suficientes para esta confirmação. Stinton et al. (2012) avaliaram a saúde mental de 19 indivíduos com SWB e seus pais e constatam resultados semelhantes aos anteriores aqui citados e revelam que sintomas de depressão também estão presentes em ambos os grupos. 
É comum a relação entre estímulos ambiental estressores e sintomas depressivos, porém a relação entre sintomas ansiosos frente a estímulos ambientais estressores dificilmente são encontrados na literatura. Esta constatação sugere maior consideração em relação ao sofrimento de estresse nos indivíduos com SWB.

\section{5 - Etiologia}

\subsection{1 - Aspectos cromossômicos e moleculares}

SWB é causada por uma microdeleção no braço longo do cromossomo 7, próximo ao centrômero, região 11.23, na qual estão deletados 25 a 28 genes (Merla et al., 2010). Figura 1 


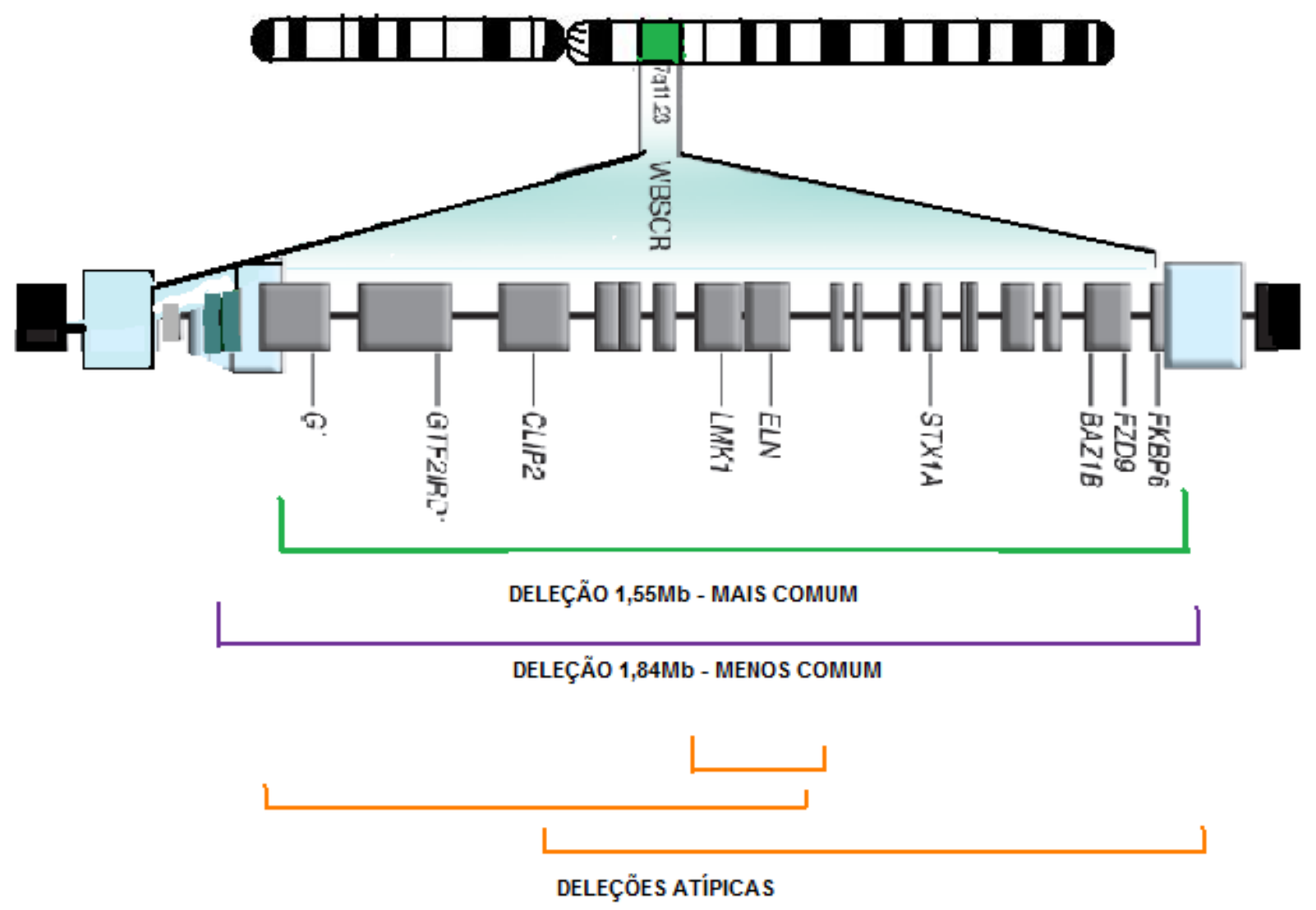

Figura 1 - Microdeleções 7q11.23 que caracteriza a SWB

O gene Elastina $(E L M)$ é uma proteína estrutural da matriz extracelular que compõe $90 \%$ das fibras elásticas as quais são responsáveis pela restauração da forma após o estiramento ou distensão de uma variedade de tecidos e sua ausência pode resultar em estenoses em veias e artérias e comprometimento de órgãos, como pulmões, intestinos e à pele (Morris, 1998). Podem-se justificar com a deleção deste gene as características faciais dismórficas, o envelhecimento precoce da pele, o tom de voz baixo e rouco, a presença de divertículos, hérnias inguinais, genitália pequena, contraturas e frouxidão articular, além das alterações cardiovasculares, como a estenose 
aórtica supravalvular, muito presentes na SWB. Porém, sua total relação a estas anomalias ainda é pouco esclarecida (Collins, 2010; Merla et al., 2010).

Os genes LIMK1, CYLN2 e GTF2I podem estar associados ao fenótipo neurocomportamental, como memória, aprendizagem, déficits cognitivos, ansiedade e fobias. O gene STX1A está relacionado ao prejuízo do metabolismo da glicose e diabetes (Pober et al., 2010). Outros genes, como RFC2, LAT2, IF4H, CLIP2, CLDN3, ABHD11 se apresentam na literatura com funções desconhecidas (Smith et al., 2009; Merla et al., 2010). A patogênese da arteriopatia na SWB pode ser a mais complexa e possivelmente está relacionada a outros genes na região crítica da SWB, tais como NCF1 que pode estar associado à hipertensão arterial. Esta pode ocorrer mesmo na infância e adolescência, com uma frequência observada de $50 \%$ dos pacientes (Del Campo et al., 2006).

Esta complexidade genotípica pode implicar em considerações acerca da possível fragilidade orgânica dos indivíduos com SWB frente ao estresse crônico.

\subsection{2 - Teste molecular}

Pode-se confirmar o diagnóstico de SWB pelo método "padrão ouro" Hibridization in situ Fluorescent (FISH), técnica que permite localizar uma seqüência específica de ácido desoxirribonucléico numa banda cromossômica 
(Stumm et al., 1999). Consiste na hibridização de uma sonda marcada com fluorescência para identificar o seu segmento complementar dentro de uma metáfase cromossômica espalhada numa lâmina. São utilizadas sondas de 2 a $100 \mathrm{~Kb}$ e pode ser feito tanto em metáfase como interfase.

O diagnóstico da SWB se confirma também com o teste molecular, que pode ser feito através do método de Marcadores Polimórficos que consiste na utilização de sondas que permitem detectar o polimorfismo que segrega juntamente com a deleção $\mathrm{q}(11.23)$. Este teste exige a coleta do material genético dos pais do portador da SWB para investigar a origem parental da microdeleção no referido cromossomo. Apesar da variabilidade fenotípica verificada nos indivíduos com SWB, parece haver pouca variação no tamanho da deleção relativa a este distúrbio genético, conforme determinado através de análise com marcadores polimórficos, sendo o tamanho $1,55 \mathrm{Mb}$ mais encontrado e o menos freqüente, $1,84 \mathrm{Mb}$. Tamanhos maiores são descritos como raros. O fenótipo na SWB pode variar dependendo do tamanho da microdeleção (Bayes et al. 2003), porém não há estudos sobre a associação de vulnerabilidade de estresse com tamanho da microdeleção.

O diagnóstico de SWB também pode ser confirmado pelo Multiplex Ligation-dependent Probe Amplification (MLPA), um método relativamente novo e fácil de detectar deleções e duplicações de sequências-alvo específicas, com a hibridação simultânea e amplificação de mais de 40 sondas diferentes em uma única reação (Schouten et al., 2002). Foi desenvolvido um kit para MLPA 
específico para a SWB, capaz de detectar microdeleções ou microduplicações de um ou mais éxons dos seguintes genes: ELN, CYLN2, TBL2, STX1A, LIMK1, RFC2 e FKBP6 (Bayés et al. 2003).

\section{6 - ESTRESSE}

\subsection{1 - Histórico Conceitual}

Um dos primeiros cientistas a demonstrar experimentalmente a ligação do estresse com o enfraquecimento do sistema imunológico foi Louis Pasteur (1822-1895). Em estudo pioneiro no final do século IX, ele observou que galinhas expostas a condições estressantes eram mais suscetíveis a infecções bacterianas que galinhas não estressadas. Desde então, o estresse é tido como um fator de risco para inúmeras patologias que afligem as sociedades humanas, como patologias cardiovasculares (arteriosclerose, derrame), metabólicas (diabetes insulino-resistente ou tipo 2), gastrointestinais (úlceras, colite), distúrbios do crescimento (nanismo psicogênico, aumento do risco de osteoporose), reprodutivas (impotência, amenorréia, aborto espontâneo), infecciosas (herpes labial, gripes e resfriados), reumáticas (lupus, artrite reumatóide), câncer e depressão (Goldstein, 2010; Evers et al.,2011).

O fisiologista Walter Cannon (1871-1945) desenvolveu estudos sob questões biológicas relacionais à homeostasia, o equilíbrio entre o organismo e 
o ambiente (Lent, 2004). Cannon (1939) ${ }^{2}$ citado por Goldstein (2011) "definiu o termo "homeostase" para descrever a manutenção dentro de limites aceitáveis de variáveis fisiológicas, como glicose no sangue e níveis de temperatura". O objetivo da homeostase implica em definir valores para as variáveis monitoradas; no entanto, os intervalos de valores aceitáveis são decididamente inconstantes. Níveis de atividade fisiológica necessários para restabelecer ou manter a homeostase diferem, dependendo continuamente de novas condições em que o organismo se encontra (Goldstein, 2011).

Diferentemente da bioquímica, Hans Hugo Bruno Selye (1907-1982) iniciou seus estudos conceituando estresse em humanos numa versão de Síndrome da Adaptação Geral, na qual se apresenta em três fases, Alarme ou Alerta que se caracteriza pelo confronto do organismo com o estressor e se prepara para lutar ou fugir; Resistência ou Defesa é a tentativa de recuperação pelo confronto do organismo com o estressor por um período prolongado ou de intensidade excessiva, obrigando o organismo se acomodar utilizando reservas adaptativas com o objetivo de reequilíbrio interno (homeostase) e Exaustão ou Esgotamento na qual o agente estressor perdura por longo tempo, impossibilitando o organismo de lutar ou fugir; ou quando vários estressores

${ }^{2}$ Cannon, WB. The wisdom of the body. W.W. Norton; New York: 1939. 
ocorrem simultaneamente, levando ao surgimento de doenças graves em nível psicológico e/ou fisiológico (Selye, $1965^{3}$ citado por (Lipp et al. 2003).

Uma definição atual de estresse, segundo Goldstein e Kopin (2007)

é como uma condição onde as expectativas, pela aprendizagem estabelecida anterior ou deduzida a partir de circunstâncias, não coincidem com percepções atuais ou previstas do ambiente interno ou externo, e esta discrepância entre o que é observado ou sentido e o que é esperado ou programado elicia respostas padronizadas ou compensatórias.

O estresse incontrolável, particularmente quando excessivo e/ou prolongado, pode produzir uma infinidade de alterações emocional e cognitiva (De Kloet e Oitzl, 1999 e Roozendaal, 2002).

Mais recentemente, pesquisas de Lipp (1998; 2000; 2002; 2007) mostram a complexidade e o percurso do estresse na criança e no adolescente. "O estresse não é uma doença. É uma condição que enfraquece o organismo e, assim oferece oportunidade para as doenças surgirem" (Lipp, 2002). De acordo com dados da Organização Mundial de Saúde (OMS), o estresse afeta mais de 90\% da população mundial e é considerado uma epidemia global.

Segundo Lipp e Novaes (2003) os fatores externos que mais causam estresse na infância são: mudanças significativas ou constantes, responsabilidades em excesso, excesso de atividades, brigas ou separações

\footnotetext{
${ }^{3}$ Selye, H. (1965). Stress a tensão da vida (2a ed.). São Paulo: Ibrasa.
} 
dos pais, morte na família, exigência ou rejeição por parte dos colegas, disciplina confusa por parte dos pais, nascimento do irmão, troca de professores ou de escola, mudança de vizinhança, pais e professores estressados, etc.. Os fatores internos são os do próprio indivíduo, que o levam a reagir e a sentir-se de determinado modo. Esses fatores que geram estresse na criança são: ansiedade, depressão, timidez, desejo de agradar, medo de fracasso, medo de que os pais morrem e ela ficar só, medo de ser ridicularizada por amigos (...). "Conforme as habilidades e os repertórios comportamentais da pessoa para enfrentar e manejar estes agentes, o nível de estresse variará".

\subsection{2 - Reações ao Estresse}

Um indivíduo pode ter sensações de medo rápidas e passageiras ou lentas e duradouras. Nos dois casos, tudo depende da natureza do estímulo que o provoca: pode ser um susto repentino ou uma ameaça que permanece nas redondezas.

Há também, o estímulo virtual: aquele que não está presente, embora possa acontecer, a qualquer momento. Nesse caso, o medo se prolonga mais ainda. Quando isso ocorre continuamente, durante muito tempo, o sentimento se transforma em um estado de tensão ou estresse e, a freqüência deste se transforma em uma emoção chamada ansiedade (Lent, 2004). Em 
determinadas situações que exigem um desempenho elevado por parte do indivíduo, as reações de "luta e fuga" são desejáveis e necessárias, pois proporcionam energia e o impulsionam para a ação. Por outro lado, se o indivíduo percebe os estímulos do ambiente como altamente ameaçadores e não tem suficientemente desenvolvidas as habilidades adequadas para lidar com seu estresse, pode permanecer por muito tempo sob o efeito das mudanças biológicas ocasionadas pela resposta de "luta e fuga". O resultado é um desgaste do organismo e podem surgir problemas de saúde, como distúrbios psicossomáticos, hipertensão arterial, problemas cardíacos, úlceras, entre outros (Lipp et al., 2003).

\subsection{3 - Complicações Orgânicas de estresse}

O indivíduo em estado de alerta diante de um agente estressor necessita de grande esforço físico que exige ajustes fisiológicos, começando pela hipófise, pelas glândulas supra-renais e por uma vasta constelação de alterações endócrinas, enzimáticas e eletrolíticas. Figura 2 


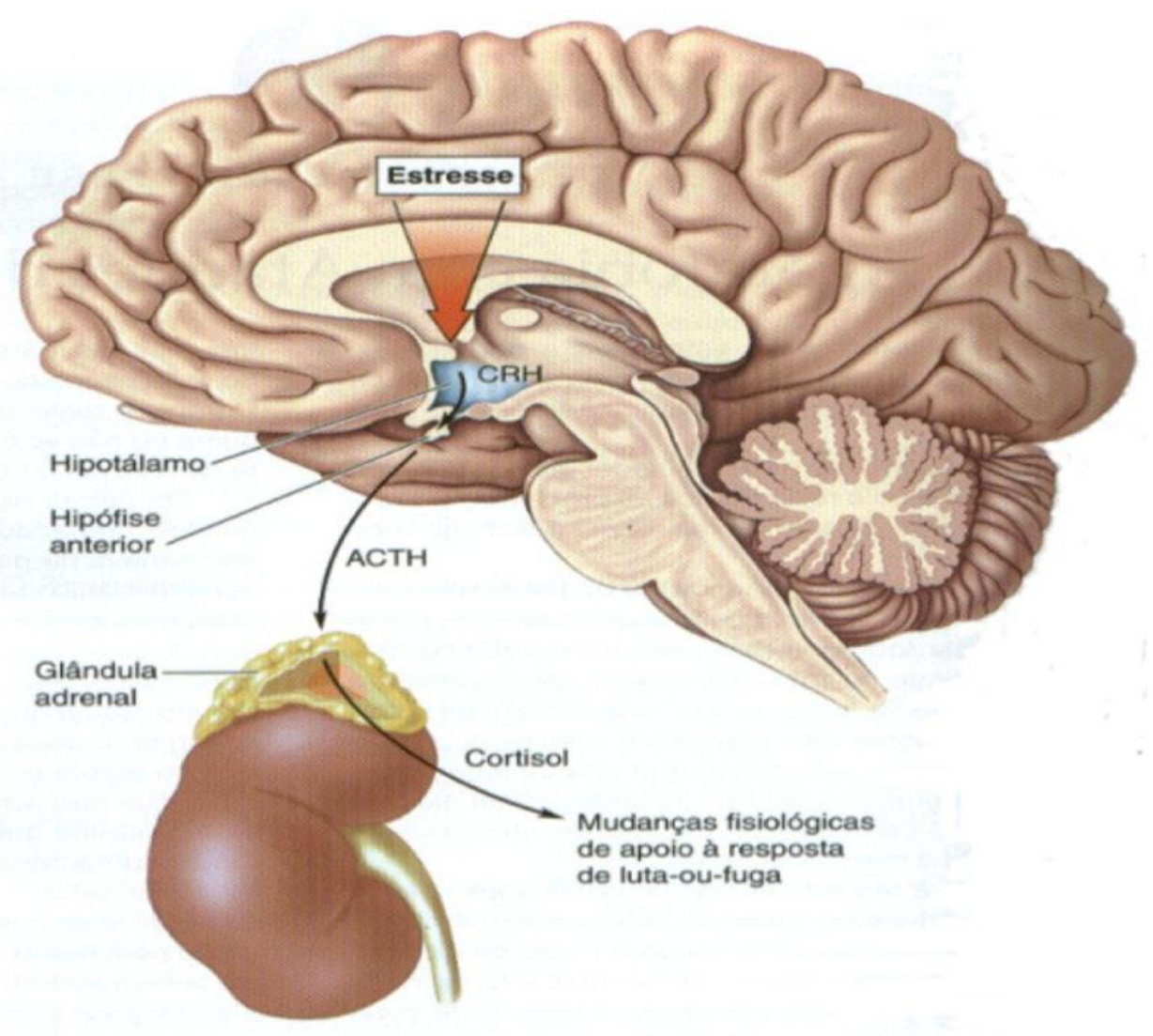

Figura 2. Esquema do eixo hipotálamo-hipófise-adrenal.

O Hipotálamo recebe informações da vias sensoriais, envia para a hipófise, esta produz o hormônio corticotrópico e é enviado para a glândula adrenal que produz o hormônio adrenocorticotropico, que ao ser lançado na corrente sanguinea, produz o hormônio glucocorticoide gerando energia para o corpo.

Fonte: www.psiquiatriageral.com.br/cérebro/texto13.htm 
A freqüência cardíaca se acelera e ocorre vasoconstrição cutânea, aumentando e redirecionando o fluxo sanguíneo para o músculo e sistema nervoso, dificultando o controle da pressão arterial. A respiração também se acelera e as vias aéreas se dilatam, resultando em aumento da oxigenação do sangue e dos tecidos. Cessa o peristaltismo digestivo, que não é necessário nesse momento, pode ocorrer sudorese, alteração no sistema imunológico, descontrole dos níveis de glicose do sangue por ativação hormonal (Lent, 2004).

Concomitantemente, a excitação emocional está associada a uma ativação global do sistema nervoso autônomo, no qual o subsistema simpático atua em situações de emergência, enquanto que o subsistema parassimpático controla as funções vegetativas. O corpo responde a praticamente qualquer evento súbito, inesperado, que pode acionar os subsistemas, cujas interferências podem ser colaborativas. Ao liberarem os mediadores químicos na corrente sanguínea, por exemplo, glucocorticóides e catecolaminas, aumentam a frequência cardíaca e pressão arterial, sobem a pressão arterial e a taxa de açúcar no sangue, que por sua vez fui menos para as vísceras e mais para os músculos, ajudando o indivíduo a lidar com a situação. Estas alterações contribuem para que o indivíduo reaja rapidamente a um estímulo estressor (McEwen, 2008).

Entretanto, a elevação crônica dos mediadores por tempo prolongado pode induzir, por exemplo, debilidade no sistema imunológico devido a falta de 
apetite, expondo o organismo à doenças, como infecções, ou pode produzir um desgaste crônico no sistema cardiovascular, que pode resultar, em longo prazo, doenças como o Acidente Vascular Encefálico e ataques cardíacos.

\subsection{4 - Estresse na Infância e Adolescência}

Fatores estressantes estão presentes no desenvolvimento infantil devido às mudanças que ocorrem nas condições internas e externas da criança, conseqüentes da passagem de um estágio ao outro (Lipp e Malagris, 2007). Estes sintomas específicos relacionados podem ser explicados, principalmente por fatores ambientais. Quando a criança é exposta a um evento estressante, seja ele bom ou ruim, ela entra em estado de alerta, ocorrendo uma ativação do sistema nervoso autônomo e da glândula pituitária, acionados pelo hipotálamo (Talge et al., 2008). Ao mesmo tempo, ocorre a ativação das glândulas suprarenais que liberam adrenalina, preparando a criança para a reação de "luta ou fuga" e provocando a inibição das atividades vegetativas, o que pode ocasionar mudanças nos hábitos alimentares (perda de apetite), alteração no sono (pesadelos e insônias) e outras alterações fisiológicas (Lipp e Novaes, 2003). Os adolescentes podem estar propensos ao estresse excessivo devido a fase em que se encontram, a qual se caracteriza em constantes mudanças físicas e 
psicológicas (Tricoli ${ }^{4}$ in: Lipp, 2007). Além disso, evidências sugerem que uma predisposição genética-biológica à reatividade neuroendócrina pode levar à respostas comportamentais anormais frente aos estímulos estressantes independente da fase da vida em que o indivíduo se encontra (Bakshi e Kalin 2000).

\subsection{5 - Estresse na Síndrome de Williams-Beuren}

As características comportamentais da SWB, como personalidade expansiva, bem marcante nesta síndrome; as alterações neurológicas como deficiência intelectual, apresentando QI em média 60 (leve a moderado); deficiência na percepção e construção visuoespacial; déficit de atenção em 73 a 87\% dos casos; ansiedade; hiperacusia em 50 a $85 \%$ dos casos; aparente linguagem e narrativa excelentes, que os diferenciam de outras síndromes com rebaixamento intelectual, podem ser passíveis de terem aumentos de níveis de excitação e, consequentemente de estresse.

Um aspecto relevante na SWB são as respostas cardiovasculares que resultam principalmente em aumento da freqüência cardíaca, da contratilidade,

\footnotetext{
${ }^{4}$ Tricoli VAC. A importância da avaliação do stress na adolescência. Anais III Congresso Brasileiro de Stress; 26 a 27 de outubro de 2007 (p. 41).
} 
do débito cardíaco e da pressão arterial devido à carência de elastina. Este quadro sugere uma predisposição ao desenvolvimento de aterosclerose, processo inflamatório excessivo e prolongado na parede vascular (Kaperonis et al., 2006; Vlastelica, 2008). Indivíduos com histórico de estresse emocional crônico geralmente têm histórico de doença cardíaca e estão em risco de serem vítimas de morte súbita (Gips, et al, 2009).

A superexposição a uma combinação de múltiplos sistemas de resposta corporais ativados (por exemplo neuronais, endócrinos, cardiovasculares) altera a habilidade do corpo em responder com eficiência às demandas ambientais. A exposição freqüente a estressores ambientais acelera o desgaste do corpo.

Estudos prévios demonstraram que experiências estressantes no início da vida afetam, a longo prazo, o desenvolvimento do sistema neuroendocrinológico, assim como as funções cognitivas e comportamentais (Heim e Nemeroff, 2001; Mello et al., 2007; Talge et al., 2008; Gunnar et al., 2009). Esta constante pode provocar alterações orgânicas, como cardiopatias, distúrbios de memória e ansiedade, muito semelhantes às complicações identificadas nas pessoas com SWB. Estas observações hipotetizam que indivíduos com SWB estão em riscos se expostos ao estresse crônico.

O eixo hipotalâmico-pituitário-adrenal (HPA) é uma resposta adaptativa ao estresse na medida em que o indivíduo se prepara para lidar com a fonte de estresse. Elevações crônicas de cortisol podem agravar o quadro clínico das crianças e adolescentes com SWB e provocar efeitos adversos sobre 0 
organismo e o cérebro que podem interferir no aprendizado e memória (Sapolsky, 2000). Estudos de McEwen \& Sapolsky, (1995) e McEwen \& Gianaros, (2010) revelam que, enquanto a resposta ao estresse é um mecanismo adaptativo, o estresse intenso agudo ou crônico pode ser a fonte de prejudiciais efeitos neurocognitivos.

Em um estudo das características da personalidade de crianças com SWB, Klein-Tasman e Mervis (2003) observaram uma prevalência de ansiedade que pode estar associada ao comportamento eufórico e a hiperacusia. As fobias específicas, muito comum nesta síndrome, podem desencadear um estresse crônico porque os estímulos se prolongam ou o indivíduo os mantém como ameaças futuras. Sons muito fortes e súbitos aversivos às crianças e adolescentes com SWB também podem ser significativos agentes estressores.

\subsection{6 - Estresse no ambiente Escolar}

\subsubsection{1 - Escola Especial}

Em 1961, o atendimento educacional às pessoas com deficiência passa ser fundamentado pelas disposições da Lei de Diretrizes e Bases da Educação 
Nacional, (LDBEN) Lei $\mathrm{n}^{\circ}$. 4.024/61, que aponta "o direito dos 'excepcionais' à educação, preferencialmente dentro do sistema geral de ensino".

A Lei no. 5.692/71, que altera a LDBEN/61, ao definir 'tratamento especial para os alunos com deficiências físicas, mentais, os que se encontrem em atraso considerável quanto à idade regular de matrícula e os superdotados", não promove a organização de um sistema de ensino capaz de atender as necessidades educacionais especiais e acaba reforçando o encaminhamento dos alunos para as classes e escolas especiais.

A escola especial se organizou tradicionalmente como atendimento educacional especializado substitutivo ao ensino comum, evidenciando diferentes compreensões, terminologias e modalidades que levaram a criação de instituições especializadas, escolas especiais e classes especiais. Essa organização, fundamentada no conceito de normalidade/anormalidade, determina formas de atendimento clínico terapêuticos fortemente ancorados nos testes psicométricos que definem, por meio de diagnósticos, as práticas escolares para os alunos com deficiência (MEC/SEESP, 2001).

Desta forma, entende-se que superproteção pode ser considerada como uma característica da Escola Especial, por sua segregação, podendo ser um fator estressante, uma vez que não dá oportunidade para a criança enfrentar desafios próprios de sua idade. Pode também gerar angústia pela capacidade da criança em perceber que não faz parte de um convívio social comum. Sugere-se que a interação social tenha um enfoque terapêutico dentro do 
ambiente escolar com crianças e adolescentes com SWB devido seu desinteresse por seus pares, pois sua personalidade superamigável contribui para minimizar preconceitos e discriminações.

\subsubsection{2 - Inclusão Educacional}

Por volta dos anos 90, o tema inclusão escolar parte de um conceito maior de "inclusão social". Esta é entendida como o processo bilateral no qual as pessoas ainda excluídas e a sociedade buscam a equiparação de oportunidades para todos (Aranha, 2001: Prieto, 2002). Na tentativa de construir uma educação inclusiva, a inclusão escolar tem estado presente nos estudos, debates e proposições de políticos, pesquisadores, gestores, professores, pais e alunos.

Educação inclusiva entende-se aqui como um processo de garantia do acesso imediato e contínuo do indivíduo com necessidades especiais ao espaço comum e da vida em sociedade, independentemente do grau de comprometimento apresentado (Aranha, 2001). Como parte integrante desse processo e contribuição essencial para determinação de seus rumos, encontrase a inclusão educacional, na qual os alunos com e sem deficiência devem 
conviver nas mesmas escolas e salas aprendendo com suas diferenças e se ajudando mutuamente no desenvolvimento de suas potencialidades. É garantida pela Constituição Federal de 1988, que elege como fundamento da República a cidadania e a dignidade da pessoa humana (art. 1ํㅜㄹ incisos II e III), e que tem como um de seus objetivos fundamentais "a promoção do bem de todos, sem preconceito de origem, raça, sexo, cor, idade e quaisquer outras formas de discriminação (art. $3^{\circ}$ inciso IV).

Portanto, para que se discuta a concretização do direito de todos à educação e plena cidadania é preciso, primeiramente, assumir o reconhecimento da exclusão que se configura pelos segmentos e pessoas envolvidas.

Inclusão educacional remete o processo e empreendimento de cada criança, e não ao de um grupo ou categoria específica (Aranha, 2001). Portanto, as escolas devem respeitar as características dos alunos e oferecer alternativas pedagógicas que atendam suas necessidades comuns e específicas, garantindo, assim, o direito às crianças e jovens com deficiências, uma educação de qualidade e a uma vida autônoma e feliz, conforme mostra o estudo sobre desvantagens sociais e adolescentes estressados de Goodman, et.al. (2004).

De acordo com as Diretrizes e Bases da Educação Nacional - Lei no 9394/96, (art. 59 incisos I ou V): 
os sistemas de ensino devem assegurar aos educandos com necessidades especiais currículos, métodos, técnicas, recursos educativos e organizações específicas que atendem às suas necessidades. Além disso, são necessários professores com especialização adequada em nível médio ou superior, com capacitação atualizada, para atendimento especializado, bem como professores do ensino regular capacitados para integração desses alunos nas classes comuns. Deve-se garantir 0 acesso igualitário aos benefícios dos programas sociais suplementares disponíveis para o respectivo nível do ensino regular.

Consta também na Lei n 9.394/96, (art. 58, parágrafo $3^{\circ}$ ) que "A educação de crianças com necessidades educacionais especiais deve ser realizada, preferencialmente, na rede regular de ensino". Devendo cada escola adaptar-se para a diferenciação de intervenção que possibilite dar oportunidades de aprendizagem e desenvolvimento mais próximo da realidade da criança quanto possível, assegurando um ambiente de paz, tranqüilidade e estabilidade no seu quadro de saúde.

Pesquisadores da área de interação social têm identificado que estudantes rejeitados socialmente interagem diferentemente, com agressividade, rejeição e ignoram outros alunos (Batista e Enumo, 2004). Essa situação pode ser considerada altamente estressante para as crianças com SWB, objeto deste estudo.

A escola é um ambiente que constantemente oferece situações novas, pois para uma efetiva aprendizagem é preciso se confrontar com o novo, com o desconhecido. E, todo enfrentamento com o estranho gera estresse - a princípio, um estresse saudável (Lipp, 2002). 
Adequação escolar é necessária para atender toda criança necessitada de atendimento educacional especializado, seja pelo aspecto pedagógico, social e ambiental (Sousa e Prieto, 2002). Na ausência desta condição, a tendência é se transformar em um fator estressor cada vez que ela não souber lidar com a ansiedade, com a hiperacusia, com a deficiência intelectual, muito presentes em crianças e adolescentes com SWB.

O fator ambiental escolar na condição da pessoa com deficiência pode ser um predito de estresse, ao considerar que a escola pode não estar preparada para receber alunos com deficiência. Orientar a gestão escolar que recebe crianças e adolescentes com SWB, quanto às suas peculiaridades, é necessário para que se diminuam possíveis fatores estressantes como, excesso de barulho agudo, adequação curricular, discriminação e outros nos diversos tipos de escolas, principalmente nas escolas em processo de inclusão para que se aperfeiçoe o atendimento educacional e se façam cumprir as leis governamentais ao que se refere à educação especial.

\section{JUSTIFICATIVA}

A condição clínica da SWB caracteriza-se pelos déficits perceptivos, atentivos e de cognição que podem contribuir para incapacitar os indivíduos no enfrentamento do estresse. 
O estresse, embora possa ser desencadeado de forma positiva, exige que a pessoa com organismo saudável, tenha recursos próprios, internos e externos para melhor combatê-lo.

Trata-se de primeiro estudo sobre estresse na SWB. A proposta é analisar os níveis de estresse em crianças e adolescentes que supostamente apresentam um organismo fragilizado por sua condição clínica.

Portanto, as hipóteses no presente estudo são: que crianças e adolescentes com SWB apresentam índice mais elevado de estresse do que crianças e adolescentes sem a síndrome; que pacientes que frequentam escola especial, por se caracterizar instituição superprotetora, podem apresentar menos estresse que pacientes de escolas de inclusão; que pacientes com deficiência intelectual moderada sofrem mais estresse e que as reações ao estresse de crianças e adolescentes com SWB podem ser diferentes de pessoas sem a síndrome. 
OBJETIVOS 


\section{2 - Objetivos}

- Determinar os níveis de estresse em crianças e adolescentes com Síndrome de Williams e comparar com o grupo controle normal sem a SWB..

- Verificar o nível de estresse entre crianças e adolescentes com SWB que frequentam escola de inclusão e escola especial.

- Correlacionar o nível de estresse em crianças e adolescentes com SWB com coeficiente de inteligência (QI).

- Caracterizar os tipos de reações de estresse em crianças e adolescentes com SWB. 
MÉTODOS 


\section{3 - Método}

\section{1 - Casuística}

O presente estudo foi retrospectivo e foi aprovado pelo Comitê de Aperfeiçoamento de Pesquisa (CAPPesq), sob o protocolo ํํ 944/08 (anexo A).

Foram avaliados 40 pacientes com SWB que estão em acompanhamento ambulatorial na Unidade de Genética do Instituto da Criança do HC-FMUSP, oriundos da cidade de São Paulo, municípios adjacentes e de outros estados do território brasileiro.

Todos os pais dos pacientes foram submetidos à entrevista inicial e assinaram termo de consentimento para a realização da pesquisa (anexo B).

Os critérios de inclusão foram crianças e adolescentes com diagnóstico confirmado pelo estudo molecular, Fluorescence in situ Hibridization (FISH), Marcadores Polimórficos ou Multiplex-Ligation dependent Probe Amplification (MLPA), idade entre 7 anos a 18 anos e estarem freqüentando escola de inclusão ou especial.

Assim na casuística de 40 pacientes estudados 21 eram do sexo masculino e 19 do sexo feminino; 27 freqüentavam escola de inclusão e 13 freqüentavam escola especial.

O grupo controle (GC) foi constituído por 40 alunos sem síndromes, de escolas comuns públicas do ensino fundamental ao médio, onde havia 
pacientes com SWB incluídos, e foram pareados por idade e sexo com o grupo com SWB.

\section{2 - Procedimentos}

\subsection{1 - Escala de Estresse Infantil - (ESI)}

Os instrumentos utilizados para a avaliação do nível e tipos de reação de estresse foi o questionário da Escala de Estresse Infantil, (ESI) de Lipp e Lucarelli (1998) e o Inventário de Sintomas de Estresse para adulto de Lipp. Ambos os instrumentos brasileiros, validados para utilização de pesquisa, e de fácil aplicação que permite diagnosticar se a criança ou o adulto, respectivamente, apresenta um quadro sintomatológico de estresse. Anexo C

O instrumento ESI surgiu como resultado da dissertação de mestrado de Maria Diva Monteiro Lucarelli, intitulado "Inventário de Sintomas de Estresse Infantil: um estudo de validação", defendida no Departamento de pósgraduação da PUCCAMP em 1997, sob orientação de Marilda E. Novaes Lipp $(\mathrm{PhD})$. Trata-se de um instrumento de alta confiabilidade, apresentando um coeficiente Cronbach Alpha de 0,90, maior que o apresentado pelo instrumento Lifestress Inventary que foi de 0,86 , considerado altamente confiável por vários estudos de Bramston \& Fogarty (2000). 
ESI é composta de 35 itens em escala de Likert de 0 a 4 pontos, relacionados às seguintes reações de estresse: físicas (itens $2 ; 6 ; 12 ; 15 ; 17$; 19; 21; 24 e 34), psicológicas (itens 4; 5; 7; 8; 10; 11; 26; 30 e 31), psicológicas com componente depressivo (itens $13 ; 14 ; 20 ; 22 ; 25 ; 28 ; 29 ; 32$; e 35 ) e psicofisiológicas (itens $1 ; 3 ; 9 ; 16 ; 18 ; 23 ; 27$ e 33).

ESI indica médias e desvio padrão de estresse para reações físicas (RF), psicológicas (RP), psicológicas com componente depressivo (RPCD), psicofisiológicas (RPF) e estresse total (T). Esta padronização permite verificar níveis de estresse (normal, Alerta, Resistência e Exaustão) nos diferentes tipos de reações. Quadro 1 e 2.

A escolha pelo instrumento ESI neste estudo foi feita por ser menos invasivo, no qual a própria criança responde as questões e, em caso de dúvida ou apenas para confirmar a veracidade das respostas, os cuidadores podem ser ouvidos. No entanto, para melhor interpretação das questões, modificou-se a estratégia de formulação de cada um dos itens da Escala de Stress Infantil. Por exemplo, no lugar de ler: "Eu me sinto assustado na hora de dormir", lia-se o item adaptado "Você se sente assustado(a) na hora de dormir?" acrescido de "por que?". Ao término da aplicação da escala, o responsável é ouvido para verificação das respostas, em caso de significativa discordância o paciente era excluído da pesquisa. Já as crianças e adolescentes do grupo controle responderam diretamente às escalas de estresse. 
Quadro 1 - Média e Desvio Padrão em relação aos fatores de estresse

\begin{tabular}{|c|c|c|}
\hline Fatores & Média & Desvio Padrão \\
\hline RF & 8,8 & 6 \\
\hline RP & 13,8 & 6,9 \\
\hline RPCD & 7,5 & 6,2 \\
\hline RPF & 9,5 & 5,3 \\
\hline TOTAL & 39,6 & 19,9 \\
\hline
\end{tabular}

$\mathrm{RF}=$ Reações Físicas; RP=Reações Psicológicas; RPCD=Reações

Psicológicas Com Componente Depressivo; RPF= Reações

Psicofisiológicas

QUADRO 2 - Tipos de reações e níveis de estresse

\begin{tabular}{|l|c|c|c|c|}
\hline Reações & Normal & Alerta & Resistência & Exaustão \\
\hline RF & 8,8 & $>8.8-14,8$ & $>14,8-20,8$ & $>20,8$ \\
\hline RP & 13,8 & $>13,8-20,7$ & $>20,7-27,6$ & $>27,6$ \\
\hline RPCD & 7,5 & $>7,5-13,7$ & $>13,7-19,9$ & $>19,9$ \\
\hline RPF & 9,5 & $>9,5-14,8$ & $>14,8-20,1$ & $>20,1$ \\
\hline TOTAL & 39,6 & $>39,6-59,5$ & $>59,5-79,4$ & $>79,4$ \\
\hline
\end{tabular}

Sendo assim, a escala possibilita verificar a existência ou não de estresse infantil além de determinar o tipo de reação mais freqüente na criança, o que facilitará um monitoramento adequado ao estresse. 


\section{Inventário de Sintomas de Stress para adulto de Lipp (ISSL)}

O Inventário de Sintomas de Stress para Adulto é um instrumento útil na identificação de quadros característicos do estresse, possibilitando diagnosticar o nível de estresse em adultos e adolescentes. Baseia-se em um modelo quadrifásico e propõe um método de avaliação do estresse em níveis (alerta, resistência, quase-exaustão e exaustão) e Sintomas (físicos e os Psicológicos). Embora o instrumento não exija que o indivíduo seja alfabetizado, as questões se apresentam subjetivas 0 suficiente para incapacitar os pacientes com SWB de respondê-las (observações feitas no ambulatório do hospital, no momento da aplicação do teste). Portanto, o instrumento foi aplicado apenas aos adolescentes do grupo controle (11 participantes com idade entre 15 a 18 anos de idade). Anexo D

\subsection{2 - Questionário}

A constatação de pacientes com SWB com nível de estresse em fase de resistência e de exaustão se fez necessário um questionário de perguntas padronizadas (fechadas), o qual foi respondido pelos pais, para caracterização sociodemográfica da amostra e duração de possíveis eventos traumáticos baseado no DSM-IV-TR (Diagnóstico e Estatísticos de Transtornos Mentais, 4⿳亠丷a edição). Anexo E 


\subsection{3 - Pré teste}

Verificou-se que a média de Quociente de Inteligência Total (QIT) da referida amostra foi 61,6 (Desvio padrão=9,3); quocientes de inteligência verbal (QIV) 68,6 (Desvio padrão=9) e de execução (QIE) 58,5 (Desvio padrão=10). Em função do resultado da avaliação cognitiva optou-se pela aplicação de um pré-teste na intenção de confirmar a confiabilidade das respostas dadas pelas crianças e adolescentes com SWB na ESI.

Foi aplicado o mesmo instrumento em momentos diferentes, em 20 crianças e adolescentes com suspeita de rebaixamento cognitivo e suas respectivas mães respondendo sobre seus filhos, totalizando 40 escalas. Todos os participantes do pré-teste foram atendidos na Secretaria dos Direitos da Pessoa com Deficiência, situado em Barueri, município da grande São Paulo.

Os resultados do pré-teste apontaram respostas semelhantes entre filhos e mães, que podem indicar confiabilidade nas respostas dos filhos. A mediana para filhos foi de: 35, mínimo: 12 e máxima: 74; mediana para as mães: 30, mínima: 6 e máxima: 64 - Teste Mann Withney: $p=0,212$. Não houve diferença estatisticamente significante. A maioria das respostas apresentou pontuação

maior dos filhos, o que pode indicar que questões as quais remetem a 
percepções internas do indivíduo passam despercebidas pelas mães, talvez pela ausência de queixas. Todos os resultados de níveis de estresse foram concordantes entre os dois grupos (filhos e mães).

\subsection{4 - Avaliação de QI}

As avaliações de QI utilizando os instrumentos WISC e WAIS foram realizadas por psicóloga Michele Moreira Nunes, doutoranda da equipe de Genética do Instituto da Criança (ICR) do Hospital das Clínicas de SP. Foi aplicado o teste de inteligência apenas ao grupo com SWB, uma vez que foi admitido que o grupo controle tinha desenvolvimento cognitivo normal, por não apresentar dificuldade escolar ou transtorno de aprendizagem.

\subsection{5 - Avaliação clínica}

Os dados clínicos dos pacientes foram obtidos através da equipe da Unidade de Genética do Instituto da Criança, no Hospital das Clínicas, da Faculdade de Medicina de São Paulo, especialmente pela Dra Rachel S. Honjo quanto à avaliação cardiovascular, urológica, neurológica e hiperacusia. 


\subsection{6 - Análise Estatística}

As informações coletadas foram submetidas à estatística descritiva, com cálculos de mediana (pela apresentação em escore com números ordinais inteiros), teste de Wilcoxon para comparação de grupos e teste de Mann Whitney para comparação de subgrupos. Para tratamento dos dados utilizouse o programa Excell - 2007, e o software BioEstat 5.0. 
RESULTADOS E DISCUSSÃO 


\section{4 - RESULTADOS E DISCUSSÃO:}

\section{1 - Quadro Clínico das crianças e adolescentes com SWB}

Os principais achados clínicos em nossa amostra de 40 pacientes com SWB foram: fácies típico (100\%), hiperacusia (95\%), personalidade amigável $(87,5 \%)$, estenose supravalvar aórtica $(62,5 \%)$. Anexo F

Estes achados foram semelhantes com estudos prévios da literatura (Sugayama, et al., 2003; Livitin et al., 2005; Gallo et al., 2008; Fishman et al., 2011).

A personalidade expansiva, boa narrativa e senso crítico presentes nos pacientes com SWB diferenciam de outras síndromes com deficiência intelectual (Sampaio et.al., 2008). Segundo relato nos estudos de Gonçalves et al. (2004) e Rossi, et al. (2007) a habilidade comunicativa e de linguagem em crianças e adolescentes com SWB dissimulam a habilidade cognitiva, denotando melhor do que parece. Neste sentido, é possível que as exigências do meio aumentem e estes indivíduos não suportem a pressão exercida sobre eles, gerando estresse. Hiperacusia é uma das características mais pronunciadas na SWB e pode ser que esta implicação clínica afete o cotidiano da vida daqueles que têm a doença, o que se tornam necessários o aconselhamento familiar, estratégias de enfrentamento e melhorares habilidades adaptativas nesta população (Elsabbagh et al., 2011).

A hiperacusia é um fator de estresse (Livitin et al., 2005). A amostra compõe, em sua maioria, de pacientes sintomáticos que, entre eles, pode haver 
um cuidado especial em relação aos sons fortes e agudos, o que ameniza a reação ao estresse.

\section{2 - Estresse em pacientes com SWB X Grupo controle}

A idade dos pacientes com SWB no presente estudo variou de 7 a 18 anos com mediana de 13 anos. O Grupo Controle foi pareado por sexo e idade.

A análise de estresse em relação ao gênero entre os grupos SWB e grupo controle mostrou que tanto meninos quanto meninas com SWB apresentaram maiores índices de estresse que meninos e meninas sem a síndrome $(p<0,001)$. No grupo com SWB as meninas apresentaram níveis mais elevados de estresse que os meninos. O nível de estresse total se mostrou em fase de alerta nos 13 pacientes com SWB e em três indivíduos do grupo controle; a fase de resistência foi observada em seis pacientes com SWB e em cinco indivíduos do grupo controle, em ambos os grupos a maioria era adolescente, com exceção de uma criança de 11 anos, com SWB; a fase de exaustão foi observada em apenas uma paciente de 18 anos, com SWB. O estresse total variou de 19 a 84 com mediana de 39 , enquanto que no grupo controle variou de 6 a 54 com mediana de 24 ( tabela 1 e figura 1 ).

No grupo com indivíduos abaixo de 14 anos, verificou-se mediana 37 para SWB e 30 para grupo controle com $p=0,004$ ao teste de Wilcoxon. Não foi 
possível comparar o grupo de indivíduos acima de 15 anos do grupo controle com o grupo de indivíduos com SWB também acima de 15 anos com o instrumento ISSL, devido a incapacidade de compreensão do segundo grupo em responder questões muito subjetivas. Porém, foram constatados nestes grupos, 4 indivíduos em nível de alerta, 2 em nível de resistência e 1 em Exaustão no grupo de SWB e 5 indivíduos em nível de resistência no grupo controle.

Os resultados indicaram níveis elevados de estresse nos indivíduos com desenvolvimento atípico e apontaram nível elevado de estresse também em algumas crianças do grupo controle, sugerindo que o enfrentamento de estresse acomete qualquer estado físico e/ou emocional, principalmente no período da adolescência.

Tabela 1 - Distribuição de escore de estresse e gênero na SWB e Grupo controle

\begin{tabular}{llllllll}
\hline SEXO(n)lescore & \multicolumn{3}{c}{ SWB } & \multicolumn{5}{c}{ GRUPO CONTROLE } & Wilcoxon(p) \\
& Med & $\min$ & $\max$ & Med & $\min$ & $\max$ & \\
\hline \hline Fem. (19) & 40 & 19 & 84 & 19 & 6 & 54 & $<0,001$ \\
Masc.(21) & 34 & 23 & 66 & 27 & 8 & 45 & $=0,002$ \\
Total (40) & 39,5 & 19 & 84 & 24 & 6 & 54 & $<0,001$ \\
\hline
\end{tabular}

Normal até 39,6 , alerta até 59,5 , resistência até 79,4 e exaustão $>79,4$ 


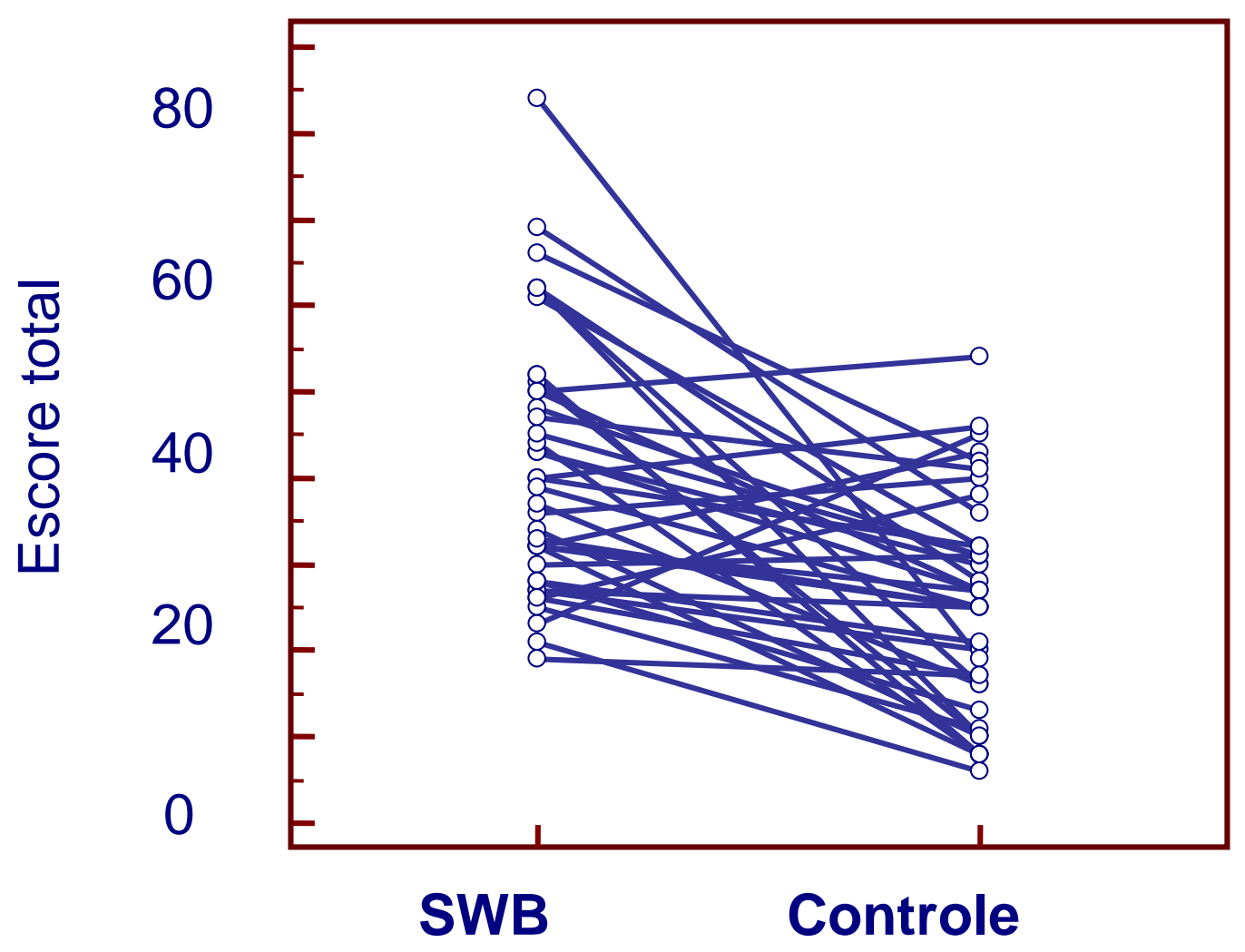

FIGURA 1 - COMPARAÇÃO DE ESTRESSE ENTRE SWB E GRUPO CONTROLE

Não há na literatura estudo semelhante de estresse na SWB, existindo apenas em duas outras síndromes: X-Frágil e Prader Willi. (Hessl et al., 2002; Gilmour et al., 2001)

No trabalho de Hessl et al. (2002) foram avaliadas 109 crianças (70 meninos e 39 meninas) com síndrome de X-frágil confirmada através de estudo molecular, e comparadas com 109 irmãos normais destes pacientes (51 meninos e 58 meninas). O nível de cortisol salivar, um hormônio do eixo hipotálamo pituitário adrenal associado com o estresse foi utilizado como 
marcador de estresse. Além disso, foi avaliado o nível de inteligência (QI) dos pacientes, psicopatologia dos pais, ambiente escolar e da casa. Foi encontrado significativo aumento de cortisol salivar, maior em meninos que em meninas com síndrome de X-Frágil e maior em crianças com QI mais baixo. Os autores concluíram que a função do HPA pode ter uma associação de fatores ambientais independente de problemas comportamentais em crianças com síndrome do X Frágil.

O trabalho de Gilmour et al. (2001) avaliou o estresse em 30 crianças com síndrome de Prader Willi comparadas com 25 crianças com a deficiência de hormônio de crescimento associada à baixa estatura, hiperfagia e dificuldade de aprendizado, utilizando os questionários CBCL (Population Child Behavior Checklist) e TRF (Teacher's Report Form) e medida de cortisol salivar. Ambos os grupos de pacientes mostraram níveis altos de cortisol indicando aumento de estresse. A análise dos questionários respondidos pelos professores mostra que as crianças avaliadas viviam em condições de alto estresse psicossocial.

\section{3 - Estresse X Ambiente escolar}

Nove dos treze pacientes $(69,2 \%)$ que frequentavam escolas especiais apresentaram níveis elevados de estresse comparados com os 11/27 (40,7\%) que frequentavam Escolas de Inclusão. O índice de estresse normal é de 39,6. A mediana de estresse em crianças e adolescentes em escolas de inclusão foi de 36 e em escolas especiais foi de 50, a diferença não foi estatisticamente 
significante com $p=0,140$ ao teste de Mann Whitney (tabela 2). O nível de estresse Total em fase Alerta foi observado em oito pacientes de escola de inclusão e cinco de escola especial; em fase de Resistência, foram encontrados três indivíduos de escola de inclusão e três de escola especial. Apenas uma paciente apresentou estresse total em fase de exaustão, com escore 84 e estudava em escola especial.

Tabela 2 - Distribuição de escore de estresse e Tipos de Escolas (SWB) ESCOLA DE INCLUSÃO ESCOLA ESPECIAL MANN \begin{tabular}{lll}
\multicolumn{2}{c}{$(\mathrm{n}=27)$} & $(\mathrm{n}=13)$ \\
Med $\min \max$ & Med $\min \max$
\end{tabular} WHITNEY(p)

Estresse

Total $36 \quad 19 \quad 66$ $50 \quad 21$

Normal até 39,6 , alerta até 59,5 , resistência até 79,4 e exaustão $>79,4$

No presente estudo, as crianças e adolescentes que frequentavam escola especial apresentaram uma tendência para níveis elevados de estresse do que crianças e adolescentes da escola de inclusão, contrariando a hipótese deste estudo. Entre outros meios influenciáveis, a escola freqüentada pela criança pode influenciar o seu nível de estresse (Lipp, et. al., 2002). As adequações nas escolas inclusivas, defendidas pela LDB (1996) se tornam necessárias para contribuir com um ambiente facilitador e menos estressante. Supõe-se que, ambientes escolares específicos se coloquem como fatores de estresse, porém a não exposição a esses, os quais promovem o encorajamento, pode contribuir para percepções deficitárias em ambientes diversos. Proporcionar aos alunos com deficiência intelectual, pequenos 
desafios à sua rotina, orientando-os quanto à resolução de problemas pode ser um indicativo de melhor enfrentamento ao estresse.

Não foi objetivo deste estudo, avaliar os ambientes escolares com seus agentes estressores. Estudos semelhantes com maior amostra se tornam necessários.

\section{4 - Estresse X Coeficiente de Inteligência (QI)}

O nível de estresse em relação ao QI, dez dos 18 (55\%) pacientes com Qk 60 apresentaram índice elevado de estresse em comparação aos dez de 22 (41\%) indivíduos com QI > 60 e < 89. O nível de estresse em fase de alerta foi observado em oito pacientes com $\mathrm{Q} \mid<60$ e cinco pacientes com $\mathrm{Q} \mid>60>89$; na fase de Resistência, dois pacientes com $\mathrm{Ql}<60$ e quatro em pacientes com QI >60>89. Uma paciente apresentou nível de estresse na fase de exaustão e seu QI Total foi de 63. A análise dos escores variou entre 23 e 62 e mediana 41 para o grupo com $\mathrm{Ql}<60$; para o grupo com $\mathrm{Ql}>60>89$ o escore variou entre19 e 84 e mediana 36 , porém a diferença entre os grupos não foi estatisticamente significante com $\mathrm{p}=0,935$ ao teste de Mann Whitney (tabela 3).

Tabela 3 - Estresse e QI na SWB

\begin{tabular}{|c|c|c|c|c|c|c|c|}
\hline & & $\begin{array}{l}\mathrm{Ql}<60 \\
(\mathrm{n}=18)\end{array}$ & & & $\begin{array}{l}>\mathrm{Ql}_{<} \\
\mathrm{n}=22\end{array}$ & & $\begin{array}{l}\text { MANN } \\
\text { WHITNEY }(p)\end{array}$ \\
\hline & Med & $\min$ & $\max$ & Med & $\min$ & $\max$ & \\
\hline Total & 41,5 & 23 & 62 & 36,5 & 19 & 84 & $=0,935$ \\
\hline
\end{tabular}

Normal até 39,6, alerta até 59,5 , resistência até 79,4 e exaustão $>79,4$ 
Ambos os estudos (Hessl et al., 2002 e Gilmour et al., 2001) mostram alto nível de estresse em pacientes afetados pela síndrome de $X$ frágil e Prader Willi respectivamente e foram concordantes com nosso estudo, sendo que o trabalho de Hessl et al.(2002) também encontrou nível de estresse mais elevado em crianças com QI mais baixo.

Com base nesse estudo é possível que o nível de inteligência interfira nas avaliações perceptivas de fatores internos e externos relacionados ao estresse, porém o fenótipo da SWB ainda é uma incógnita. É possível que esta incongruência se justifique pelo fato de que a personalidade expansiva, empatia e comunicação fluente com estratégias para críticas possam facilitar a percepção dos pacientes com SWB aos estressores, que os tornam mais vulneráveis a distúrbios nesta situação.

\section{5 - Estresse X Tamanho da microdeleção}

Quanto ao tamanho da microdeleção encontrada na SWB não se observou diferença no nível de estresse entre os pacientes de $1,55 \mathrm{Mb}$ e 1.84Mb. tabela 4. 
Tabela 4 - Estresse e tamanho da microdeleção na SWB

\begin{tabular}{|c|c|c|c|c|c|c|c|}
\hline & \multicolumn{2}{|c|}{$\begin{array}{c}1,55 \mathrm{Mb} \\
(\mathrm{n}=34)\end{array}$} & \multicolumn{3}{|c|}{$\begin{array}{l}1,84 M b \\
(n=6)\end{array}$} & & \multirow[t]{2}{*}{$\begin{array}{l}\text { MANN } \\
\text { WHITNEY }(p)\end{array}$} \\
\hline & Med & $\min$ & $\max$ & Med & $\min$ & $\max$ & \\
\hline Estresse & & & & & & & \\
\hline Total & 39,5 & 19 & 84 & 39,5 & 26 & 51 & $=0,402$ \\
\hline
\end{tabular}

Normal até 39,6 , alerta até 59,5 , resistência até 79,4 e exaustão $>79,4$

Não há na literatura nenhum estudo sobre comparação de estresse e tamanho de microdeleção em citogenética.

\section{6 - Estresse X Tipos de Reações}

Foram observadas reações de estresse em pacientes com SWB, sendo $13(48 \%)$ de escola de inclusão e 10 (77\%) de escola especial, para reações físicas; 5 (18\%) de escola de inclusão e 6 (46\%) de escola especial para reações psicológicas; 16 (59\%) de escola de inclusão e 9 (69\%) de escola especial para reações psicológicas com componentes depressivos e 14 (52\%) de escola de inclusão e 5 (38\%) de escola especial para reações psicofisiológicas. Enquanto que no GC as reações mais frequentes foram físicas em 18 indivíduos. Tabela 5, Anexo G 
Tabela 5 - Reações de estresse na SWB entre escolas de inclusão e especial e grupo controle

\begin{tabular}{lcccccccc}
\hline \multicolumn{1}{c}{ SWB } \\
\hline \multirow{2}{*}{ REAÇÕES } & $\begin{array}{c}\text { ESCOLA } \\
\text { INCLUSÃO } \\
\text { N }=27\end{array}$ & $\begin{array}{c}\text { ESCOLA } \\
\text { ESPECIAL } \\
\text { N }=13\end{array}$ & & & GC \\
& Fem & Masc & Fem & Masc & TOTAL & Fem & Masc & TOTAL \\
\hline \hline Físicas & 7 & 6 & 3 & 7 & 23 & 8 & 10 & 18 \\
Psicológicas & 3 & 2 & 2 & 4 & 11 & 7 & 8 & 15 \\
Psicológicas CD & 12 & 4 & 3 & 6 & 25 & 8 & 7 & 15 \\
Psicofisiológicas & 9 & 5 & 2 & 3 & 19 & 4 & 3 & 7 \\
\hline
\end{tabular}

As respostas mais pontuadas que indicaram reações físicas estão indicadas no quadro 3.

QUADRO 3 - Respostas mais frequentes em reações físicas (SWB)
"Demoro para conseguir usar o banheiro" - 10/40
"Tenho diarreia" - 9/40
"Tenho vontade de chorar" - 5/40
"Minhas pernas e braços doem" - 9/40
“"Tenho dor de barriga" - 13/40
"Sinto muito sono" $-21 / 40$

Os resultados do presente estudo apontaram reações Psicológicas com componente depressivo em 25/40 pacientes com SWB, sendo mais frequentes em pacientes que frequentavam escola de inclusão. 
Crianças e adolescentes com SWB apresentam déficit intelectual que os incapacitam de lidarem adequadamente com questões relacionadas aos fatores internos. É possível que o estresse possa afetar aspectos emocionais nessas condições.

As respostas mais pontuadas que indicaram reações psicológicas com componente depressivo estão no quadro 4.

\title{
QUADRO 4 - Respostas mais frequentes em reações psicológicas com componente depressivo(SWB)
}

\author{
"Sinto que tenho pouca energia para fazer as coisas" - 12/40 \\ "De repente, passei a não gostar mais de estudar" - 8/40 \\ "Não tenho vontade de fazer as coisas" - 19/40 \\ "Tenho andado muito esquecido" - 14/40 \\ "Brigo com minha família em casa" - 11/40
}

Portanto, observou-se que no grupo com SWB o nível de estresse foi mais elevado nas reações físicas (56\%) e reações psicológicas com componentes depressivos $(62,5 \%)$. Os níveis de estresse total em resistência e exaustão foram encontrados em $20 \%$ nas reações físicas e reações psicológicas com componentes depressivos, mais frequentes em crianças e adolescentes que frequentam escola especial, conforme mediana de estresse. Anexo $\mathrm{H}$ 
O resultado que aponta pacientes com SWB e QI abaixo de 60 em nível de estresse mais elevado com reações físicas e psicológicas com componentes depressivos sugere que a deficiência intelectual não filtra os fatores tanto internos como externos de tais indivíduos

\section{7 - Caracterização Sociodemográfica}

A constituição familiar mais comum na amostra dos pacientes com SWB foi de quatro pessoas (14/40), conforme respostas encontradas nos questionários. Destes, 2 famílias têm histórico de separação conjugal e a mediana de estresse deste grupo foi de 49 . O nível de estresse foi maior em cinco famílias as quais ninguém trabalhava e que dependiam de auxílio bolsafamília e/ou pensão ou aposentadoria, obtendo-se a mediana 63, min. 61 e max. 66. Anexo H

Destas cinco famílias, as quais ninguém trabalhava, quatro famílias consideraram a situação econômica como regular a péssima.

Não há estudo na literatura sobre estresse relacionado às condições socioeconômicas de pessoas com SWB, porém Evans e Schamberg (2009) revelaram que a pobreza durante a idade infantil é um importante fator de estressor que pode provocar danos na idade adulta. Entretanto, é possível que indivíduos com SWB em condição de pobreza sejam afetados precocemente pelo estresse. 
Vinte e quatro dos quarenta pacientes que não faziam outra atividade além da escola apresentaram maior estresse, mediana foi de 43 , enquanto pacientes que faziam outras atividades, tais como atividades esportivas, aulas de reforço escolar ou terapia o nível de estresse foi considerado normal. Nossos resultados indicaram a possibilidade de que crianças e adolescentes com SWB em tempo ocioso podem estar em enfrentamento de estresse.

No aspecto social, $36 / 40$ pacientes interagiam socialmente e apenas quatro pacientes se queixaram de não ter amigos, apresentando índices mais altos de estresse. Sete pacientes tinham perfil de isolamento, com índices elevados de estresse, a mediana foi de 47 . Tabela 6

Tabela 6 - Estresse em relação ao aspecto social (SWB)

\begin{tabular}{lccccc}
\hline ASPECTO SOCIAL & $\mathbf{N}$ & Mediana & Min & Max. & MW(p) \\
\hline Tem amigos & 36 & 38 & 19 & 84 & \\
Não tem amigos & 4 & 44 & 36 & 61 & 0,17 \\
Brigas Freq & 26 & 39 & 21 & 84 & \\
Não briga & 14 & 40 & 19 & 69 & 0,42 \\
Isola & 7 & 47 & 19 & 69 & \\
Não se isola & 33 & 36 & 21 & 84 & 0,08 \\
Sai sozinho & 9 & 43 & 28 & 84 & \\
Não sai sozinho & 31 & 36 & 19 & 69 & 0,07 \\
\end{tabular}

Normal até 39,6, alerta até 59,5, resistência até 79,4 e exaustão $>79,4$ 
Trinta e um dos quarenta pacientes, cujos responsáveis não permitiam que saíssem sozinhos, apresentaram níveis normais de estresse, enquanto nove que saiam sozinhos apresentaram maiores níveis de estresse com mediana de 43.

Os sinais de isolamento podem ser resultado de estresse excessivo, que pode desencadear o desenvolvimento de quadro depressivo. Estes sinais de depressão são também muito comuns na SWB. Espera-se que "sair sozinho" seja uma atitude de independência e supõe-se melhor condição de enfrentamento de estresse, porém nossos resultados indicaram maiores índices de estresse entre os pacientes que têm autonomia para saírem sozinhos. A necessidade de ter que provar aos outros ou a si mesmo que é capaz é um sentimento que exige muita energia, se configurando em fatores de estresse externalizantes e podem provocar desgastes físicos e emocionais (Lipp ET al., 2003).

Na SWB há um contraste entre habilidades deficitárias e preservadas que se associam com graus diversos de deficiência intelectual (Fisch et al.,2007; Vicari et al., 2001). Podemos atribuir a deficiência intelectual como limitadora de enfrentamento de agentes estressores.

Crianças e adolescentes de escola especial não são representados por série e a mediana de estresse foi de 50, mínimo 21 e máximo 69.

Dos pacientes que estudavam em escola de inclusão, 18 pacientes apresentaram índices normais de estresse, enquanto 10 pacientes de $4^{\underline{a}}$ e $5^{\underline{a}}$ 
séries apresentaram estresse em nível de alerta, com mediana 39 e 41, respectivamente. Anexo I

Geralmente, as crianças e adolescentes que frequentam escola especial são menos expostos a agentes estressores e como têm maiores prejuízos em habilidades intelectuais, se configuram em fatores de estresse internalizantes, que os tornam mais vulneráveis a reações de estresse em ambientes diversos.

A análise do estresse por série escolar mostrou que o estresse em crianças e adolescentes com SWB independe da série que cada um se encontra, entretanto, pressupõe-se que há um indício de que alunos de $4^{\underline{a}}$ e $5^{\mathrm{a}}$ série, por se encontrarem em início da adolescência, podem justificar um nível mais elevado de estresse nesse período.

Embora não há estudo sobre estresse na SWB, encontra-se na literatura pré adolescentes com desenvolvimento normal que apresentam nível de estresse mais elevado por sua idade crítica e por se encontrar em período turbulento, cheio de mudanças que o torna mais vulnerável a perturbações (Romeo et al., 2006 e Goodman et al., 2005).

Consta no prontuário de uma menina com SWB, 18 anos, freqüentando a $7^{a}$ série, informações sobre constantes enureses noturnas, porém as avaliações urológicas e urodinâmicas não apontaram nenhuma alteração. Em entrevista, a mãe revela que a paciente se incomoda com as supervisões, não compreende o por quê de não aprender a ler e escrever e se queixa de frequentes episódios de discriminação no ambiente escolar. Na escala ESI apresentou pontuação 
alta para "Brigas frequentes com a família", "Fico nervosa com tudo" e "Sinto pouca energia para fazer as coisas". Seu escore de estresse total foi de 84 .

Não foi possível correlacionar o grupo de SWB com grupo controle por série, devido alterações na LDBEN (1996), Lei oํ 11.114, de 16 de maio de 2005, que modifica a matrícula de crianças no ensino fundamental, a partir de 2006, o que desconfigurou as amostras que poderiam ser pareadas por idade e série escolar.

A maioria dos nossos pacientes não foi alfabetizada e apenas nove pacientes dos que frequentavam escola de inclusão tinham sido alfabetizados. Seu QI variou de um mínimo 51 e um máximo 77 com mediana 62.

Os 14/40 pacientes que foram reprovados apresentaram índices elevados de estresse, mediana 41, porém a diferença não foi estatisticamente significante, com $p=0,243$. Os $13 / 40$ que resistiam em ir para a escola apresentaram índices elevados de estresse, com mediana 47, não houve diferença estatisticamente significante com $p=0,015$ no teste de Mann Whitney. Tabela 7 
Tabela 7 - Estresse em relação a situação escolar (SWB)

$\begin{array}{llllll}\text { ASPECTO ESCOLAR } & \mathbf{N}^{\circ} & \text { Mediana } & \text { Min } & \text { Max } & \text { MW }\end{array}$

\begin{tabular}{|c|c|c|c|c|c|}
\hline Alfabetizado & 9 & 47 & 19 & 69 & \\
\hline Não alfabetizado & 31 & 37 & 21 & 84 & $p=0,38$ \\
\hline Repetente & 14 & 41 & 19 & 66 & \\
\hline Não repetente & 26 & 38 & 21 & 84 & $p=0,24$ \\
\hline Resiste em ir à escola & 13 & 47 & 27 & 69 & \\
\hline Não resiste & 27 & 34 & 19 & 84 & $p=0.01$ \\
\hline
\end{tabular}

Normal até 39,6, alerta até 59,5, resistência até 79,4 e exaustão $>79,4$

Foram encontrados na amostra, pacientes com QI total abaixo de 60 alfabetizados e alguns pacientes com QI total acima de 80 que não são alfabetizados. Esta observação sugere que os sintomas reativos de não aprender podem estar implicados com o perfil apresentado pelas crianças e adolescentes com SWB. As queixas mais frequentes dos pacientes estudados foram: excesso de barulho (60\%), discriminação (58\%), não compreensão da lição e excesso de tarefas (35\%), exigência da letra cursiva (25\%). Em relação 
ao excesso de barulho, Livitin et al. (2005) constataram que a sensibilidade auditiva pode ser um predito de estresse em crianças e adolescentes com SWB. Estudo de Wälinder et al. (2007) avaliaram crianças normais em sala de aula de escola comum e constatou alteração da pressão arterial e o nível de cortisol devido ao excesso de barulho. Este estudo contribui para sugerir que o excesso de barulho pode ser um importante fator estressante para crianças e adolescentes com SWB uma vez que eles apresentam hipersensibilidade auditiva e alterações cardiovasculares pela própria patologia.

Escrever implica em movimentos dos músculos e articulações e essa é uma das atividades aversivas das crianças e adolescentes com SWB, conforme respostas dadas ao questionário. Estudo prospectivo e longitudinal (Aasland, et al., 1997) encontrou persistência da dor músculo-esquelético relacionado ao estresse escolar, estabelecendo uma associação entre fatores psicossociais e dor músculo-esquelético na infância. Estudos sobre estresse associado à dor músculo-esquelética na SWB tornam-se necessários para orientações às pessoas que atendem estes indivíduos.

Indicadores neste estudo constataram que crianças e adolescentes com SWB em reprovação do ano escolar ou em discriminação por seus pares podem estar em enfrentamento ao estresse acima da normalidade.

A prevalência de ansiedade do tipo fobia específica associada à sons altos/agudos na SWB (Leyfer, Woodruff-Borden e mervis, 2006) sugeriu que ambientes barulhentos e imprevisíveis sejam indicadores de importantes agentes estressores (Wallinder et al., 2007). 
O resultado do presente estudo apontou para índices elevados de estresse em crianças e adolescentes com SWB, o qual sugeriu monitoramento em ambientes específicos.

Observou-se que tais componentes fenotípicos na SWB pareados com as características do estresse prolongado apontaram para a necessidade de cuidados especiais em indivíduos com a síndrome.

Mais estudos sobre estresse na SWB são necessários para que se ofereça melhor qualidade de vida às crianças e adolescentes com esta patologia. 
CONCLUSÃO 


\section{5 - Conclusão}

- Os níveis de estresse em crianças e adolescentes com SWB foram mais elevados em relação ao grupo controle normal sem a SWB com a diferença estatisticamente significante $(p<0.001)$

- Não houve diferença estatisticamente significante entre o nível de estresse e o tipo de escola, valor de QI e o tamanho da deleção nos pacientes com SWB, embora os níveis de estresse em crianças e adolescentes que frequentaram escola especial e indivíduos com $\mathrm{Ql}<60$ fossem mais elevados..

- Os tipos de reações de estresse mais frequentes foram Físicas e Psicológicas com Componentes Depressivos.

O presente estudo alerta sobre os prejuízos físicos e emocionais que o estresse pode causar às crianças e adolescentes com SWB, que podem estar interferindo nas relações sociais, atividades de vida diária e desempenho acadêmico. Futuras pesquisas sobre estresse na SWB se fazem necessárias, visando melhorar a qualidade de vida. 
ANEXOS 
Anexo A - Aprovação do CAPPesq

Anexo B - Termo de Consentimento Livre e Esclarecido

Anexo C - Questionário Sociodemográfico

Anexo D - ESI Escala de Stress Infantil

Anexo E - ISSL Inventário de Sintomas de Stress de Lipp

Anexo F - Caracterização do quadro clínico

Anexo G - Estresse e Tipos de reações na SWB

Anexo $\mathrm{H}$ - Estresse em relação ao aspecto familiar na SWB

Anexo I - Estresse em relação a série escolar

Anexo $\mathrm{J}$ - Artigo nacional completo

Anexo $\mathrm{H}$ - Artigo internacional completo 


\section{Anexo A - Aprovação do CAPPesq}

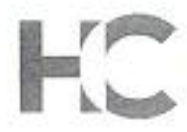

\section{APROVAÇĀO}

A Comissảo de Ética para Análise de Projetos de Pesquisa CAPpesq da Diretoria Clínica do Hospital dos Cilinicas e da Faculidade de Medicina do Universidade de são Paulo, em sessăo de 15/04/2009, AProvou o Protocolo de Pesquisa $n^{\circ}$ 0944/08, intitulado: "O ESTRESSE EM CRIANÇAS E ADOLESCENTES COM SÍNDROME DE WILLIAMS-BEUREN NO CONTEXTO ESCOLAR apresentado pelo Deportamento de PEDIATRIA, inclusive o termo de Consentimento Livre e Esclarecido.

Cobe ao pesquisador eloborar e apresentar ó CAPPesa. os relatórios parciais e final sobre a pesquisa [Resduçōo do Conselho Nacional de Saúde $n^{\circ} 196$, de 10/10/1996, inciso IX.2, letra "c"l.

Pescuisodor (a) Responsóvel: Chong Ae Kim

Pesquisador $\{a \mid$ Executante: Vera Alice Alcàntaka dos Santos Amaral

CAPPesq. 15 de Abril de 2009

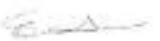

Prot. Dr. Eduardo Massad Presidente da Comissăo de Ética para Análise de Projetos de Pesquisa

Comissä de Etica para Analige de Prcjetes de Pasqusa do HCFMUSP e da FMUSe Dietcris Clirica do Haspital das Clinicas da Faculaade de Medicina da Universidade de sao Paulo Rua Ovidio"Pros de Campos. 225, $5^{\circ}$ andar - CEP 08403010 - Sas Paulo - SP Fore 0113068 6442 Fax 01190696482 e-mat cappesqghenet usp br / secretariacappesq2 \&ghenet usp br 
Anexo B - Termo de Consentimento Livre e Esclarecido

\section{HOSPITAL DAS CLÍNICAS DA FACULDADE DE MEDICINA DA UNIVERSIDADE DE SÃO PAULO-HCFMUSP}

TERMO DE CONSENTIMENTO LIVRE E ESCLARECIDO

DADOS DE IDENTIFICAÇÃO DO SUJEITO DA PESQUISA OU RESPONSÁVEL LEGAL

1.NOME:

DOCUMENTO DE IDENTIDADE № : SEXO :.$M \square F$ $\square$

DATA NASCIMENTO:

ENDEREÇO №

. APTO:

BAIRRO:

CEP: CIDADE TELEFONE: DDD (...........)

2.RESPONSÁVEL LEGAL

NATUREZA (grau de parentesco, tutor, curador etc.) DOCUMENTO DE IDENTIDADE : SEXO: $M \square F \square$

DATA NASCIMENTO.: .

ENDEREÇO: № APTO:

BAIRRO CEP: TELEFONE: DDD CIDADE:

\section{DADOS SOBRE A PESQUISA}

1. TÍTULO DO PROTOCOLO DE PESQUISA: O ESTRESSE EM CRIANÇAS E ADOLESCENTES COM SÍNDROME DE WILLIAMS-BEUREN NO CONTEXTO ESCOLAR

2. PESQUISADOR : Chong Ae Kim

CARGO/FUNÇÃO: Chefe da Unidade de Genética do ICR INSCRIÇÃO CONSELHO REGIONAL CRM 40.054 
UNIDADE DO HCFMUSP: Unidade de Genética do Instituto da Criança

3. AVALIAÇÃO DO RISCO DA PESQUISA:

$\begin{array}{lll}\text { RISCO MÍNIMO } \quad \mathrm{x} \square & \text { RISCO MÉDIO } \quad \square \\ \text { RISCO BAIXO } & \square & \text { RISCO MAIOR }\end{array}$

4.DURAÇÃO DA PESQUISA : 24 meses 
5 - Como você já sabe sua criança ou adolescente nasceu com uma doença genética chamada síndrome de Williams que causa atraso e dificuldade escolar necessitando de uma atenção maior por parte de professores.

O objetivo deste estudo é verificar a presença e o grau de estresse sofrido pelo seu filho(a) que frequenta escola comum em processo de inclusão ou escola especial.

6 -É um trabalho novo que ajudará a conscientizar pais, professores e diretores de escolas sobre as conseqüências que pode levar o estresse em crianças e adolescentes com síndrome de Williams e proporcionar melhorias no ambiente escolar visando qualidade de vida.

Aos pais, cujos filhos foram avaliados com alto grau de estresse, poderão também, ser oferecido o serviço de orientação Psicológica para aprenderem a lidar com o estresse.

7 - Os pais, juntamente com seu filho, serão convocados, por telefone, ao ambulatório de Genética do Instituto da Criança HCFMUSP, para entrevista e preenchimento de um questionário para coleta de informações sobre a rotina do paciente e situação escolar. Será agendada uma data para a aplicação do questionário da Escala de estresse Infantil composto por 35 perguntas, aos pacientes, neste mesmo local.

8 - A aplicação do questionário exigirá apenas tempo dos pacientes e respectivos pais, oferecendo nenhum risco ou desconforto decorrentes da pesquisa. Como segurança, fica à sua disposição a assistência no HCFMUSP para eventualidades.

9 - As respostas das entrevistas e questionários, bem como da Escala de Estresse Infantil serão analisadas em conjunto com as respostas de outros pacientes envolvidos na pesquisa, sem ter de revelar o nome de cada um. 
10 - Os pais poderão receber informações sobre os resultados parciais ou conclusivos sempre que assim o desejarem, garantida a atualização.

11 - A participação neste estudo seja dos pacientes ou dos pais não implica em gastos ou despesas pessoais, assim como não há prêmios em valores de qualquer espécie.

12 - Toda e qualquer informação obtida através de entrevistas, questionários e leitura de prontuários serão utilizadas somente para o desenvolvimento da pesquisa sobre estresse em crianças e adolescentes com Síndrome de Williams-Beuren em ambientes escolares específicos.

13 - A qualquer momento, os pais poderão entrar em contato com profissionais responsáveis pela pesquisa para esclarecimento de eventuais dúvidas. O principal investigador é a $\mathrm{Dr}^{\mathrm{a}}$ Chong Ae Kim, que pode ser encontrada no endereço Av. Dr Enéas Carvalho de Aguiar, 647 - Telefone (11) 3069-8671. Em caso de alguma dúvida ou consideração da ética da pesquisa, entre em contato com o comitê de Ética em Pesquisa (CEP) - Rua Ovídio Pires de Campos, 225 - 5o andar - 3069-6442 ramais 16, 17, 18 ou 20, Fax: 3069-6442 ramal 26 - Email: cappesq@hcnet.usp.br

14 - Os pais e/ou pacientes têm total liberdade de, a qualquer momento, deixar de participar desta pesquisa, retirando seu consentimento sem ter qualquer prejuízo ao atendimento e tratamento que vem realizando no Hospital das Clínicas.

Acredito ter sido suficientemente informado a respeito das informações que li ou que foram lidas para mim, descrevendo o estudo "ESTRESSE EM CRIANÇAS E ADOLESCENTES COM SÍNDROME DE WILLIAMSBEUREN NO CONTEXTO ESCOLAR"

Eu discuti com a Dra Chong Ae Kim sobre a minha decisão em participar nesse estudo. Ficaram claros para mim quais são os propósitos do estudo, os procedimentos a serem realizados, seus desconfortos e riscos, as garantias de 
confidencialidade e de esclarecimentos permanentes. Ficou claro também que minha participação é isenta de despesas e que tenho garantia do acesso a tratamento hospitalar quando necessário. Concordo voluntariamente em participar deste estudo e poderei retirar o meu consentimento a qualquer momento, antes ou durante o mesmo, sem penalidades ou prejuízo ou perda de qualquer benefício que eu possa ter adquirido, ou no meu atendimento neste Serviço 
Assinatura do paciente/representante legal

Data 11

Assinatura da testemunha

Data 11

para casos de pacientes menores de 18 anos, analfabetos, semi-analfabetos ou portadores de deficiência auditiva ou visual.

(Somente para o responsável do projeto)

Declaro que obtive de forma apropriada e voluntária o Consentimento Livre e Esclarecido deste paciente ou representante legal para a participação neste estudo.

Assinatura do responsável pelo estudo Data 


\title{
Escala de Stress Infantil - ESI
}

\author{
CADERNO DE APLICAÇÃo
}

Marilda Emmanuel Novaes Lipp / Maria Diva Monteiro Lucarelli

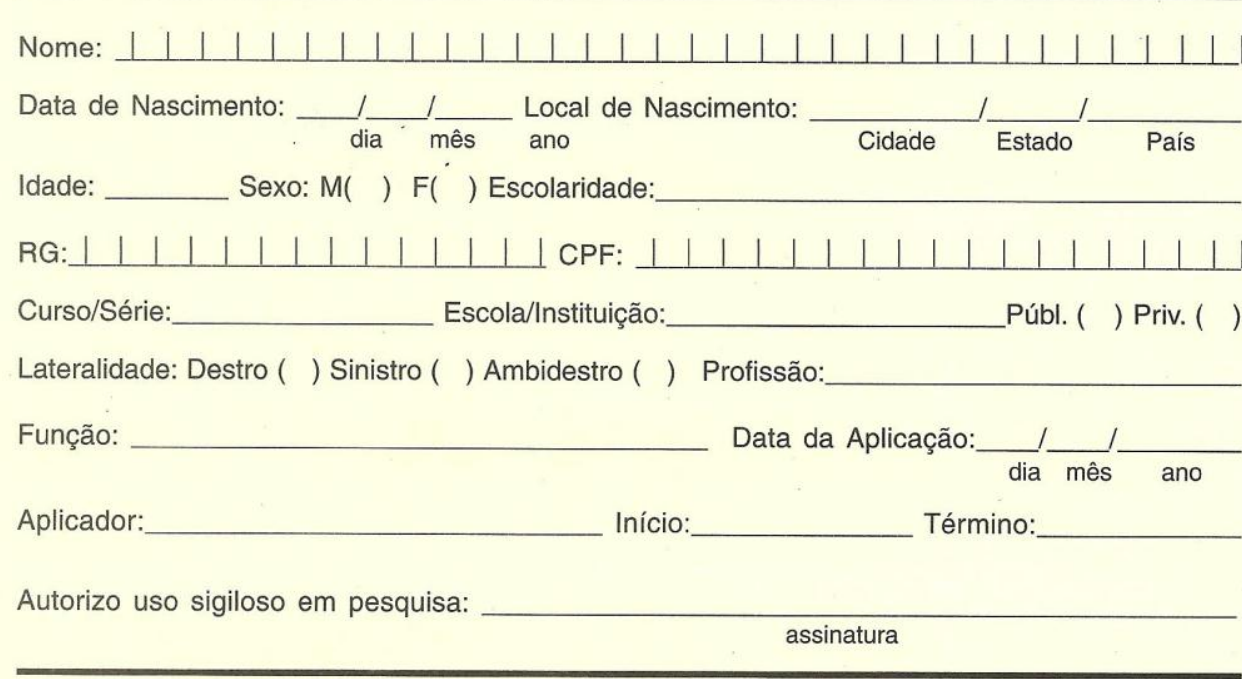

INSTRUÇŌES: Você encontrará nas questôes abaixo coisas que as crianças podem ter ou sentir. Você deverá mostrar o quanto acontece com você o que está descrito em cada questão, pintando os desenhos assim:

— Se NUNCA acontece, deixe em branco $\bigoplus$

- Se acontece UM POUCO, pinte UMA PARTE $\varnothing$

— Se acontece ÀS VEZES, pinte DUAS PARTES $\theta$

— Se acontece QUASE SEMPRE, pinte TRÊS PARTES

— Se SEMPRE acontece, pinte TODAS AS PARTES

1. Estou o tempo todo me mexendo e fazendo coisas diferentes.

2. Demoro para conseguir usar o banheiro.

3. Tenho dificuldade de prestar atenção.

4. $\quad$ Eu me sinto assustado na hora de dormir. $\bigoplus$

5. Fico preocupado com coisas ruins que podem acontecer. $\bigoplus$ 
— Se NUNCA acontece, deixe em branco $\bigoplus$

— Se acontece UM POUCO, pinte UMA PARTE $\oslash$

- Se acontece ÀS VEZES, pinte DUAS PARTES $\theta$

— Se acontece QUASE SEMPRE, pinte TRÊS PARTES

— Se SEMPRE acontece, pinte TODAS AS PARTES

6. Raspo um dente no outro fazendo barulho. $\bigoplus$

7. Fico nervoso com tudo. $\bigoplus$

8. $\quad$ Sinto aflição por dentro. $\bigoplus$

9. Tenho ficado tímido, envergonhado. $\bigoplus$

10. Eu me sinto triste. $\bigoplus$

11. Minhas mãos ficam suadas. $\bigoplus$

12. Tenho diarréia. $\bigoplus$

13. Sinto que tenho pouca energia para fazer as coisas.

14. De repente, passei a não gostar mais de estudar. $\bigoplus$

15. Tenho vontade de chorar. $\bigoplus$

16. Quando fico nervoso, gaguejo. $\bigoplus$

17. Quando fico nervoso, fico com vontade de vomitar.

18. Meu coração bate depressa, mesmo quando não corro ou pulo. $\bigoplus$

19. Minhas pernas e braços doem.

20. Tenho vontade de bater nos colegas, sem razăo. $\bigoplus$ 
— Se NUNCA acontece, deixe em branco $\bigoplus$

— Se acontece UM POUCO, pinte UMA PARTE $\oplus$

— Se acontece ÀS VEZES, pinte DUAS PARTES

- Se acontece QUASE SEMPRE, pinte TRÊS PARTES

— Se SEMPRE acontece, pinte TODAS AS PARTES

21. Quando fico nervoso durante o dia, molho a cama à noite.

22. Tenho vontade de sumir da vida. $\bigoplus$

23. Tenho dificuldade para respirar. $\bigoplus$

24. Tenho dor de barriga. $\bigoplus$

25. Penso que sou feio, ruim, que não consigo aprender as coisas.

26. Tenho medo. $\bigoplus$

27. Tenho comido demais. $\bigoplus$

28. Não tenho vontade de fazer as coisas. $\bigoplus$

29. Tenho andado muito esquecido. $\bigoplus$

30. Tenho dificuldade de dormir. $\oplus$

31. Não tenho fome. $\bigoplus$

32. Brigo com minha família em casa. $\bigoplus$

33. Estou sempre resfriado, com dor de garganta. $\bigoplus$

34. Sinto muito sono. $\bigoplus$

35. Não tenho vontade nenhuma de me arrumar. $\bigoplus$ 
Anexo D - Inventário de Sintomas de Stress para adulto de Lipp (ISSL)

\section{INVENTÁRIO DE SINTOMAS DE STRESS PARA ADULTOS DE LIPP (ISSL) \\ Marilda Emmanuel Novaes Lipp}

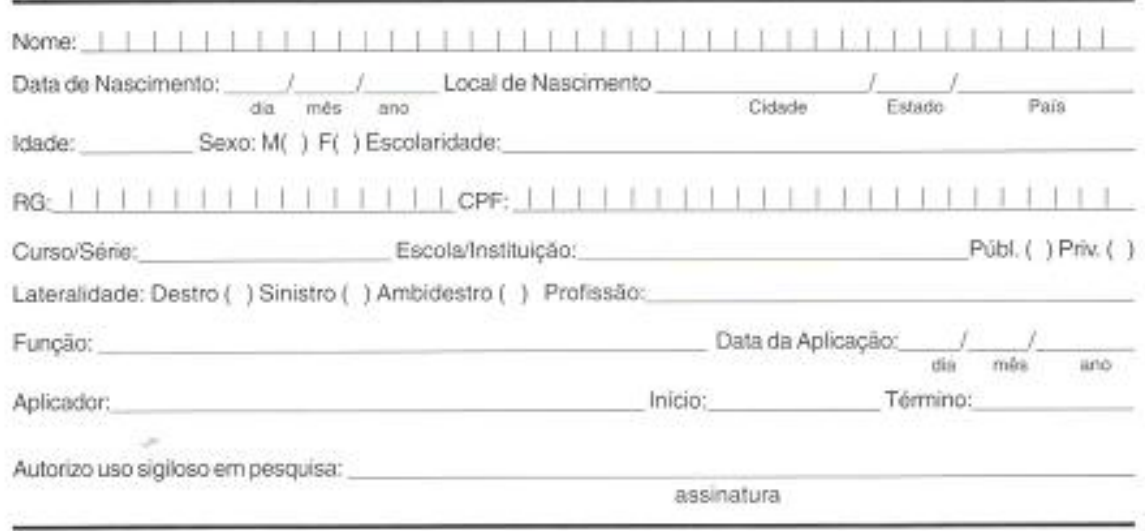

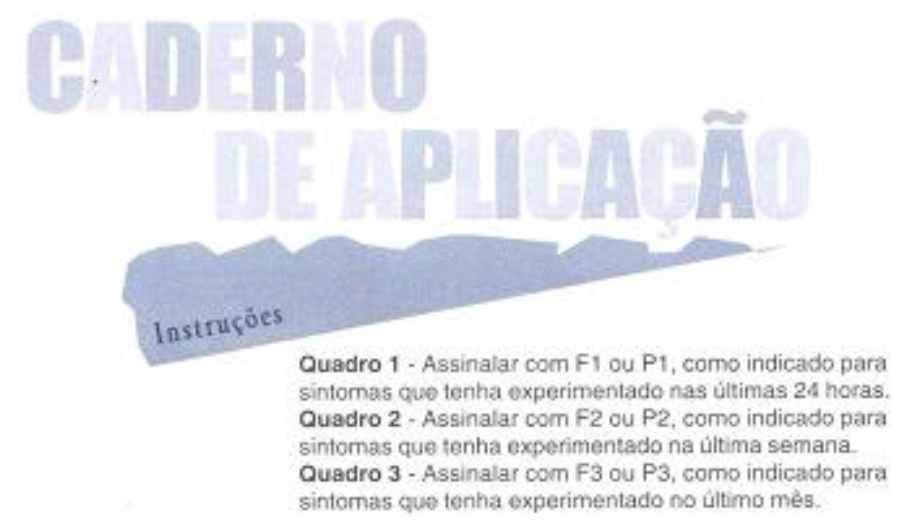


Anexo E - Questionário Sociodemográfico

FACULDADE DE MEDICINA DA UNIVERSIDADE DE SÃO PAULO

HOSPITAL DAS CLÍNICAS - INSTITUTO DA CRIANÇA

\section{QUESTIONÁRIO}

Nome do paciente:

D. Nasc.

Filiação:

Escolaridade:

Nome da escola:

Tipo de escola: ( ) Comum ( ) Especial

( ) Particular ( ) Pública

Medicação dos últimos três meses:

Aspecto Familiar:

Constituição da família:

Moram juntos: ( ) sim ( ) não

Por que?

Há desentendimentos freqüentes entre os membros da família?

( ) sim ( ) não

Quantas pessoas trabalham fora:

Ocupação do paciente:

Qual a situação econômica da família:

Eventos que aconteceram nos últimos três meses:

Aspecto Escolar

É repetente? () não ( ) sim

Por que?

Há resistência em ir á escola? ( ) não （） sim

Quais das situações abaixo são queixas freqüentes:

( ) não sabe ler

( ) não sabe escrever

( ) não entende a lição

( ) Professora brava

( ) Muitas exigências

( ) Muita lição

( ) Muito barulho

( ) Os alunos são bagunceiros e colocam apelidos

( ) Exigência da letra cursiva

( ) Sente-se diferente dos outros

Eventos que aconteceram nos últimos três meses:

\section{Aspecto Social}

Tem amigos ( ) sim ( ) não

Faz amizade com facilidade ( ) sim ( ) não

Brigas constantes com os amigos ( ) sim ( ) não

Prefere ficar só ( ) sim ( ) não

Sai sozinho ( ) sim ( ) não

Faz pequenos passeios/compras: ( ) sim ( ) não

Eventos que aconteceram nos últimos três meses:

Informante:

Data: 


\section{Anexo F -}

Caracterização do quadro clínico dos pacientes com SWB

\begin{tabular}{|c|c|c|c|c|c|c|c|c|c|c|}
\hline & Paciente & 1 & 2 & 3 & 4 & 5 & 6 & 7 & 8 & 9 \\
\hline & Sexo & $\mathrm{M}$ & $\mathrm{M}$ & $\mathrm{M}$ & $\mathrm{M}$ & $\mathrm{F}$ & $\mathrm{M}$ & $\mathrm{F}$ & $\mathrm{F}$ & $\mathrm{M}$ \\
\hline & $\begin{array}{l}\text { Déficit } \\
\text { Cognitivo (QI) }\end{array}$ & 85 & 51 & 56 & 65 & 51 & 65 & 63 & 63 & 50 \\
\hline 四定 & $\begin{array}{l}\text { Comportament } \\
\text { o T. Amigável }\end{array}$ & + & + & + & + & - & + & + & + & + \\
\hline 安至 & Ansiedade & + & + & + & + & - & - & - & + & - \\
\hline & $\begin{array}{l}\text { Músculo- } \\
\text { esquelético }\end{array}$ & + & + & - & - & - & + & - & - & + \\
\hline 总全 & $\begin{array}{l}\text { Prolapso da } \\
\text { válvula mitral }\end{array}$ & - & - & + & - & - & - & - & - & - \\
\hline$<0$ & $\begin{array}{l}\text { Hipertensão } \\
\text { Arterial } \\
\end{array}$ & + & - & - & - & + & - & - & - & + \\
\hline 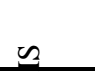 & EA Renal & - & - & - & - & - & - & - & - & + \\
\hline$\sum_{1=1}^{\mathbb{1}} 0$ & $\begin{array}{l}\text { Insuficiência } \\
\text { Renal }\end{array}$ & - & - & - & - & - & - & - & - & - \\
\hline 它佫 & Enurese & + & - & - & - & - & - & - & - & + \\
\hline
\end{tabular}


CONTINUA

Caracterização do quadro clínico dos pacientes com SWB

\begin{tabular}{|c|c|c|c|c|c|c|c|c|c|c|}
\hline & Paciente & 10 & 11 & 12 & 13 & 14 & 15 & 16 & 17 & 18 \\
\hline & Sexo & $\mathrm{M}$ & M & $\mathrm{M}$ & M & $\mathrm{M}$ & M & $\mathrm{F}$ & M & M \\
\hline \multirow{5}{*}{ 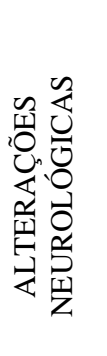 } & Déficit Cognitivo (QI) & 83 & 56 & 56 & 50 & 62 & 56 & 60 & 60 & 51 \\
\hline & Comportamento T. Amigável & + & + & + & + & + & + & + & + & + \\
\hline & Hiperacusia & + & + & + & + & + & + & + & + & + \\
\hline & Ansiedade & - & + & - & - & + & - & + & + & - \\
\hline & Músculo-esquelético & - & - & - & - & + & - & - & + & - \\
\hline \multirow{4}{*}{ 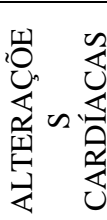 } & EASV & + & + & + & - & - & - & + & - & - \\
\hline & EAP & - & - & - & + & - & + & + & - & - \\
\hline & Prolapso da válvula mitral & - & - & + & + & - & + & - & - & - \\
\hline & Hipertensão Arterial & + & - & - & + & - & - & - & - & - \\
\hline \multirow{4}{*}{ 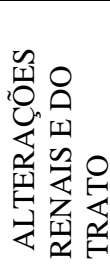 } & EA Renal & + & - & - & + & - & - & - & - & - \\
\hline & Hipoplasia renal & - & - & - & - & - & - & - & - & - \\
\hline & Insuficiência Renal & - & - & - & - & - & - & - & - & - \\
\hline & Enurese Noturna & $+^{*}$ & + & - & + & - & - & - & - & - \\
\hline
\end{tabular}

* já foi tratado 
CONTINUA

Caracterização do quadro clínico dos pacientes com SWB

\begin{tabular}{|c|c|c|c|c|c|c|c|c|c|c|}
\hline 2 & Paciente & 19 & 20 & 21 & 22 & 23 & 24 & 25 & 26 & 27 \\
\hline & Sexo & $\mathrm{M}$ & $\mathrm{F}$ & $\mathrm{F}$ & $\mathrm{F}$ & $\mathrm{F}$ & $\mathrm{F}$ & $\mathrm{F}$ & $\mathrm{M}$ & $\mathrm{F}$ \\
\hline$\infty$ & Déficit Cognitivo (QI) & 62 & 77 & 74 & 77 & 63 & 52 & 62 & 80 & 52 \\
\hline 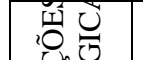 & Comportamento Típico Amigável & - & - & + & + & + & + & + & + & + \\
\hline 80 & Hiperacusia & - & + & + & + & + & + & + & + & + \\
\hline 告 & Ansiedade & + & + & + & + & + & + & + & + & + \\
\hline $\bar{Z}$ & Músculo-esquelético & - & + & + & - & - & - & - & - & - \\
\hline 0 & EASV & + & + & + & + & + & - & - & + & - \\
\hline 至出 & EAP & + & - & - & + & + & + & - & - & - \\
\hline $\operatorname{sen}^{2} \frac{2}{4}$ & Prolapso da válvula mitral & - & + & + & - & - & - & + & - & - \\
\hline 0 & Hipertensão Arterial & - & - & - & - & - & - & _- & - & - \\
\hline & EA Renal & - & - & - & - & - & - & - & - & - \\
\hline 这要 & Hipoplasia renal & - & - & - & - & - & - & - & - & - \\
\hline 㦴, & Insuficiência Renal & + & - & - & - & - & - & - & - & - \\
\hline 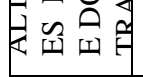 & Enurese & + & - & - & + & + & - & + & - & - \\
\hline
\end{tabular}


CONTINUA

Caracterização do quadro clínico dos pacientes com SWB

\begin{tabular}{|c|c|c|c|c|c|c|c|c|c|c|}
\hline 2 & Paciente & 28 & 29 & 30 & 31 & 32 & 33 & 34 & 35 & 36 \\
\hline & Sexo & $\mathrm{F}$ & $\mathrm{F}$ & $\mathrm{F}$ & $\mathrm{F}$ & $\mathrm{M}$ & $\mathrm{F}$ & $\mathrm{F}$ & $\mathrm{F}$ & $\mathrm{M}$ \\
\hline & $\begin{array}{l}\text { Déficit } \\
\text { Cognitivo (QI) }\end{array}$ & 52 & 58 & 56 & 69 & 71 & 62 & 59 & 56 & 56 \\
\hline & $\begin{array}{l}\text { Comportament } \\
\text { o Típico } \\
\text { Amigável }\end{array}$ & - & + & + & + & + & + & + & + & + \\
\hline$\frac{\pi}{4}$ & Hiperacusia & + & + & + & + & + & + & + & + & + \\
\hline & Ansiedade & - & + & - & + & + & + & + & + & - \\
\hline & $\begin{array}{l}\text { Músculo- } \\
\text { esquelético }\end{array}$ & - & - & - & - & - & - & - & - & + \\
\hline$=\infty$ & EASV & + & - & + & - & - & + & + & + & + \\
\hline 0,0 & EAP & + & - & - & - & + & - & + & - & - \\
\hline 空 & $\begin{array}{l}\text { Prolapso da } \\
\text { válvula mitral } \\
\end{array}$ & - & - & - & - & - & - & - & - & - \\
\hline \& & $\begin{array}{l}\text { Hipertensão } \\
\text { Arterial }\end{array}$ & + & + & - & - & - & - & + & - & - \\
\hline & EA Renal & - & - & - & - & - & - & - & - & - \\
\hline 60 & $\begin{array}{l}\text { Hipoplasia } \\
\text { renal }\end{array}$ & - & - & - & - & - & - & - & - & - \\
\hline 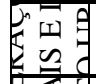 & $\begin{array}{l}\text { Insuficiência } \\
\text { Renal } \\
\end{array}$ & - & - & - & - & - & - & - & - & - \\
\hline 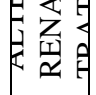 & Enurese & - & + & - & - & - & + & + & - & - \\
\hline
\end{tabular}


CONCLUSÃO

Caracterização do quadro clínico dos pacientes com SWB

\begin{tabular}{|c|c|c|c|c|c|}
\hline 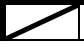 & Paciente & 37 & 38 & 39 & 40 \\
\hline & Sexo & $\mathrm{F}$ & $\mathrm{M}$ & $\mathrm{M}$ & M \\
\hline & Déficit Cognitivo (QI) & 63 & 53 & 61 & 62 \\
\hline 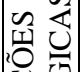 & Comportamento Típico Amigável & + & - & + & + \\
\hline 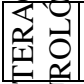 & Hiperacusia & + & - & + & + \\
\hline \&罗 & Ansiedade & + & - & - & - \\
\hline & Músculo-esquelético & - & - & - & - \\
\hline 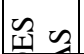 & EASV & - & + & + & + \\
\hline $\begin{array}{l}U \\
\mathbb{S}\end{array}$ & EAP & - & - & - & + \\
\hline 贸党 & Prolapso da válvula mitral & + & + & - & + \\
\hline & Hipertensão Arterial & - & - & - & + \\
\hline & EA Renal & - & - & - & - \\
\hline ○ & Hipoplasia renal & - & - & - & - \\
\hline$\approx 0$ & Insuficiência Renal & - & - & - & - \\
\hline 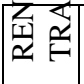 & Enurese & + & - & - & - \\
\hline
\end{tabular}


Anexo G

Associação entre as reações de estresse e níveis de estresse na SWB

\begin{tabular}{|c|c|c|c|c|c|c|c|c|}
\hline \multirow[t]{2}{*}{ Reações Físicas } & \multicolumn{5}{|c|}{$\begin{array}{l}\text { Escola de Inclusão } \\
\qquad N(27)\end{array}$} & \multicolumn{3}{|c|}{$\begin{array}{c}\text { Escola Especia } \\
\mathrm{N}(13)\end{array}$} \\
\hline & $\mathrm{n}$ & Med & Max & Min & $n$ & Med & Max & Min \\
\hline Alerta $(14,8)$ & 11 & 12 & 14 & 9 & 4 & 10 & 14 & 9 \\
\hline Resistência $(20,8)$ & 0 & 0 & - & - & 5 & 17 & 19 & 16 \\
\hline Exaustão ( >20,8) & 2 & 23 & 25 & 21 & 1 & 21 & 21 & 21 \\
\hline
\end{tabular}

Normal até 39,6 , alerta até 59,5 , resistência até 79,4 e exaustão $>79,4$ 
CONTINUA

\section{REAÇÕES PSICOLÓGICAS}

\begin{tabular}{|c|c|c|c|c|c|c|c|c|c|}
\hline \multirow{2}{*}{\multicolumn{2}{|c|}{$\begin{array}{l}\text { REAÇÕES } \\
\text { Psicológicas }\end{array}$}} & \multicolumn{5}{|c|}{$\begin{array}{l}\text { Escola de Inclusão } \\
\qquad N(27)\end{array}$} & \multicolumn{3}{|c|}{$\begin{array}{l}\text { Escola Especial } \\
\qquad N(13)\end{array}$} \\
\hline & & $n$ & Med & Max & Min & $n$ & Med & Max & Min \\
\hline Alerta & 20,7 & 4 & 16 & 18 & 15 & 5 & 18 & 19 & 16 \\
\hline \multicolumn{2}{|c|}{ Resistência 27,6 } & 1 & 23 & 23 & 23 & 1 & 22 & 22 & 22 \\
\hline Exaust & o >27,6 & 0 & - & - & - & 0 & - & - & - \\
\hline
\end{tabular}

Normal até 39,6 , alerta até 59,5 , resistência até 79,4 e exaustão $>79,4$ 
CONTINUA

\section{REAÇÕES PSICOLÓGICAS COM COMPONENTES DEPRESSIVOS ASSOCIADAS AO NÍVEL DE ESTRESSE}

\begin{tabular}{|c|c|c|c|c|c|c|c|c|}
\hline $\begin{array}{l}\text { REAÇÕES } \\
\text { PCD }\end{array}$ & & Esc & $\begin{array}{l}\mathrm{a} \text { de } \\
\mathrm{N}(27\end{array}$ & usão & & & $\begin{array}{l}\text { pla Es } \\
\mathrm{N}(13\end{array}$ & cial \\
\hline & $\mathrm{n}$ & Med & Max & Min & $n$ & Med & Max & Min \\
\hline Alerta (até 13) & 15 & 10 & 13 & 8 & 4 & 10 & 11 & 8 \\
\hline $\begin{array}{l}\text { Resistência } \\
\text { (até 19) }\end{array}$ & 3 & 15 & 15 & 15 & 2 & 15 & 17 & 14 \\
\hline $\begin{array}{l}\text { Exaustão } \\
(>19)\end{array}$ & 0 & - & - & - & 3 & 21 & 23 & 20 \\
\hline
\end{tabular}

Normal até 39,6 , alerta até 59,5, resistência até 79,4 e exaustão $>79,4$ 
CONTINUA

REAÇÕES PSICOFISIOLÓGICAS

\begin{tabular}{|c|c|c|c|c|c|c|c|c|}
\hline \multirow[t]{2}{*}{$\begin{array}{l}\text { REAÇÕES } \\
\text { PSICOFISIOLÓGICAS }\end{array}$} & & \multicolumn{4}{|c|}{$\begin{array}{l}\text { Escola de Inclusão } \\
\qquad \mathrm{N}(27)\end{array}$} & \multicolumn{3}{|c|}{$\begin{array}{l}\text { Escola Especial } \\
\qquad N(13)\end{array}$} \\
\hline & $n$ & Med & Max & Min & $\mathrm{n}$ & Med & $\operatorname{Max}$ & Min \\
\hline (até 14) & 10 & 12 & 14 & 10 & 3 & 12 & 13 & 11 \\
\hline Resistência (até 20) & 4 & 18 & 18 & 16 & 1 & 16 & 16 & 16 \\
\hline Exaustão (>20) & 0 & - & - & - & 1 & 23 & 23 & 23 \\
\hline
\end{tabular}


Anexo $\mathrm{H}$ - Estresse em relação ao aspecto familiar (SWB)

\begin{tabular}{lcccc} 
ASPECTO FAMILIAR & $\mathrm{N}^{0}$ & Mediana & Max & Min \\
Constituição 2 & 1 & 25 & - & \\
Constituição 3 & 9 & 33 & 50 & 36 \\
Constituição 4 & 14 & 49 & 84 & 21 \\
Constituição 5 & 6 & 36 & 61 & 19 \\
Constituição >5 & 10 & 36 & 62 & 28 \\
Trabalham fora 1 & 21 & 43 & 84 & 23 \\
Trabalham fora 2 & 12 & 27 & 52 & 19 \\
Trabalham fora 3 & 2 & 49 & 62 & 36 \\
Ninguém trabalha & 5 & 62 & 66 & 61 \\
Paciente se ocupa & 16 & 33 & 61 & 23 \\
Paciente não se ocupa & 24 & 43 & 84 & 19 \\
\hline
\end{tabular}

Normal até 39,6 , alerta até 59,5 , resistência até 79,4 e exaustão $>79,4$ 


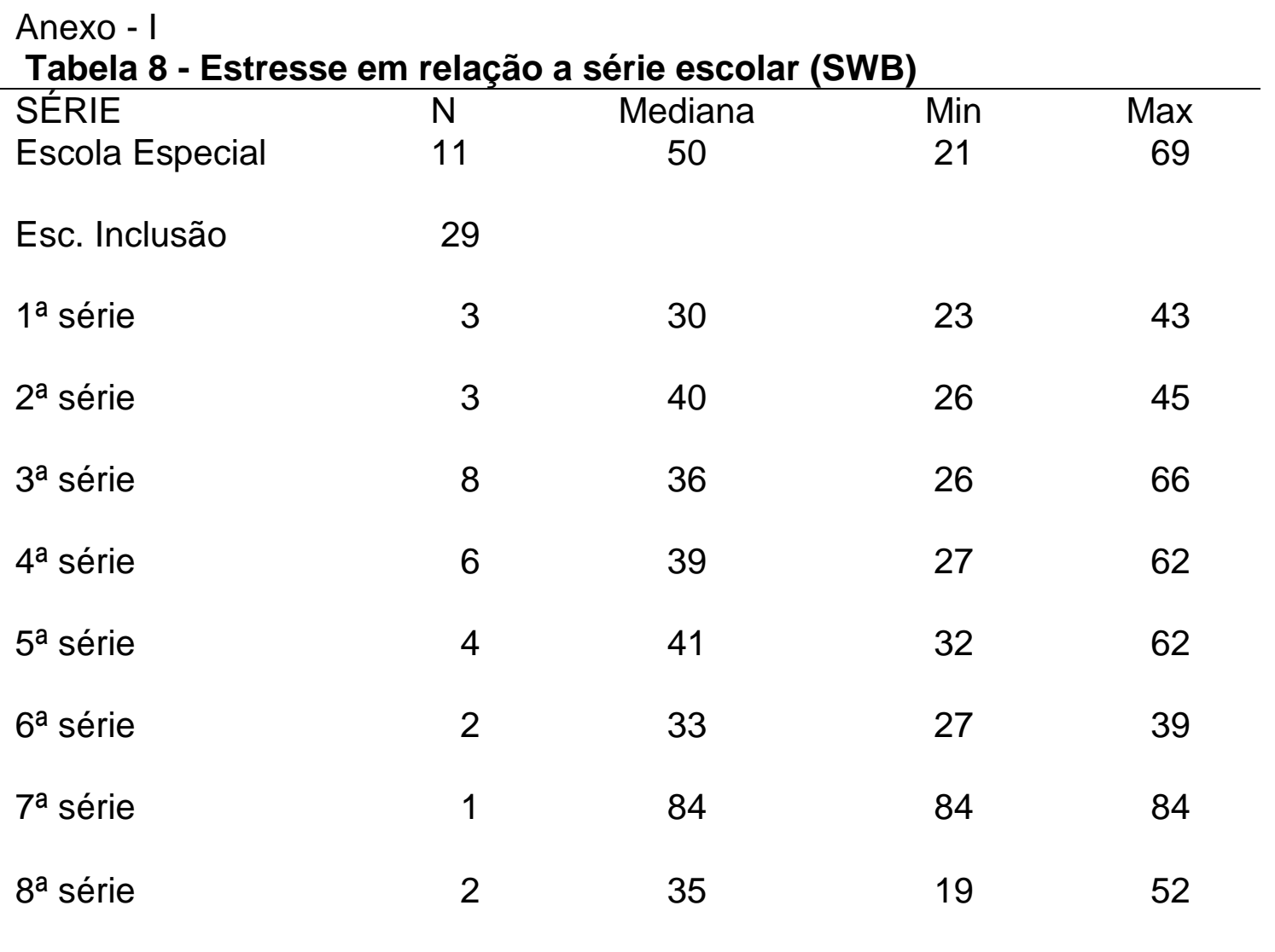

Normal até 39,6, alerta até 59,5, resistência até 79,4 e exaustão >79,4 
ABRAPEE

Associação Brasileira de Psicologia Escolar e Educacional

CNPJ 66068 818/0001-54 Inscrição Estadual Isenta

Maringá, 03 de setembro de 2012.

Prezados Vera Alice Alcantara dos Santos Amaral

Michele Moreira Nunes

Rachel Sayuri Honjo

Roberta Lelis Dutra

Francisco Baptista Assumpção Jr

Chong Ae Kim

O manuscrito intitulado "Estresse em crianças e adolescentes com Síndrome de WilliamsBeuren no contexto escolar." (PEE 662) de vossa autoria foi analisado e aprovado para publicação na revista Psicologia Escolar e Educacional.

Agradecemos por vossa colaboração.

Atenciosamente,
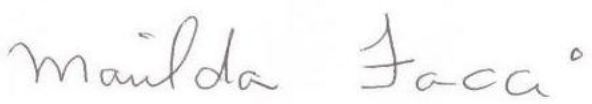

Marilda Gonçalves Dias Facci

ABRAPEE - Associação Brasileira de Psicologia Escolar e Educacional

Editora Responsável: Prf. ${ }^{a}$ Dr. ${ }^{a}$ Marilda Gonçalves Dias Facci

Universidade Estadual de Maringá Av. Colombo, 5.790 - Campus Universitário - Bloco: 10/sala 10 Maringá/Paraná CEP 87020-900 - Fone: (44) 3011-5308 E-mail: revistaabraapee@yahoo.com.br 
Estresse em pacientes molecularmente confirmados com Síndrome de WilliamsBeuren em idade escolar

Estresse na Síndrome de Williams-Beuren

Stress in molecularly-confirmed patients with Williams-Beuren syndrome in school age.

Stress in Williams-Beuren Syndrome 


\section{RESUMO}

Síndrome de Williams-Beuren é uma doença de múltiplos órgãos causada por microdeleção de 25 genes no cromossomo 7 (q11.23), sugerindo uma vulnerabilidade ao estresse. Objetivamos determinar se pacientes em idade escolar com síndrome de Williams-Beuren apresentam níveis elevados de estresse. Avaliamos 40 crianças e adolescentes, com diagnóstico de síndrome de WilliamsBeuren e grupo controle. Os instrumentos utilizados: Escala de Estresse Infantil (ESI), Escala de Inteligência para Crianças (WISC), Escala de Inteligência para Adultos (WAIS), e um questionário semiestruturado. No grupo com o SWB, 50\% tinham altos níveis de estresse em comparação com 28,6\% no grupo controle, diferença altamente significativa estatisticamente $(\mathrm{p}<0,001)$. De escola de inclusão, 40,7\% apresentaram maior estresse; escola especial de 69,2\% (p>0,140). Indivíduos com síndrome de Williams mostram índice elevado de estresse. Este estudo destaca a necessidade de orientação sobre a síndrome a pais e gestão escolar, com foco na redução de possíveis fatores ambientais estressantes.

Palavras-chave: Síndrome de Williams-Beuren; Estresse; Crianças e Adolescentes. 


\section{ABSTRACT}

Williams-Beuren syndrome is a multiorgan disease caused by microdeletion of 25 genes on chromosome 7 (q11.23), suggesting a vulnerability to stress. The objective was to determine whether patients in school age with Williams-Beuren syndrome have high levels of stress. We studied 40 children and adolescents, with confirmed diagnosis of Williams-Beuren syndrome and control group. The instruments used: Child Stress Scale (ESI), Intelligence Scale for Children (WISC), Adult Intelligence Scale (WAIS), and a questionnaire semi-estructured. In the group with SWB, 50\% had high levels of stress compared with $28.6 \%$ in the control group, statistically highly significant difference $(\mathrm{p}<0.001)$. In Inclusion school, 40.7\% had higher stress; special school $69.2 \%$ ( $p>0,140$ ) difference was not statistically significant. Individuals with Williams syndrome show high level of stress. This study highlights the need for guidance about the syndrome to parents and school management, with focus on reducing of possible environmental stressors factors.

Keywords: Williams syndrome, Stress, Children and Adolescents 


\section{Introdução}

A Síndrome de Williams-Beuren (SWB) é uma anomalia congênita rara causada por uma microdeleção hemizigótica do braço longo do cromossomo 7, banda 11.23, incluindo 25 a 35 genes (Bayés; Magano; Rivera; Flores; Perez Jurado, 2003; Merla; Ucla; Guipponi e Reymond, 2002). Pode apresentar alterações cardiovasculares, principalmente estenose aórtica supravalvar, estenose aórtica pulmonar, e hipertensão (Sugayama; Koch; Furusawa; Leone e Kim 2004; Tassabehji e Urban, 2006; Pober, Johnson e Urban, 2008), além de anormalidades renais e alterações no trato urinário (Sammour; Gomes; Duarte; Trigo - Rocha; Srougi, 2006); anormalidades endocrinológicas, as quais incluem problemas na tireóide (Selicorni; Fratoni; Pavesi; Bottigelli; Arnaboldi e Milani, 2006). A incidência da síndrome é estimada entre 1:8000 e 1:20.000 nascidos vivos (Collins; Kaplan; Somes; Roma, 2010) e prevalência de 1:7.500 (Stromme; Bjornstad e Ramstad, 2002).

Estudos sobre fenótipo cognitivo, comportamental, social e de linguagem em pessoas com a síndrome descrevem padrões consistentes de deficiência intelectual em níveis variados, comportamentos elevados de sociabilidade e empatia, bom desempenho em tarefas que demandam uso de linguagem expressiva, prejuízos em habilidades de linguagem receptiva (Rossi, Moretti-Ferreira e Giacheti, 2007; Tassabehji, Donnai e 2006b); hiperacusia, comportamentos estereotipados, agressividade, comorbidades psiquiátricas como fobias específicas, transtorno de ansiedade generalizada, transtorno de déficit de atenção e hiperatividade (Meyer-Lindenberg; Mervis; Sarpal 
e cols., 2005; Pober, 2010; Leyfer, Woodruff-Borden e Mervis, 2009; Nunes, 2010; Levitin, Cole, Lincoln e Bellugi, 2005; Gothelf; Farber; Raveh; Apter e Attias, J 2006).

Este perfil sugere que pessoas com SWB se expressam das mais variadas formas, com limitações que se confrontam entre a patologia e o que se espera de um padrão de normalidade provido da sociedade. Esta demanda de adequações provavelmente interferirá no desenvolvimento de habilidades adequadas de comunicação, socialização, realização de atividades da vida diária, desempenho acadêmico, dentre outras (Vicari, Bellucci e Carlesimo, 2001; Fish e Nance, 2007). Pressupõe-se que exigências desajustadas, como padrões de comportamento, de argúcia e de aptidão contraditórias ao que se espera da deficiência intelectual, possam aumentar a vulnerabilidade de pessoas com SWB a reações de estresse, por suas condições clínicas.

Selye (1973) conceituou estresse como "qualquer adaptação requerida à pessoa"20. Estresse é definido por Lipp (2003) como:

[...] uma reação do organismo, com componentes físicos e/ou psicológicos, causada pelas alterações psicofisiológicas que ocorrem quando a pessoa se confronta com uma situação que, de um modo ou de outro, a irrite, amedronte, excite ou confunda, ou mesmo que a faça imensamente feliz (Lipp; Arantes; Buriti, e Witzig 2003, p. 51). A literatura descreve diversos fatores associados ao estresse. São fatores externos iluminação inadequada, excesso de barulho, dificuldades na interação social (discriminação) e falta de estimulação para o desenvolvimento de outras habilidades etc. Dentre os fatores internos são citados pensamentos e ideias do próprio indivíduo em relação ao meio em que se encontra. Conforme as habilidades e os repertórios 
comportamentais da pessoa para enfrentar e manejar estes agentes, o nível de estresse variará o que pode comprometer o sistema neuroendocrinológico, funções cognitivas e comportamentais (Heim e Nemeroff, 2001; Mello, Marcinichen , Madruga e cols, 2007; Talge, Donzella e Gunnar, 2008).

McEwen e cols (McEwen \& Gianaros, 2010) revelam que, enquanto a resposta ao estresse é um mecanismo adaptativo, o estresse intenso agudo ou crônico pode ser a fonte de prejudiciais efeitos neurocognitivos.

Hartley e cols (Hartley \& MacLean Jr, 2005) discutem sobre ações educativas às pessoas com deficiência intelectual e seus cuidadores visando situações estressantes e auxiliando-as em avaliar com precisão o controle sobre eventos modificáveis podem diminuir as oportunidades para essas pessoas experimentar o stress.

Selye (1956 p. 128-139) estudou o excesso de hormônios pituitário e adrenal no organismo estressado e constatou consequências da influência nociva de agentes estressores, como doenças renais e cardiovasculares.

O eixo hipotalâmico-pituitário-adrenal (HPA) age como mediador das respostas adaptativas aos estímulos potencialmente estressores à medida que o indivíduo se prepara para lidar com a fonte de estresse (Fuchs; Flügge; Ohl e cols., 2001). Quando esse eixo se apresenta disfuncional podem ocorrer elevações crônicas e persistentes de cortisol, provocando agudizações nas alterações cardíacas, pulmonares e renais, agravando o quadro clínico das crianças e adolescentes com SWB submetendo-se ao risco de morte súbita, que muitos autores já apresentam como relacionada à própria síndrome (Wessel, Motz, Pankau, e Bursch, 1997; Gips, Zaitsev e Hiss, 2009). 
Tendo em vista a gravidade de muitas dessas reações fisiológicas para o desenvolvimento de crianças e adolescentes com SWB, o presente estudo tem como objetivo verificar se crianças e adolescentes com SWB que frequentam escolas de inclusão e escolas especiais apresentam índices elevados de estresse, de maneira a oferecer orientações para adequado ambiente escolar e melhor qualidade de vida.

\section{Método}

Os dados coletados para a amostra ocorreram em três momentos: primeiro em entrevista com as famílias das crianças e adolescentes com SWB, durante a qual preencheram o questionário de caracterização social e demográfica. O segundo encontro destinou-se à avaliação de inteligência das crianças e adolescentes. E o terceiro encontro foi dedicado à aplicação da escala ESI, apenas em crianças e adolescentes com SWB. Os pacientes foram agendados por telefone, atendidos individualmente em sala ambulatorial do Instituto da Criança do HCFMUSP. A duração da avaliação de estresse transcorreu em torno de 40 minutos a uma hora para cada indivíduo.

Por se tratar de amostras independentes, foram utilizados para tratamento dos dados a mediana e o teste não-paramétrico de Mann Whitney.

Este estudo representa uma amostra de 40 pacientes consecutivos de conveniência, sendo 21 indivíduos do sexo masculino e 19 do feminino com SWB, todos com idade entre 7 e 18 anos, com diagnósticos clínicos confirmados e atendidos pelo HC. O grupo, a convite da Associação Brasileira da Síndrome de Williams e do 
Departamento de Genética do Instituto da Criança do HC, foi composto por moradores de diversos bairros da cidade e da grande São Paulo, bem como de outros Estados do território brasileiro.

O critério de inclusão foi a confirmação do diagnóstico da SWB através de exames FISH, Molecular ou MLPA, constando a microdeleção hemizigótica no cromossomo 7 (q11.23), ter idade entre 7 a 18 anos e estarem matriculados no ensino fundamental ou escola especial. Todos os pais dos pacientes foram submetidos à entrevista inicial, assinaram termo de consentimento para a realização da pesquisa e responderam a um questionário de perguntas padronizado. Com o questionário pretendia-se uma caracterização social e demográfica da amostra e, com base no Manual Diagnóstico e Estatístico de Transtornos Mentais (DSM-IV-TR) de 1995 apontar possíveis eventos traumáticos aos quais os participantes poderiam ter sido expostos nos últimos seis meses.

O instrumento de coleta de dados utilizado foi a Escala de Stress Infantil (ESI) para crianças e adolescentes (LIPP). O ESI é um instrumento padronizado, brasileiro, validado para utilização de pesquisa e de fácil aplicação, que permite diagnosticar se a criança apresenta um quadro sintomatológico de estresse. O ESI é de alta confiabilidade, apresentando um coeficiente Cronbach Alpha de 0,90, maior que o apresentado pelo instrumento Lifestress Inventary (de 0,86), considerado altamente confiável por vários estudos de mesma finalidade (Bramston e Fogarty, 2000). O questionário é composto por 35 perguntas devidamente organizadas para detectar Reações Físicas (RF), Reações Psicológicas (RP), Reações Psicológicas com Componentes Depressivos (RPCD) e Reações Psicofisiológicas (RPF). A escolha pelo instrumento ESI neste estudo foi feita por ser menos invasivo, no qual a própria 
criança responde as questões. No entanto, para melhor interpretação das questões, modificou-se a estratégia de formulação de cada um dos itens da Escala de Stress Infantil. Por exemplo, no lugar de ler: "Eu me sinto assustado na hora de dormir", lia-se o item adaptado "Você se sente assustado(a) na hora de dormir?" acrescido de “por que?". Ao término da aplicação da escala, o responsável era ouvido para verificação das respostas, em caso de significativa discordância o paciente era excluído da pesquisa.

A avaliação de Quociente de Inteligência (QI) foi realizada por psicóloga da equipe do Departamento de Genética do HC, coautora deste trabalho.

Em função do resultado de avaliação cognitiva apresentado por algumas crianças e adolescentes com SWB, optou-se pela realização de um pré-teste na intenção de confirmar a confiabilidade na aplicação do instrumento ESI. Foi aplicado o mesmo instrumento em 20 crianças e adolescentes com suspeita de rebaixamento cognitivo e em suas respectivas mães respondendo sobre seus filhos, em momentos diferentes totalizando 40 escalas. As respostas foram comparadas. Todos os participantes do pré-teste são pacientes com rebaixamento cognitivo, atendidos na Secretaria dos Direitos da Pessoa com Deficiência, situado em Barueri, município da grande São Paulo.

A pesquisa foi aprovada pela Comissão De Ética Para Análise de Projetos de Pesquisa (CAPPesq), Número 944/08 do Hospital das Clínicas (HC) da Faculdade de Medicina da Universidade de São Paulo (FMUSP). 


\section{Resultados}

Os resultados do pré-teste apontaram respostas semelhantes entre filhos e mães, que podem indicar confiabilidade nas respostas dos filhos. A mediana para filhos foi de: 35, mínimo: 12 e máxima: 74; mediana para as mães: 30, mínima: 6 e máxima: 64 Teste Mann Withney: $p=0,212$. Não houve diferença estatisticamente significante. A maioria das respostas apresentou pontuação maior dos filhos, o que pode indicar que questões as quais remetem a percepções internas do indivíduo passam despercebidas pelas mães, talvez pela ausência de queixas. Todos os resultados de níveis de estresse foram concordantes entre os dois grupos (filhos e mães).

A amostra analisada no presente estudo apresentou idade em média 12 anos, mínima 7 e máxima 18, $(\mathrm{DP}=3,26)$. Foi constatada em todos os participantes a prevalência de deficiência mental, de acordo com resultados obtidos nos testes de inteligência com Escala de Inteligência para Crianças de Wechsler (WISC-III) e Escala de Inteligência para adultos de Wechsler (WAIS-III). Verificou-se que a média de Quociente de Inteligência Total (QIT) do grupo foi 68,5 (Desvio padrão=8,89) - compatível com deficiência mental leve à moderada.

A análise de estresse em relação ao sexo entre os grupos SWB e GC mostra que tanto meninos quanto meninas com SWB têm mais estresse que meninos e meninas sem a síndrome $(\mathrm{p}<0,001)$, conforme tabela 1 e figura 1. 
Tabela 1:

Estresse e Gênero na SWB e na GC

\begin{tabular}{|c|c|c|c|c|c|c|c|c|c|}
\hline \multirow{2}{*}{ Sexo } & \multicolumn{4}{|c|}{ SWB } & \multicolumn{4}{|c|}{ GC } & \multirow[b]{2}{*}{ MW } \\
\hline & $\mathrm{N}$ & Mdn & Min & Max & $\mathrm{N}$ & Mdn & Min & Max & \\
\hline
\end{tabular}

$\begin{array}{llllllllll}\text { Fem } & 19 & 40 & 19 & 84 & 19 & 17 & 6 & 54 & \mathrm{p}<0,001\end{array}$

$\begin{array}{llllllllll}\text { Masc } & 21 & 34 & 23 & 66 & 21 & 25 & 8 & 45 & \mathrm{p}<0,001\end{array}$

Nota. Fem = Feminino; Masc $=$ Masculino; $\mathrm{GC}=$ Grupo Controle; Mdn= Mediana; MW= Mann Whitney. Normal até 39,6, alerta até 59,5, resistência até 79,4 e exaustão $>79,4$.

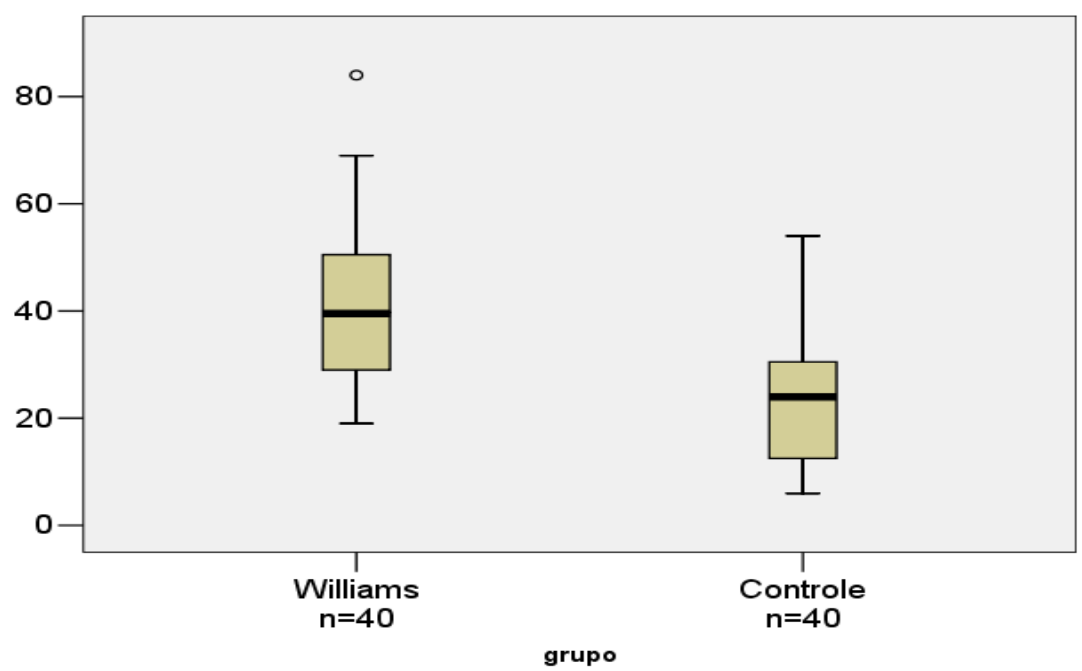

Figura 1 - Comparação de estresse entre SWB e Grupo Controle

Em ambos os grupos, SWB e GC, os indivíduos com mais de 14 anos apresentaram níveis mais elevados de estresse (64\% e $45 \%$ respectivamente) em comparação aos grupos de menor idade ( $45 \%$ e $24 \%$ respectivamente). 
A comparação do nível de estresse entre os grupos de indivíduos com SWB indica que meninas apresentam índice elevado de estresse, não houve diferença estatisticamente significante $(\mathrm{p}=0,74)$, conforme tabela 2 .

Tabela 2:

Estresse e Gênero na SWB

\begin{tabular}{|c|c|c|c|c|c|}
\hline & \multicolumn{4}{|c|}{ SWB } & \multirow[b]{2}{*}{$\operatorname{tMW}(\mathrm{p})$} \\
\hline & $\mathrm{N}$ & Mdn & Min & Max & \\
\hline Fem & 19 & 40 & 19 & 84 & \\
\hline Masc & 21 & 34 & 23 & 66 & $\mathrm{p}=0,74$ \\
\hline
\end{tabular}

Nota. Normal até 39,6, alerta até 59,5, resistência até 79,4 e exaustão >79,4.

Em relação ao ambiente escolar, o resultado mostra que não há diferença significante estatisticamente $(\mathrm{p}=0,140)$ de estresse entre o grupo de crianças e adolescentes com SWB que frequenta escolas de inclusão em comparação com o que frequenta escolas especiais, ver tabela 3 .

Tabela 3:

Estresse Escolar na SWB

\begin{tabular}{llllll}
\hline Escola & $\mathrm{N}$ & Mediana & Min & Max & tMann Witney $(\mathrm{p})$ \\
\hline \hline Inclusão & 27 & 36 & 19 & 66 & \\
Especial & 13 & 50 & 21 & 84 & $\mathrm{p}=0,140$ \\
\hline \multicolumn{4}{l}{ Nota. Normal até 39,6 , alerta até } & 59,5, resistência até 79,4 e exaustão $>79,4$
\end{tabular}


A amostra de crianças e adolescentes com SWB foi dividida em dois grupos considerando o nível de QI apresentado nos testes de inteligência: um primeiro grupo com QI abaixo de 60 e um segundo grupo com QI acima de 60 e abaixo de 89. O resultado indica maior estresse em crianças e adolescentes com QI menor de 60, diferença não significante estatisticamente $(\mathrm{p}=0,935)$, tabela 4 .

Tabela 4:

\section{Estresse e QI na SWB}

\begin{tabular}{lcclcc}
\hline QI & $\mathrm{N}$ & Mediana & Min & Max & tMann Witney $(\mathrm{p})$ \\
\hline$<60$ & 18 & 41,5 & 23 & 62 & \\
$>60<89$ & 22 & 36,5 & 19 & 84 & $\mathrm{p}=0,935$ \\
\hline \multicolumn{7}{l}{ Nota. Normal até 39,6 , alerta até } & 59,5, resistência até & 79,4 e exaustão $>79,4$
\end{tabular}

Foram analisados também os níveis de estresse em crianças e adolescentes com SWB em ambientes escolares específicos. Dos 27 indivíduos que frequentam escolas de inclusão, 16 (59\%) encontram-se em nível normal de estresse (mediana=31), 8 (30\%) estão em estado de alerta (mediana 46) e 3 (11\%) em estado de resistência, (mediana 62). Dos 13 que frequentam escola especial, 4 (31\%) encontram-se em nível normal de estresse (mediana 26), 5 (38\%) estão em estado de alerta (mediana 50), 3 (23\%) em estado de resistência (mediana 62) e 1 (8\%) apresenta estado crônico (nível de estresse 84). Vide tabela 5. 
Tabela 5:

Níveis de Estresse entre crianças e adolescentes com SWB em Escola de Inclusão e Escola Especial

\begin{tabular}{|c|c|c|c|c|c|c|c|c|}
\hline Escola (n.) & Nor. & Mdn & $\begin{array}{l}\text { AL } \\
\text { (1DP) }\end{array}$ & Mdn & $\begin{array}{l}\text { RES } \\
\text { (2DP) }\end{array}$ & Mdn & $\begin{array}{l}\mathrm{EX} \\
(>2 \mathrm{DP})\end{array}$ & $\mathrm{Mdn}$ \\
\hline INCL (27) & $\begin{array}{l}16 \\
(59 \%) \\
04\end{array}$ & 31 & $\begin{array}{l}8 \\
(30 \%) \\
5\end{array}$ & 46 & $3(11 \%)$ & 62 & 0 & \\
\hline ESP (13) & $(31 \%)$ & 26 & $(38 \%)$ & 50 & $3(23 \%)$ & 62 & $1(8 \%)$ & 84 \\
\hline
\end{tabular}

Nota. INCL=Inclusão; ESP=Especial; NOR=Normal; AL= Alerta; RES=Resistência; EX=Exaustão; Mdn=Mediana. Normal até 39,6, alerta até 59,5, resistência até 79,4 e exaustão $>79,4$.

As respostas ao questionário aplicado para analisar a situação escolar das crianças e adolescentes com SWB revelam que mais da metade da amostra queixa-se de excesso de barulho e discriminação, $60 \%$ e $58 \%$ respectivamente, seguido de queixa de muita lição, $35 \%$, ver tabela 6 .

Tabela 6:

Respostas sobre queixa escolar das crianças e adolescentes com SWB

\begin{tabular}{lll}
\hline QUEIXA - N=40 & N & $\%$ \\
\hline Não sabe ler & 5 & 12 \\
Não sabe escrever & 8 & 20 \\
Não entende a lição & 9 & 22 \\
Exigência da letra cursiva & 10 & 25 \\
Professor bravo & 8 & 20 \\
Muita lição & 14 & 35 \\
Muito barulho & 24 & 60 \\
Discriminação & 23 & 58 \\
Sente-se diferente dos outros & 10 & 25 \\
\hline
\end{tabular}

A maioria dos pacientes desta amostra não foi alfabetizada, apenas nove pacientes que frequentavam escola de inclusão foram alfabetizados, cujo QI variou em mínimo 
51 e máxima 77 e mediana 62. Alguns pacientes com QI total acima de 80 não conseguiram ser alfabetizados.

Os 14/40 pacientes que repetiram o ano, bem como os 13 que resistiam em ir para a escola apresentaram nível elevado de estresse, em média 43,4 e 47,7 respectivamente.

A leitura nos prontuários revelou que $87,5 \%$ da amostra apresentam personalidade expansiva e amigável; 95\% apresentam hiperacusia; 65\%, ansiedade; Estenose aórtica supravalvar, 62,5\%; estenose aórtica pulmonar, 32,5\%; Prolapso da válvula mitral, $25 \%$ e $17,5 \%$ apresentam Hipertensão arterial. Foram constatados também que 2,5\% apresentam estenose da artéria renal e insuficiência renal; 30\% apresentam enurese noturna e 27,5\% tem alteração músculo-esquelética.

\section{Discussão}

O presente estudo confirma a presença de índice elevado de estresse nas crianças e adolescentes com SWB. Não foi encontrado na literatura nenhum estudo sobre estresse na SWB, apenas duas pesquisas (Hessl e cols., 2002; Gilmour, Skuse e Pembrey, 2001) utilizaram indicadores biológicos de estresse os quais avaliaram síndromes diferentes, tendo apenas deficiência intelectual como característica semelhante. O primeiro avaliou o nível de cortisol salivar em 109 crianças com síndrome de X-Frágil comparadas com 109 irmãos sem a síndrome constatou um significativo aumento deste indicador hormonal que foi maior em meninos do que em meninas e, ainda mais elevado em crianças com QI mais baixo. Outro estudo 
avaliou o estresse em pessoas com deficiência intelectual, analisado em 26 crianças com Síndrome de Prader Willi comparadas com 24 crianças com síndrome da baixa estatura e hiperfagia (HSS) e 20 crianças normais, utilizando os questionários Inventário de Comportamentos para Crianças e Adolescentes (CBCL) e Questionário para Professores (TRF) e medida de cortisol salivar. Os resultados indicaram níveis altos de cortisol no grupo de SPW, seguido do grupo HSS, seguido do grupo controle. A análise dos questionários mostrou a presença de diversos agentes estressores psicossociais no ambiente do qual participam as crianças com SPW e HSS. Estes resultados comparados com o presente estudo, embora com metodologias diferentes, mas focados na alteração do eixo HPA, foram concordantes e sugerem que o estresse pode estar comprometendo o sistema neuroendócrino autônomo da síndrome indicativa (Gunnar e cols., 2009).

A personalidade superamigável, a boa narrativa e o senso crítico presentes na população com SWB diferenciam-na de outras síndromes com deficiência intelectual. Os riscos de um otimismo desadaptativo, muito freqüente na SWB, o qual pode ser irrealista, podem levar o indivíduo a lidar de maneira inadequada em certas circunstâncias que pode ter consequiências desagradáveis que propiciem o estresse. Esta característica pode também facilitar a percepção desta população com SWB em relação a estímulos estressores do meio, principalmente no caso dos adolescentes, devido a sua idade crítica, num período turbulento, cheio de mudanças que os tornam mais vulneráveis a perturbações (Romeo e Mc-Ewen, 2006; Goodman, McEwen, Dolan, Schafer-Kalkhoff, Adler, 2005).

Crianças e adolescentes que frequentam escola especial são menos expostos a agentes estressores, entretanto, por terem maiores prejuízos em habilidades 
intelectuais e por ficarem menos expostos ao contato social mais amplo, acabam ficando mais vulneráveis a reações de estresse em ambientes diversos (Hartley e cols., 2005). Propor-lhes pequenos desafios e incentivá-los à independência são ações que podem contribuir para amenizar esse quadro. Segundo Lipp e cols. (Lipp, Souza, Romano e Covolan 1991), as crianças adequadamente criadas são menos vulneráveis ao estresse e dele se recuperam com maior facilidade, pois seu poder de adaptação e seus recursos internos lhes são de valia nas horas críticas.

O ambiente escolar per si dispõe dos mais variados agentes estressores, principalmente quando se trata de inclusão educacional se esta não se encontra eficazmente estruturada. Estando os alunos expostos a ambientes com excessivos estímulos sonoros, por exemplo, correm risco de terem a pressão arterial e o nível de cortisol alterado (Wälinder, Gunnarsson, Runeson, e Smedje, 2007). Segundo dados dos prontuários clínicos, $85 \%$ da amostra apresenta hiperacusia, o que remete a um desconforto doloroso. As queixas mais frequentes foram: excesso de barulho, o que pode estar associado à presença de hiperacusia; discriminação, apesar do grau de deficiência intelectual, evidenciou-se que o senso crítico e a percepção do meio relacionados à habilidade de se comunicar estão presentes nesta população; e excesso de tarefas, o qual denota que a ação do professor diverge do conhecimento das características de déficit de atenção e déficit nas funções executivas nesta síndrome.

As alterações cardiovasculares e renais são características que podem ser indícios elegíveis para afirmar que indivíduos com SWB são mais vulneráveis ao estresse em ambientes diversos, principalmente no ambiente escolar. Considera-se que professores nervosos e impacientes, instruções confusas, privação das necessidades 
fisiológicas urgentes e frequentes, tarefas em excesso, desvalorização das potencialidades dos alunos, competição demais entre os colegas, desrespeito às diferenças e às limitações se configuram em fortes fatores estressores externos e que têm uma grande participação no desenvolvimento do estresse infantil (Lipp e Lucarelli,1998), sendo, portanto imprescindíveis orientações, neste sentido, às instituições que atendem crianças e adolescentes com SWB.

\section{Conclusão}

Os resultados obtidos com este estudo mostram que crianças e adolescentes com SWB apresentam índices elevados de estresse. Não houve diferença estatisticamente significante entre o nível de estresse e gênero, tipo de escola e valor de QI nos pacientes com SWB.

Os tipos de reações de estresse mais acentuados foram Físicas e Psicológicas com Componentes Depressivos. As queixas mais frequentes de sintomas psicológicos neste estudo foram relativas à insegurança, desânimo e choro excessivo; de sintomas físicos, hiperatividade, dores de barriga e enurese noturna. Estes sintomas são oriundos de fontes externas, como qualquer evento do ambiente que exija adaptação - saber ler e escrever, barulho excessivo, independência nas atividades novas e de rotina, etc., e de fontes internas, as quais se caracterizam pela forma que o indivíduo enfrenta situações novas ou de cotidiano, seus pensamentos e atitudes. Quando bem equilibradas estas fontes proporcionam predisposição à mudanças, sensação de controle e motivação para envolvimento efetivo em alguma área da vida. 
Foram observados tanto nas respostas dos questionários como nas escalas que crianças e adolescentes com SWB não têm recursos próprios para manejo de estratégias ou técnicas para lidar com estresse, seja por suas condições clínicas, seja por estarem em ambientes inadequados.

Em face à fragilidade orgânica de crianças e adolescentes com SWB, os achados apontam para a necessidade de capacitação de educadores e pais em relação à síndrome, capaz de incentivá-los a desenvolver ambientes controlados que permitam às crianças a aquisição de autonomia e independência, a estimulação de habilidades cognitivas e habilidades da vida diária.

Mostram-se importantes avaliações periódicas de estresse nesta população, seja através de escalas ou por medidas de cortisol, pois a fim de evitar o agravamento do quadro clínico.

Embora a amostra tenha sido pequena, os resultados deste estudo apontam índices elevados de estresse em crianças e adolescentes com SWB. Não foi encontrado na literatura nenhum estudo semelhante, o que dificultou comparações específicas. Sugere-se, portanto, pesquisas futuras neste formato.

\section{Referências}

Bayés, M.; Magano, L.F.; Rivera, N.; Flores, R.; Perez Jurado, L.A. (2003). Mutational mechanisms of Williams-Beuren syndrome e deletions. Am J Hum Genet, 73, 131-51.

Bramston, P. e Fogarty, G. (2000). The assessment of emotional distress experienced by people with an intellectual disability: a study of different methodologies. Research in Developmental Disabilities, 21, 487-500. 
Collins, R.T.; Kaplan, P.; Somes, G.W.; Roma, J.J. (2010). Long-term outcomes of patients with cardiovascular abnormalities and Williams syndrome. Am J Cardiol, 105(6), 874-8.

Fish, G.S. e Nance, W. (2007). Studies of age-correlated features of cognitivebehavioral development in children and adolescents with genetic disorders. Am J Med Genet A, 143A(20), 2478-89.

Fuchs, E.; Flügge, G., Ohl, F. e cols. (2001). Psychosocial stress, glucocorticoids, and structural alterations in the tree shrew hippocampus. Physiol Behav,73(3), 28591.

Gilmour, J.; Skuse, D. e Pembrey, M. (2001). Hyperphagic short stature and PraderWilli syndrome: a comparison of behavioural phenotypes, genotypes e indices of stress. British Journal of Psychiatry,179, 129-37.

Gips H, Zaitsev K e Hiss J. "Scared to death"--lethal cardiac arrhythmia caused by emotional stress. Harefuah. 2009 Feb;148(2):84-6, 140.

Goodman, E.; McEwen, B.S.; Dolan L.M.; Schafer-Kalkhoff, T.; Adler, N.E. (2005). Social disadvantage and adolescent stress. Journal of Adolescent Health, 37, 484-92.

Gothelf, D.; Farber, N.; Raveh, E.; Apter, A.; Attias, J. (2006). Hyperacusis in Williams Syndrome: Characteristics and associated neuroaudiologic abnormalities. Neurology, 66(3), 390-5.

Hartley SL, MacLean WE Jr. (2005). Perceptions of stress and coping strategies among adults with mild mental retardation: insight into psychological distress. Am J Ment Retard. 110:285-97. 
Hessl, D.; Glaser, B.; Dyer-Friedman, J.; Blasey, C.; Hastie, T.; Gunnar, M.; Reiss, A.L. (2002). Cortisol and behavior in fragile $\mathrm{X}$ syndrome. Psychoneuroendocrinology, 27, 855-72.

Levitin, D.J.; Cole, K.; Lincoln, A. e Bellugi, U. (2005). Aversion, awareness, and attraction: investigating claims of hyperacusis in the Williams syndrome phenotype. Journal of Child Psychology and Psychiatry, 46(5), 514-23.

Leyfer, O.; Woodruff-Borden, J. e Mervis, C.B. (2009). Anxiety Disorders in Children with Williams Syndrome, Their Mothers, and Their Siblings: Implications for the Etiology of Anxiety Disorders. J Neurodev Disord, 1(1), 4-14.

Lipp, M.; Souza, E.A.P.; Romano, A.S.F.; Covolan, M.A. (1991) Como enfrentar o

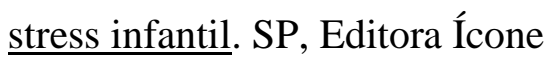

Lipp, M. e Lucarelli, M.D. (1998). Escala de Stress Infantil - ESI. [S.l.]: Casa do Psicólogo.

Lipp, M.; Arantes, J.P.; Buriti, M.S. e Witzig, T. (2003). O estresse em escolares. Psicol. Esc. Educ. SP, 4(1), 51-6.

McEwen BS \& Gianaros PJ, Central role of the brain in stress and adaptation: Links to socioeconomic status, health, and disease. Ann N Y Acad Sci. 2010 February ; 1186: 190-222.

Mello DM, Marcinichen DR, Madruga D, Branco R, Paschoalini MA, et al. (2007) Involvement of NK1 receptors in metabolic stress markers after the central administration of substance P. Behav Brain Res 181(2): 232-238.

Merla, G.; Ucla, C.; Guipponi, M. e Reymond, A. (2002). Identification of additional transcript in the Williams-Beuren Syndrome critical region. Hum Genet, 110, 42938. 
Meyer-Lindenberg, A.; Mervis, C.B. e Sarpal, D. e cols. Functional, structural, and metabolic abnormalities of the hippocampal formation in Williams syndrome. $\underline{\mathrm{J} \text { Clin }}$ Invest, $115,1888-95$.

Nunes, M.M. (2010). Avaliação do funcionamento cognitivo de pacientes com

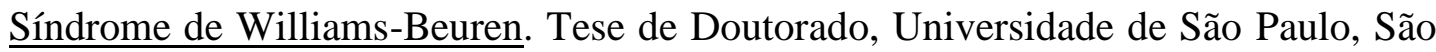
Paulo-SP.

Pober, B.R. (2010). Williams-Beuren syndrome. N Engl J Med, 362(3), 239-52.

Romeo RD, Mc-Ewen BS. Stress and the adolescent brain. Ann NY Acad Sci. 2006;1094:202-14.

Pober, B.; Johnson, M. e Urban, Z. (2008). Mechanisms and treatment of cardiovascular disease in Williams-Beuren syndrome. J. Clin. Invest, 118, 1606-15. Rossi, N.F.; Moretti-Ferreira, D. e Giacheti, C.M. (2007). Perfil comunicativo de

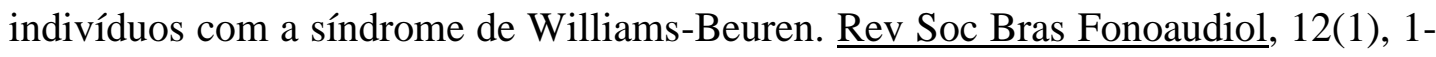
9.

Sammour, Z.M.; Gomes C.M.; Duarte, R.J.; Trigo - Rocha, F.E.; Srougi, M. (2006). Voiding dysfunction and the Williams-Beuren syndrome: a clinical and urodynamic investigation. Urol. 2006, 175(4), 1472-6.

Selicorni, A. Fratoni, A.; Pavesi, M.A.; Bottigelli, M.; Arnaboldi, E. e Milani, D. (2006). Thyroid anomalies in Williams syndrome: investigation of 95 patients. Am j Med Genet A, 140(10), 1098-101.

Selye, H. (1956) The stress of life. McGraw-Hill Book Company, Inc Selye, H. (1973). The evolution of the stress concept. Am Sci, 61, 692-9.

Stromme, P.; Bjornstad, P.G. e Ramstad, K. (2002). Prevalence estimation of Williams syndrome. J. Child Neurol, 17, 269-71. 
Sugayama, S.M.M.; Koch, V.H.K.; Furusawa, É.A.; Leone, C. e Kim, C.A. (2004). Renal and urinary findings in 20 patients with Williams-Beuren syndrome diagnosed by fluorescence in situ hybridization (FISH). Rev. Hosp. Clin. Fac. Med. S. Paulo, 59(5), 266-72.

Talge NM, Donzella B e Gunnar MR, Fearful Temperament and Stress Reactivity Among Preschool-Aged Children. Infant Child Dev. 2008 ; 17(4): 427-445.

Tassabehji, M. e Donnai, D. (2006). More or less? Segmental duplications and deletions in the Williams-Beuren syndrome region provide new insights into language development. European Journal of Human Genetics, 14, 507-8.

Tassabehji, M. e Urban, Z. (2006) Congenital heart disease: Molecular diagnostic of supravalvular aortic stenosis. Methods Mol Med, 126, 129-56.

Vicari, S.; Bellucci, S. e Carlesimo, G.A. (2001). Procedural learning déficit in children with Williams syndrome. Neuropsychology, 7(39), 665-77.

Wälinder, R.; Gunnarsson, K.; Runeson, R. e Smedje, G. (2007). Physiological and physiological stress reactions in relation to classroom noise. Scand J work Environ Health, 33(4), 260-66.

Wessel, A.; Motz, R.; Pankau, R. e Bursch, J.H. (1997). Arterial hypertension and blood pressure profile in patients with Williams-Beuren syndrome. Z Kardiol, 86, 251-7. 
O artigo intitulado "Perceptions of psychosocial stress in children and adolescents with Williams-Beuren syndrome" foi submetido no Neurocase com Fator de Impacto de 1.069 e está em análise. 


\section{Perceptions of psychosocial stress in children and adolescents with Williams-Beuren syndrome}

Authors: Vera Alice Alcantara dos Santos Amaral ${ }^{\text {; }}$ Caio Robledo DC Quaio ${ }^{1}$; Michele Moreira Nunes ${ }^{1}$; Rachel S Honjo ${ }^{1}$; Roberta Lelis Dutra ${ }^{1,2}$; Leslie D Kulikowski $^{1,2}$; Francisco Assumpção ${ }^{3}$; Maria Cristina Teixeira ${ }^{4}$; Israel Gomy ${ }^{1}$; Debora Romeo Bertola ${ }^{1}$; Chong Ae Kim.

1- Genetics Unit, Instituto da Criança da Faculdade de Medicina da Universidade de São Paulo, São Paulo - SP, Brazil; 2- LIM3 Faculdade de Medicina da Universidade de São Paulo, São Paulo - SP, Brazil; 3Faculdade de Psicologia da Universidade de São Paulo, São Paulo - SP, Brazil; 4- Universidade Presbiteriana Mackenzie, São Paulo - SP, Brazil

Corresponding author:

Address: Unidade de Genética - ICr.

Av. Dr. Enéas Carvalho de Aguiar, 647, São Paulo - SP. Brazil CEP: 05403000 .

Phone: +55(11)2661-8671

Fax: $+55(11) 2661-8503$

E-mail: chong.kim@icr.usp.br

Conflict of Interest: none declared.

Number of pages: 10 . 


\section{Perceptions of psychosocial stress in children and adolescents with Williams-Beuren syndrome}

Abstract

The objective of this study is to determine perceptions of psychosocial stress in individuals with Williams-Beuren syndrome (WBS) and to identify the major events that might modulate these reactions. A standard questionnaire based on axis IV of DSM-IV-TR, the WISC-III/WAIS-III and Lipp's Stress Scale for children and adults were administered to 40 individuals with WBS and 40 control individuals. The major event related to stress reactions in patients with WBS was excessive noise. Patients with WBS presented statistically significant higher levels of stress. Our findings indicate that individuals with WBS are at risk for stress.

Keywords: Williams syndrome, Stress, Children and Adolescents, Genetics, Dysmorphology. 


\section{Introduction}

Williams-Beuren syndrome (WBS) is a multisystem disorder with an overall incidence varying from $1: 8,000$ to $1: 20,000$ live newborns. WBS is characterized by cardiovascular disease (supravalvular aortic stenosis), distinctive facies, connective tissue abnormalities, growth abnormalities and endocrine abnormalities. Its neurological involvement is marked by a specific cognitive profile, unique personality and intellectual disability (Pober, 2010). WBS is associated with hemizygous deletion of 1.5 to $1.8 \mathrm{Mb}$ on chromosome 7q11.23, which contains approximately 28 genes (Pober, 2010; Committee on Genetics, 2002).

Psychological studies on WBS describe varying degrees of intellectual disability, weakness in visuospatial construction and executive function, good sociability with a marked overfriendliness, empathy and strengths in verbal short-term memory and language with fluent speech and hyperacusis. These studies also show stereotyped behaviors, aggressiveness and some psychiatric disorders, such as generalized anxiety and attention deficit hyperactivity disorder (Pober, 2010; Committee on Genetics, 2002; Leyfer , Woodruff-Borden \& Mervis, 2009; Tassabehji \& Donnai, 2006; Levitin, Cole, Lincoln \& Bellugi, 2005; Vicari, Bellucci \& Carlesimo, 2001; Fisch, Carpenter, Howard-Peebles, Holden, Tarleton, Simensen \& Nance, 2007; MeyerLindenberg, Mervis \& Berman, 2006).

Despite the fact that patients with WBS present some preserved intellectual abilities, they usually show several limitations of adaptive behavior, which may be found in other syndromes with intellectual disability. These limitations may interfere with the development of several cognitive skills and increase the vulnerability of these patients to stress (Vicari et al., 2001; Fisch et al., 2007). Indeed, it is known that individuals with intellectual disability are at 1.5 to 3 times greater risk of behavioral, social and psychiatric disorders and psychological maladjustment than are their healthy peers (Whelan \& Mathews, 2011; Leyfer, Woodruff-Borden, Klein-Tasman, Fricke \& Mervis, 2006). 
Stress is an organic reaction to triggering stimuli, with physical and psychological components. Stress is mediated by the hypothalamic-pituitaryadrenal axis (Selye, 1973; Sapolsky, Romero \& Munck, 2000). Stress may lead to physiological alterations of several systems, including the cardiovascular system. This organic reaction may play a role in decompensating or increasing the severity of underlying diseases, such as the congenital cardiomyopathy of WBS, thereby increasing the morbidity and mortality related to cardiovascular diseases (Grippo \& Johnson, 2009; Penninx, Beekman, Honig, Deeg, Schoevers, van Eijk \& van Tilburg, 2001; Frasure-Smith, Lespérance \& Talajic, 1995). Various events may trigger a stress reaction, from life-threatening events to minor events, such as excessive noise or difficulties in social interaction.

Other studies indicate that children with WBS experience increased behavioral difficulties, such as nervousness, depression, phobias and aggression (Leyfer et al., 2009). Furthermore, when the affected organ--the brain--is the organ most intimately related to the capacity to adjust, the prognosis for successful coping decreases further (Whelan \& Mathews, 2011). Few studies have addressed the theme of stress in individuals with neurodevelopmental disorders and genetic medical conditions. The objective of this study is to determine perceptions of stress in individuals with WBS and to identify the major events in their lives that might modulate a stress reaction.

\section{Methods}

The participants were 21 male and 19 female patients (total $=40$ individuals) with genetically confirmed WBS (a microdeletion in 7q11.23 was confirmed either by FISH (fluorescence in situ hybridization), MLPA (multiplex ligationdependent probe amplification) or polymorphic markers). All of the participants were assisted at the Genetics Unit of our service. The patients' ages ranged from $7-18$ years, with a mean of 12.6 years ( $S D=3.26$ years). 
Six patients had a microdeletion of $1.84 \mathrm{Mb}$ in the WBS critical region and 34 patients had a $1.55 \mathrm{Mb}$ microdeletion. This group of individuals was designated the "case group".

The control group, which was age- and gender-matched, was composed of 40 individuals selected from regular public schools in São Paulo, Brazil, where the patients with WBS attended classes.

The Local Ethical Committee approved this study and written informed consent was obtained from all participants.

The Wechsler Intelligence Scales for Children and Adults, third edition (WISC-III and WAIS-III, respectively) were administered only to patients with WBS because we assumed that the control group had normal intelligence (Wechsler, 1991; Wechsler, 1997). The WISC-III is an individually administered intellectual ability assessment normed for 6 years to 15 years and 11 months. The WAIS-III is an individually administered intellectual ability assessment normed for 16 to 89 years. The average total Intelligence Quotient (IQ) of the case group was 68.5 (SD: 8.89) and the means for verbal and executive intelligence were 58.5 (SD: 10.08) and 61.6 (SD: 9.3), respectively. These values indicate that most individuals with WBS may be regarded as having mild to moderate intellectual disability.

\section{Measures}

a) The standard questionnaire on axis IV of DSM-IV-TR: a standard questionnaire based on axis IV (Psychosocial and Environmental Problems) of DSM-IV-TR (American Psychiatric Association, 1994) was administered to the parents of every individual in the case group each time the individuals of the groups were assessed. The standard questionnaire assessed problems to determine the presence of life events in the previous 6 months that might influence the level of stress. These problems were grouped into the following categories as 
axis IV: problems with primary support, problems related to the social environment, educational problems, occupational problems, housing problems, economic problems, problems with access to health care services and problems related to interactions with the legal system/crime (American Psychiatric Association, 1994).

b) The Lipp's Stress Scale for children and adults (Lipp's Children Stress Scale/ Lipp's Adult Stress Scale) (Lucarelli \& Lipp, 1999): these scales were administered to 40 individuals with WBS and 40 control individuals. The Lipp's Children Stress Scale is an individually administered stress assessment normed for ages 7 years to 14 years and 11 months and Lipp's Adult Stress Scale is normed for ages 15 years or over (normal reference score: <39.6). These scales are composed of 35 objective items that measure reactions related to stress and assess four groups of reactions: physical, psychological, psychological with depressive components and psychophysiologic. Each item of the scale is graded by a Likert scale from zero to four. Therefore, the total score of each scale is composed of the sum of each item and may vary from zero to 140 .

Considering the presence of intellectual disability in the majority of WBS patients, a pre-test was conducted in an attempt to confirm the reliability of the ESI instrument. We used the same instrument for 20 children and adolescents with suspected intellectual disability and for their mothers, responding about their children, at different times, for a total of 40 scales. The responses were compared. The results of the pretest showed similar responses for children and mothers, which may indicate reliability in the children's responses. The median for children was 35 , with a minimum of 12 and a maximum of 74 and the median for mothers was 30, with a minimum of 6 and a maximum of 64 , Mann Whitney $p=0.212$. There was no statistically significant difference between the groups. Most child respondents had higher scores, which may indicate that issues that refer to the internal perceptions of the 
individual go unnoticed by the mother, perhaps due to the absence of complaints. All results of stress levels were consistent between the two groups (children and mothers).

A statistical analysis comparing the differences between the WBS and control groups was performed using the Wilcoxon test with a significance of $p<0.01$. The Mann Whitney test was used for comparisons between the subgroups of patients with WBS stratified by gender, IQ level and attendance at special and regular schools.

\section{Results}

Patients with WBS presented higher levels of stress (mean: 39.5; range: 1984) when compared with the control group (mean: 24; range: 6-54). This difference was statistically significant $(p<0.001)$. The standard questionnaire on axis IV of the DSM-IV-TR applied to the parents of the WBS group revealed the prevalence of the following major events related to stress reactions in patients with WBS: a) problems related to the social environment: excessive noise (60\%) and discrimination (58\%); b) educational problems: excessive homework (35\%), the need to learn cursive letters $(25 \%)$, the feeling of being different from the normal peers $(25 \%)$ and illiteracy (12\%).

The greater number of participants with indicators of stress concentrated in the alert phase (13 of 40 participants in the group with WBS (32.5\%) and three participants in the CG). In the group with WBS, girls had a median total stress level above the normal range (39.6 points) with a minimum of 19 and a maximum of 84 points, compatible with the exhaustion phase.

There were no statistically significant differences between the stress levels of children with WBS depending on the type of school $(p=0.140)$, although the median observed in children at special schools was higher than the median for children in regular school. 
We did not find any statistically significant difference when comparing the subgroups of patients with WBS stratified by gender ( $p: 0.74$ ), level of intelligence quotient (patients with $I Q<60 \times I Q \geq 60 ; p$ : 0.935), size of microdeletion (1.55 Mb $\times 1.84 \mathrm{Mb} ; \mathrm{p}: 0.402)$ and attendance at special schools versus regular schools ( $p: 0.14$ ).

\section{Discussion}

We used an objective scale to study the level of stress in patients with WBS. We found that the levels of stress in these patients were significantly elevated when compared to the control group of normal individuals. We did not find a direct relation between the level of stress and IQ, gender, the size of the microdeletion in $7 q 11.23$ or the availability of special education. This is the first study in the literature to address this issue in WBS.

Elevated stress levels were previously found in studies of patients with intellectual disability, such as in Prader-Willi syndrome and Fragile- $X$ syndrome (Hessl, Glaser, Dyer-Friedman, Blasey, Hastie, Gunnar \& Reiss AL, 2006; Gilmour, Skuse \& Pembrey, 2001; Hartley \& MacLean, 2005). Some of these studies report a greater prevalence and greater impact of stress, suggesting that increased vulnerability to stress is a characteristic of people with intellectual disability. Nevertheless, we did not find a direct correlation between the level of stress and IQ level in patients with WBS. One possible explanation for this incongruence is the fact that the overfriendly personality, empathy, fluent speech and preserved critical judgment may increase perceptions of stressors among patients with WBS, making this group more vulnerable to disturbances in this situation (Romeo \& McEwen, 2006). Additionally, excessive noise was a frequent and significant stressor in our study, but hyperacusis is frequently under-recognized and under-addressed by clinicians.

Another important subject is the increased level of stress in the families of patients with intellectual disability (Hartley et al., 2005). Familial stress may 
be derived from several aspects of the interaction between individuals with intellectual disability and their family members, such as frustration and fear of future outcomes. This interaction may also contribute to the level of stress in WBS.

Hartley et al. (Hartley et al., 2005) propose that educating people with mild intellectual disability and their caregivers about common stressful situations and aiding individuals with mild intellectual disability in accurately appraising control over modifiable events may decrease opportunities for these individuals to experience stress. We also recommend that hyperacusis must be addressed properly because it was the most important stressor found in our study.

Our results show that psychological reactions with depressive components and physical reactions were the most prevalent reactions in the group with WBS. The presence of these reactions indicates the need for interventions for people with WBS and their families. The permanence of these reactions may become a risk factor for the development of mental health problems in this group. WBS affects the neurobehavioral development of patients through the decline of resilient factors, such as the presence of intellectual disability. If stress reactions are observed, then greater impairment in the development of these individuals is expected.

In summary, we consider patients with WBS at risk for stress because we found an increased prevalence of higher levels of stress in this population compared to the subjects in the control group. Hyperacusis was the most common stressor and should be properly addressed in an attempt to improve the quality of life of patients with WBS.

\section{References}

1- American Psychiatric Association. (1994). Diagnostic and Statistical Manual of Mental Disorders: DSM-IV- 4th ed. Washington, DC: American Psychiatric Association. 
2- Committee on Genetics. (2002). American Academy of Pediatrics: Health care supervision for children with Williams syndrome. Pediatrics. 109:329.

3- Fisch GS, Carpenter N, Howard-Peebles PN, Holden JJ, Tarleton J, Simensen R, Nance W. (2007). Studies of age-correlated features of cognitive-behavioral development in children and adolescents with genetic disorders. Am J Med Genet A. 143A:2478-89.

4- Frasure-Smith N, Lespérance F, Talajic M. (1995). Depression and 18-month prognosis after myocardial infarction. Circulation. 91:9991005.

5- Gilmour J, Skuse D, Pembrey M. (2001). Hyperphagic short stature and Prader--Willi syndrome: a comparison of behavioural phenotypes, genotypes and indices of stress. Br J Psychiatry. 179:129-37.

6- Grippo AJ, Johnson AK. (2009). Stress, depression and cardiovascular dysregulation: a review of neurobiological mechanisms and the integration of research from preclinical disease models.

Stress. 12:1-21.

7- Hartley SL, MacLean WE Jr. (2005). Perceptions of stress and coping strategies among adults with mild mental retardation: insight into psychological distress. Am J Ment Retard. 110:285-97.

8- HessI D, Glaser B, Dyer-Friedman J, Blasey C, Hastie T, Gunnar M, Reiss AL. (2006). Cortisol and behavior in fragile X syndrome. J Child Psychol Psychiatry. 47:602-10.

9- Levitin DJ, Cole K, Lincoln A, Bellugi U. (2005). Aversion, awareness, and attraction: investigating claims of hyperacusis in the Williams syndrome phenotype. J Child Psychol Psychiatry. 46:514-23.

10-Leyfer O, Woodruff-Borden J, Mervis CB. (2009). Anxiety Disorders in Children with Williams Syndrome, Their Mothers, and Their Siblings: Implications for the Etiology of Anxiety Disorders. J Neurodev Disord. $1: 4-14$.

11-Leyfer OT, Woodruff-Borden J, Klein-Tasman BP, Fricke JS, Mervis CB. (2006). Prevalence of Psychiatric Disorders in 4 - 16-Year-Olds 
with Williams Syndrome. Am J Med Genet B Neuropsychiatr Genet. 141B: 615-622.

12-Lucarelli MDM, Lipp MEN. (1999). Validity of the child stress symptoms inventory. Psicol Reflex Crit. 12:71-88.

13-Meyer-Lindenberg A, Mervis CB, Berman KF. (2006). Neural mechanisms in Williams syndrome: a unique window to genetic influences on cognition and behavior. Nat Rev Neurosci. 7:380-93.

14-Penninx BW, Beekman AT, Honig A, Deeg DJ, Schoevers RA, van Eijk JT, van Tilburg W. (2001). Depression and cardiac mortality: results from a community-based longitudinal study. Arch Gen Psychiatry. 58:221-7.

15-Pober BR. (2010). Williams-Beuren syndrome. N Engl J Med. 362:239-52

16-Romeo RD, McEwen BS. (2006). Stress and the adolescent brain. Ann NY Acad Sci. 1094:202-14.

17-Sapolsky RM, Romero LM, Munck AU. (2000). How do glucocorticoids influence stress responses? Integrating permissive, suppressive, stimulatory, and preparative actions. Endocr Rev. 21:55-89.

18-Selye H (1973) The evolution of the stress concept. Am Sci. 61:692-9.

19-Tassabehji M, Donnai D. (2006). More or less? Segmental duplications and deletions in the Williams-Beuren syndrome region provide new insights into language development. Eur J Hum Genet. 14:507-8.

20-Vicari S, Bellucci S, Carlesimo GA. (2001). Procedural learning deficit in children with Williams syndrome. Neuropsychologia. 39:665-77.

21-Wechsler D. (1991). Wechsler Intelligence Scale for Children (WISC). 3rd ed. San Antonio: Psychological Corporation.

22-Wechsler D. (1997). WAIS-III: administration and scoring manual. San Antonio: Psychological Corporation.

23-Whelan TB, Mathews MJ. (2011). Integrative Developmental Neuropsychology. A general systems and social-Ecological Approachto the Neuropsychology of Children with Neurogenetic 
Disorders. In: Goldstein, S and Reynolds, C.R (eds). Handbook of Neurodevelopmental and Genetic Disorders in Children. New YorkLondon: The Guilford Press, 2nd ed.

24-Whelan TB, Mathews MJ. (2011). Integrative Developmental Neuropsychology. A general systems and social-Ecological Approachto the Neuropsychology of Children with Neurogenetic Disorders. In: Goldstein, S and Reynolds, C.R (eds). Handbook of Neurodevelopmental and Genetic Disorders in Children.New YorkLondon: The Guilford Press, 2nd ed. 
REFERÊNCIAS BIBLIOGRÁFICAS 


\section{6 - Referências bibliográficas}

Aasland A, Flatö B, Vandvik I. Psychosocial factors in children with idiopathic musculoskeletal pain: a prospective, longitudinal study. Acta Paediatr 1997;86(7):740-746.

Aranha MSF. Paradigmas da relação da sociedade com as pessoas com deficiência. In Revista do Ministério Público do Trabalho, Ano XI, n. 21, março, 2001, pp. 160-173.

Bakshi VP e Kalin NH. Corticotropin-releasing hormone and animal models of anxiety: gene-environment interactions. Biol Psychiatry. 2000 Dec 15;48(12):1175-98.

Bayés M, Magano LF, Rivera N, Flores R, Pérez Jurado LA. Mutational mechanisms of Williams-Beurens syndromedeletions. Am J Hum Genet 2003; 73: 131-51.

Blomberg, S., Rosander, M., Andersson, G., 2006. Fears, hyperacusis and musicality in Williams syndrome. Res. Dev. Disabil. 27, 668-680.

Brasil (1988) Congresso Nacional. Constituição da República Federativa do Brasil, DF: Senado, 1988.

Brasil. Congresso Nacional. Lei de Diretrizes e Bases da Educação Nacional - LDB n. 9.394, de 20 de dezembro de 1996. Diário Oficial da União, 23 de dezembro de 1996. 
Brasil. Ministério da Educação. Secretaria de Educação Especial. Diretrizes Nacionais para a Educação Especial na Educação Básica. Secretaria de Educação Especial - MEC/SEESP, 2001.

Bramston P e Fogarty $\mathrm{G}$. The assessment of emotional distress experienced by people with an intellectual disability: a study of different methodologies. Research in Developmental Disabilities 21 (2000) 487-500

Cannon, WB.(1939) The wisdom of the body. W.W. Norton; New York.

Catterall C, Howard S, Stojanovik V, Szczerbinski M, Wells B. Investigating prosodic ability in Williams syndrome. Clin Linguist Phon. 2006;20(7-8):5318.

Collins RT, Kaplan P, Somes GW, Roma JJ. Long-term outcomes of patients with cardiovascular abnormalities and williams syndrome. Am J Cardiol . 201015 de março, 105 (6) :874-8.

de Kloet ER, Oitzl MS, Joels M (1999) Stress and cognition: are corticosteroids good or bad guys? Trends Neurosci 22(10): 422-426.

Dirckx, J.H. (2001). Stedman's concise medical dictionary for the health professions. Philadelphia: Lippincott, Ed. Williams \& Wilkins.

Del Campo M, Antonell A, Magano LF, Muñoz FJ, Flores R, Bayés M, Pérez Jurado LA. Hemizygosity at the NCF1 gene in patients with Williams-Beuren 
syndrome decreases their risk of hypertension. AM J Hum Genet. 2006; 78 (4):533-42.

Elsabbagh M;. Cohen $\mathrm{H}$;. Cohen M; Rosen S; Karmiloff-Smith A. Severity of hyperacusis predicts individual differences in speech perception in Williams Syndrome. Journal of Intellectual Disability Research volume 55 part $6 \mathrm{pp}$ 563-571 june 2011

Evans GW \& Schamberg MA. Childhood poverty, chronic stress, and adult working memory. PNAS; April 21, 2009, vol. 106 no. 16: 6545-6549

Evers AW, Zautra A, Thieme K. Stress and resilience in rheumatic diseases: a review and glimpse into the future. Nat Rev Rheumatol. 2011 Jun $21 ; 7(7): 409-15$

Fisch GS, Carpenter N, Howard-Peebles PN, Holden JJ, Tarleton J, Simensen R, Nance W. Studies of age-correlated features of cognitivebehavioral development in children and adolescents with genetic disorders. Am J Med Genet A. 2007 Oct 15;143A(20):2478-89.

Fishman I; Yam A; Bellugi U; Mills D. Language and sociability: insights from Williams syndrome. J Neurodevelop Disord (2011) 3:185-192.

Gallo F; Klein-Tasman BP; Gaffrey MS; Curran P. Expecting the Worst: Observations of Reactivity to Sound in Young Children with Williams Syndrome. Res Dev Disabil. 2008 ; 29(6): 567-581. 
Gilmour J, Skuse D e Pembrey M. Hyperphagic short stature and Prader-Willi syndrome: a comparison of behavioural phenotypes, genotypes e indices of stress. British Journal of Psychiatry (2001), 179, 129-137

Goldstein DS. Adrenal Responses to Stress. Cell Mol Neurobiol. 2010 ; 30(8): 1433-1440.

Gips H, Zaitsev K e Hiss J. "Scared to death"--lethal cardiac arrhythmia caused by emotional stress. Harefuah. 2009 Feb;148(2):84-6, 140.

Gonçalves et al. Funcionamento cognitivo e produção narrativa na síndrome de Williams: Congruência ou dissociação neurocognitiva? 2004; vol.4, $n^{\circ} 3$, PP. 623-638

Goodman E, McEwen B S, Dolan ML, Shafer-kalkhoff T e Adler NE. Social disadvantage and adolescent stress. Journal of Adolescent Health. 2005; 37 : 484-92.

Gothelf D, Farber N, Raveh E, Apter A, Attias J. Hyperacusis in Williams Syndrome: Characteristics and associated neuroaudiologic abnormalities. Neurology. 2006; 66 (3): 390-5

Gunnar MR, Frenn K, Wewerka SS, Moderate versus severe early life stress: Associations with stress reactivity and regulation in 10-12-year-old 
children Ryzin MJV et al., Psychoneuroendocrinology. 2009 January ; 34(1): 62-75.

Heim C, Nemeroff CB (2001) The role of childhood trauma in the neurobiology of mood and anxiety disorders: preclinical and clinical studies. Biol Psychiatry 49(12): 1023-1039.

HessI D, Glaser B, Dyer-Friedman J, Blasey C, Hastie T, Gunnar M, Reiss AL. Cortisol and behavior in fragile $X$ syndrome. Psychoneuroendocrinology 27 (2002) 855-872

Johnson LB, Comeau M, Clarke KD. Hyperacusis in Williams syndrome. J Otolaringol. 2001; 30 (2): 90-2.

Kaperonis EA, Liapis CD, Kakisis JD, Dimitroulis D, Papavassiliou VG. Inflammation and atherosclerosis. Eur J Vasc Endovasc Surg. 2006 Apr;31(4):386-93.

Klein-Tasman, B.P., Mervis, C.B., 2003. Distinctive personality characteristics of 8-, 9-, and 10-year-olds with Williams syndrome. Dev. Neuropsychol. 23, 269-290.

Laws G, Bishop D. Pragmatic language impairment and social deficits in Williams syndrome: a comparison with Down's syndrome and specific language impairment. Int J Lang Commun Disord. 2004;39(1):45-64. 
LDB (1998) Lei no 9394/96: Diretrizes e bases da educação nacional. São Paulo: SE 1998.

Lent R, Cem bilhões de neurônios. Editora Atheneu, Niterói - RJ, 2004

Levitin DJ, Cole K, Lincoln A, Bellugi U. Aversion, awareness and attraction: investigating claims of hyperacusis in the Williams syndrome phenotype. J Child Psychol Psychiatry. 2005; 46 (5): 514-23.

Leyfer OT, Woodruff-Borden J, Mervis CB. Anxiety Disorders in Children with Williams Syndrome, Their Mothers, and Their Siblings: Implications for the Etiology of Anxiety Disorders. J Neurodev Disord. 2009 March 1; 1(1): 4-14. doi:10.1007/s11689-009-9003-1.

Lipp MEN. Crianças estressadas: causas, sintomas e soluções. Editora Papirus, 2000.

Lipp MEN. O controle do stress e hipertensão arterial sistêmica. In: III Congresso Brasileiro de Stress, 2007, São Paulo Anais. São Paulo: Associação Brasileira de stress e centro Psicológico de controle de Stress.

Lipp MEN, Arantes JP, Buriti MS, Witzig T. O estresse em escolares. Psicol. Esc. Educ. v6 n.1 2002. 
Lipp MEN; Malagris LEN; Novais LE. Stress ao longo da vida. São Paulo, Ed. Ícone, 2007

Lipp, MEN e Novaes LE. Crianças estressadas: causas, sintomas e soluções. $2^{\circ}$ edição. Campinas: Editora Papirus, 2003.

Lipp MEN e Rocha JC. Stress, Hipertensão Arterial e Qualidade de vida. São Paulo, Editora Papirus, 1998.

Lipp MEN e Rocha JC. Pressão alta e stress: o que fazer agora? Um guia de vida para o hipertenso. Campinas, Papirus, 2007.

Lucarelli MD, Tricoli VAC, Proença IM. Adquirindo conhecimento para diagnosticar o stress emocional. In: III Congresso Brasileiro de Stress; 2007; São Paulo, SP. V.1, p. 95

MANTOAN MTE. Caminhos pedagógicos da inclusão: como estamos implementando a educação (de qualidade) para todos nas escolas brasileiras. São Paulo, SP: Memnon, 2001

Margis R,Picon P, Cosner AF, Silveira RO. Relação entre estressores, estresse e ansiedade. R. Psiquiatr.RS 25(suplemento 1): 65-74, abril 2003

McEwen BS, Biron CA, Brunson KW, Bulloch K., Chambers WH., Dhabhar FS, Goldfarb R.H, Kitson R.P, Miller A.H, Spencer R.L, Weiss JM., 1997. The role of adrenocorticoids as modulators of immune function in health and 
disease: neural, endocrine and immune interactions. Brain Res Brain Res Rev 23, 79-133.

McEwen BS \& Sapolsky RM, Stress and cognitive function. Curr Opin Neurobiol. 1995 Apr;5(2):205-16.

McEwen BS \& Gianaros PJ, Central role of the brain in stress and adaptation: Links to socioeconomic status, health, and disease. Ann $N Y$ Acad Sci. 2010 February ; 1186: 190-222.

Mello DM, Marcinichen DR, Madruga D, Branco R, Paschoalini MA, et al. (2007) Involvement of NK1 receptors in metabolic stress markers after the central administration of substance P. Behav Brain Res 181(2): 232-238.

Merla G, Ucla C, Guipponi M, Reymond A. Identification of additional transcript in the Williams- Beuren Syndrome critical region. Hum Genet 2002; 110: 429-38.

Mervis CB, Robinson BF, Bertrand J, Morris CA, Klein-Tasman BP, Armstrong SC. The Williams syndrome cognitive profile. Brain Cogn. 2000;44(3):604-28.

Meyer-Lindenberg A, Mervis CB, Sarpal D, Koch P, Steele S, Kohn P, Marenco S, Morris CA, Das S, Kippenhan S, et al (2005b) Functional,structural, and metabolic abnormalities of the hippocampal formation in Williams syndrome.J Clin Invest 115: 1888-1895 
Meyer-Lindenberg, A., Mervis, C.B., Berman, K.F. (2006). Neural mechanisms in Williams syndrome: a unique window to genetic influences on cognition and behavior. Nature Reviews Neuroscience, 7, 380-93.

Morris CA, Demsey SA, Leonard CO, Dilts C, Blackburn BL. Natural history of Williams syndrome: physical characteristics. J Pediatr 1988;113(2):318-26.

Morris CA. Genetic aspects of supravalvular aortic stenosis. Current Opinion in Cardiology 13:214-219, 1998.

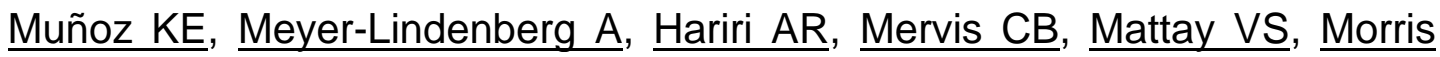
$\underline{\mathrm{CA}}$, Berman KF . Abnormalities in neural processing of emotional stimuli in Williams syndrome vary according to social vs. non-social content. Neuroimage. 2010 Mar;50(1):340-6. Epub 2009 Dec 11.

Nunes MM. Avaliação do funcionamento cognitivo de pacientes com Síndrome de Williams-Beuren.(Tese) 125p Faculdade de Medicina da Universidade de São Paulo 2010

Organização Mundial de Saúde. Classificação de transtornos mentais e de comportamento da CID-10. Descrições clínicas e diretrizes diagnósticas. Porto Alegre: Artes Médicas; 1993. 
Osborne L e Pober B. Genes and cognition in Williams syndrome. Journal of the American Academy of Child and adolescent Psychiatry, (2001). 40, 73235.

Phillips, D.P., \& Carr, M.M. (1998). Disturbances of loudness perception. Journal of the American Academy of Audiology, 9, 371-379.

Pober BR. Williams-Beuren syndrome. N Engl J Med. 201021 de janeiro, 362 (3) :239-52.

Prieto RG. Atendimento escolar de alunos com necessidades educacionais especiais: indicadores para análise de políticas públicas. In Revista UNDIME - RJ. Ano III, n.o 1, I Semestre de 2002. pp. 5-14.

Prins $Y$, Crous L, Louw QA. A systematic review of posture and psychosocial factors as contributors to upper quadrant musculoskeletal pain in children and adolescents. Physiother Theory Pract. 2008 Jul-Aug;24(4):221-42.

Reich P, DeSilva RA, Lown B, Murawski BJ. Acute psychological disturbances preceding lifethreatening ventricular arrhythmias. JAMA. 1981; 246(3):233-235.

Rhodes SM, Riby DM, Matthews K, Coghill DR. Attention-deficit/hyperactivity disorder and Williams syndrome: shared behavioral and neuropsychological profiles. Clin Exp Neuropsychol. 2011 Jan;33(1):147-56

Romeo RD, McEwen BS. Stress and the adolescent brain. Ann NY Acad Sci. 2006; 1094: 202-14. 
Roozendaal B (2002) Stress and memory: opposing effects of glucocorticoids on memory consolidation and memory retrieval. Neurobiol Learn Mem 78(3):578-595.

Rossi NF, Moretti-Ferreira D e Giacheti CM, Perfil comunicativo de indivíduos com a síndrome de Williams-Beuren. Rev Soc Bras Fonoaudiol. 2007;12(1):1-9

Simon TJ. Cognitive Characteristics of Children with Genetic Syndromes. Child Adolesc Psychiatr Clin N Am. 2007 July ; 16(3): 599-616.

Sammour ZM, Gomes CM, Duarte RJ, Trigo - Rocha FE, Srougi M. Voiding dysfunction and the Williams - Beuren syndrome: a clinical and urodynamic investigation. Urol. 2006; 175 (4): 1472-6.

Sapolsky RM, Romero LM, Munck AU. How do glucocorticoids influence stress responses? Integrating permissive, suppressive, stimulatory, and preparative actions. Endocrine Reviews 2000;21:55-89.

Selye HHB(1973) The evolution of the stress concept. Am Sci 61:692-699.

Sousa, SMZL e Prieto, RG. A educação especial. In: OLIVEIRA, Romualdo Portela de e ADRIÃO, Theresa (orgs.). Organização do ensino no Brasil. São Paulo: Xamã, 2002. 
Stinton C, Tomlinson K, Estes Z. Examining reports of mental health in adults with Williams syndrome. Research in Developmental Disabilities 33 (2012) 144-152

Stromme, P., Bjornstad, P.G., and Ramstad, K. 2002. Prevalence estimation of Williams syndrome. J. Child Neurol. 17:269-271.

Sugayama SMM, Koch VHK, Furusawa ÉA, Leone C e Kim CA. Renal and urinary findings in 20 patients with Williams-Beuren syndrome diagnosed by fluorescence in situ hybridization (FISH). Rev. Hosp. Clin. Fac. Med. S. Paulo 59(5):266-272, 2004.

Talge NM, Donzella B e Gunnar MR, Fearful Temperament and Stress Reactivity Among Preschool-Aged Children. Infant Child Dev. 2008 ; 17(4): 427-445.

Tassabehji M e Urban Z. Congenital heart disease: Molecular diagnostic of supravalvular aortic stenosis. Methods Mol Med. 2006; 126: 129-56.

Tassabehji M e Donnai D, More or less? Segmental duplications and deletions in the Williams-Beuren syndrome region provide new insights into language development European Journal of Human Genetics (2006) 14, 507-508. 
Tiet QQ; Bird HR; Davies M; Hoven C; Cohen P; Jensen PS; Goodman S. Adverse life events and resilience. Journal of the American Academy of Child and Adolescent Psychiatry. Vol.37.issue 11. USA pp. 1191-1200.1998.

Venes, D., Thomas, C.L., \& Taber, C.W. (Eds.). (2001). Taber's cyclopedic medical dictionary (19th edn). Philadelphia: F.A. Davis.

Vicari S.; Bellucci S; Carlesimo G.A. Procedural learning déficit in children with Williams syndrome. Neuropsychologia, v.39, n.7, p.665-677, 2001.

Vlastelica M, Emotional stress as a trigger in sudden cardiac death. Psychiatr Danub. 2008 Sep;20(3):411-4.

Wälinder R, Gunnarsson K, Runeson R e Smedje G. Physiological and physiological stress reactions in ralation to classroom noise. Scand $J$ work Environ Health. 2007; 33 (4): 260-66.

Wechsler D. Wechsler Intelligence Scale for Children (WISC). 3rd ed. San Antonio: Psychological Corporation; 1991.

Wechsler D. WAIS-III: administration and scoring manual. San Antonio: Psychological Corporation; 1997.

Wessel A, Motz R, Pankau R, Bursch, JH. Arterial hypertension and blood pressure profile in patients with Williams-Beuren syndrome. Z Kardiol 1997; 86: $251-7$

Williams, J.C.P.; Barratt-Boyes, B.G.; Lowe, J.B. Supravascular aortic stenosis. Circulation, v. 24, p. 1311-1318, 1961. 
Zalzstein E, Moes CA, Musewe NN, Freedom RM. Spectrum of cardiovascular anomalies in Williams-Beuren syndrome. Pediatr Cardiol 1991;12(4):219-23. 